\title{
Peltigericolous fungi from Finland - three genera and six species new to Finland.
}

\author{
ARTO PUOLASMAA, ANNE TOIVANEN, TARJA MARSH, SEPPO HUHTINEN and SOILI \\ STENROOS
}

PUOlAsmaA, A., TOIVANEN, A., MARSh, T., HUHTINEN, S. \& STENROOS, S. 2012: Peltigericolous fungi from Finland - three genera and six species new to Finland. - Karstenia 52: 1-50. HELSINKI. ISSN 0453-3402.

Over 2500 Finnish herbarium specimens of the lichen genus Peltigera were screened in search for lichenicolous fungi. A total of ca 1200 records of 41 species in 27 genera was made. The species Dacampia rufescentis, Hawksworthiana peltigericola, Hobsoniopsis santessonii, Phoma epiparmelia, Stigmidium peltideae and Xenonectriella lutescens, as well as the genera Hawksworthiana, Hobsoniopsis and Xenonectriella are reported as new to Finland. Species descriptions with illustrations are provided along with habitat descriptions and known distribution in the Nordic countries.

Key words: Ascomycetes, lichenicolous, lichen-forming fungi, Peltigera, peltigericolous.

Arto Puolasmaa \& Tarja Marsh \& Seppo Huhtinen, Herbarium, University of Turku, FI-20014Turku, Finland; e-mails: arto.puolasmaa@utu.fi; tarja.marsh@utu.fi; seppo. huhtinen@utu.fi

Anne Toivanen, Iisakintie 34, FI-14200 Turenki, Finland; e-mail: anne.j.toivanen@ gmail.com

Soili Stenroos, Botanical Museum, Finnish Museum of Natural History, University of Helsinki, P.O.Box 7, FI-00014 Finland; e-mail: soili.stenroos@helsinki.fi

\section{Introduction}

Lichenicolous fungi are an ecologically defined group of species that form obligate, often host specific associations with lichens. Their mode of nutrition ranges from pathogenity to commensalism; with saprotrophism or mild parasitism probably being the most common. Over 1800 species have been described and a checklist of species described so far, with an extensive list of cited literature, has been compiled by Lawrey and Diederich $(2003,2011)$. The genus Peltigera Willd. is known to host an unusually large number of lichenicolous fungi, many of which are known only from this host genus (e.g. Hawksworth 1980, Vitikainen 1994, Hawsworth \& Miadlikowska 1997, Martínez \& Hafellner 1998). The knowledge of peltigericolous microfungi and microlichens in Finland was previously scanty and this is the first systematic attempt to resolve the diversity and distribution of species assiociated with Peltigera in Finland. The genus Peltigera is common and widespread on most continents with 28 species reported from Finland (Stenroos et al. 2011). It includes large, foliose lichens that are mainly muscicolous or 
terricolous. The thallus of Peltigera is broad and lobed, the ventral surfaces lack a cortex, thus leaving the lower medulla exposed (Vitikainen 1994). The lichenicolous microfungi usually occupy species-specific infection sites on the host.

\section{Material and methods}

Herbarium specimes of Peltigera from TUR, TUR-V and $\mathrm{H}$ were scanned for lichenicolous fungi. The host material consisted of ca 2500 specimens. Separation and identification of species were done by Arto Puolasmaa during 2003-2010. Searching microfungi from the dried specimens was done using a Leica S6E StereoZoom -microscope. Microscopical characteristics were studied with a Leica DMLB2 -microscope. Drawings were made using a drawing tube attached to the microscope. All measurements and drawings were made from dried material which was first mounted in water and subsequently in Congo Red (CR) to provide contrast. All species descriptions are based on measurements made during these examinations. Mean values of the length and width of spores, number of spores measured and number of collections studied are given. The specimens which were studied microscopically, and on which the species descriptions or drawings are based, are marked with an asterisk in the list of examined specimens. The reported occurrence of species in Sweden and Norway is derived from Santesson's Checklist of Fennoscandian Lichen-forming and Lichenicolous Fungi (Nordin et al. 2010). The species are presented in alphabetical order.

\section{Results and discussion}

The search of Finnish herbarium material yielded ca 1200 records of peltigericolous microfungi. In all, 41 species in 27 genera were identified. Six species and three genera are reported as new to Finland. Species are presented below with species descriptions, illustrations and distribution maps.

\section{Arthonia fuscopurpurea (Tul.) R. Sant.} - Figs. 1, 44 A

Ascomata apothecioid, arthonioid, 0.5-2 mm diam. Asci 20-34 × 12-18 $\mu$ m, mean $28.8 \times$ $14.9,(n=17$, one collection $)$, bitunicate, sackshaped, often prominently thickened at the apex, foot slender, 8-spored. Ascospores 10-14 × 4-5 $\mu \mathrm{m}$, mean $11.6 \times 4.4 \mu \mathrm{m}(\mathrm{n}=32$, one collection $)$, septate, upper cell shorter, broader and more rounded than the lower cell, may contain gut- tules and appear dark-coloured inside. Paraphysoids of ascal length or longer, 2-3 $\mu \mathrm{m}$ diam, septate, branched. Excipulum composed of rounded, thin-walled cells, $0.5 \mu \mathrm{m}$ diam.

Hosts: Peltigera hymenina (Ach.) Delise, $P$. canina (L.) Willd. and P. rufescens (Weiss) Humb. Peltigera didactyla (With.) J.R. Laundon and P. scabrosa Th. Fr. have also been reported as hosts for A. fuscopurpurea (Nordin et al. 2010). Zhurbenko \& Grube (2010) list lichens in genera Dactylina Nyl., Lecania A. Massal., Lecanora Ach., Nephroma Ach., Pseudocyphellaria Vain., Psoroma Ach. ex Michx. and Solorina Ach. that have also been reported as hosts, but consider those accounts doubtful.

Arthonia fuscopurpurea forms dark-brown, rough-surfaced, $0.5-2 \mathrm{~mm}$ wide, elevated patches on the dorsal thallus of the host. Sometimes these patches merge forming larger areas. Often these patches are surrounded by a white ring of bleached host tissue. May be confused with $A$. peltigerea.

A. fuscopurpurea is an easily visible parasite whose host species are widely distributed and abundant, therefore we conclude that the sole record indicates genuine rarity of the species in Finland. The species was first recorded from Finland by Toivanen (2008). Reported also from Norway and Sweden.

Specimen studied: Varsinais-Suomi. Naantali, Rymättylä, Pakinainen, 17.V.1937 Auer (TUR)*.

\section{Arthonia peltigerea Th. Fr. - Figs. 2, 44 B}

Ascomata apothecioid, arthonioid, $0.5 \mathrm{~mm}$ diam. Asci 31-59 × 15-23 $\mu \mathrm{m}$, mean $48.2 \times 18.7 \mu \mathrm{m}$ ( $n=10$, two collections), bitunicate, ellipsoid, often prominently thickened at the apex, 8 -spored. Ascospores 14-19 × 4-6 $\mu \mathrm{m}$, mean $16.9 \times 5.6$ $\mu \mathrm{m}$ ( $\mathrm{n}=20$, two collections), ellipsoid-elongate, septate, upper cell slightly broader and more rounded than the lower cell, no guttules observed. Paraphyses of same lenght as the asci, 2-3 $\mu \mathrm{m}$ diam, septate, sometimes branched. 
A

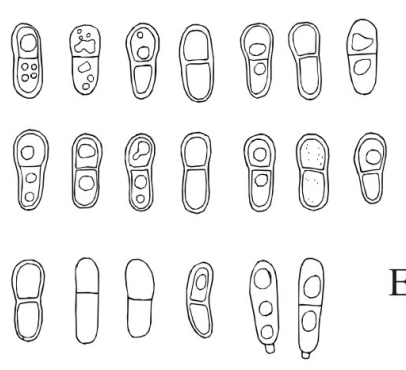

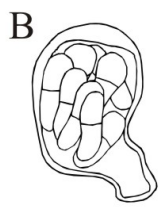

E

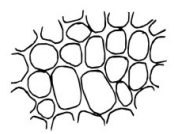

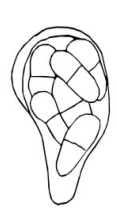

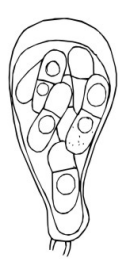

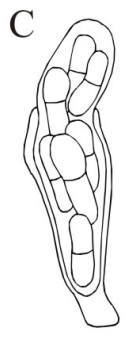

F
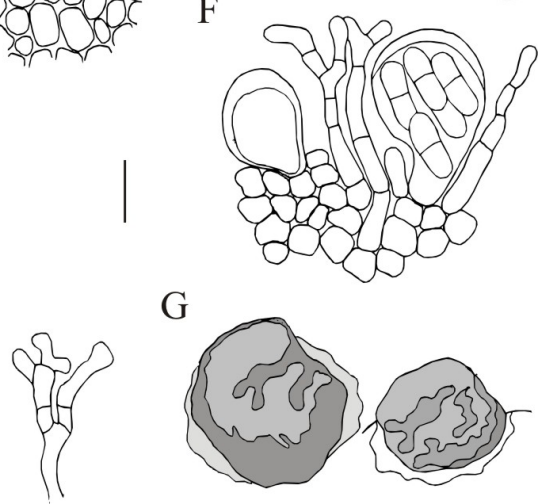

$\mathrm{G}$

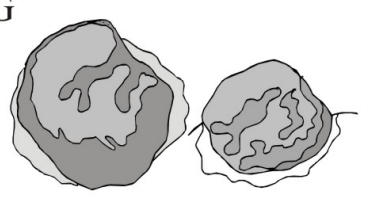

Fig. 1. Arthonia fuscopurpurea (1937 Auer), $\mathrm{A}=$ spores, $\mathrm{B}=$ asci, $\mathrm{C}=\mathrm{a}$ discharging, bitunicate ascus, $\mathrm{D}=$ paraphyses, $\mathrm{E}=$ excipulum, $\mathrm{F}=$ asci, paraphyses and medullary excipulum, $\mathrm{G}=$ elevated patches on host thallus caused by $A$. fuscopurpurea. Bars (A-F) $10 \mu \mathrm{m}$, (G) $1 \mathrm{~mm}$.

Hosts: Peltigera rufescens. Arthonia peltigerea has also been reported from the thalli of $P$. leucophlebia (Nyl.) Gyeln., Solorina saccata (L.) Ach., S. bispora Nyl. and S. octospora Arnold (Nordin et al. 2010).

Arthonia peltigerea forms dark-brown, either rough- or smooth-surfaced, partly immersed, $0.5 \mathrm{~mm}$ wide patches on the dorsal thallus of the host. It differs from A. fuscopurpurea by its darker apothecia and larger ascospores. The species was first recorded from Finland by Toivanen (2008). It has been classified as NT (Near Threatened) in the 2010 Red List of Finnish Species (Jääskeläinen et al. 2010). Reported also from Norway and Sweden.

Specimens studied: Keski-Pohjanmaa. Kokkola, Kälviä, 2.VIII.1923 Kujala (H). Kittilän Lappi. Kolari, Äkäsjokisuu 13.VII.2003 Haikonen 22560 (H). Enontekiön Lappi. Enontekiö, Kilpisjärvi, Jehkats 30.VII.1956 Huuskonen (H, TUR); N-Jehkats, 15.VIII.1958 Huuskonen $(\mathrm{H})^{*}$; Toskalharji, 6.VIII.1947 Huuskonen $(\mathrm{H})$; Toskaljärvi, VIII.1947 Huuskonen $(\mathrm{H})^{*}$.
Capronia peltigerae (Fuckel) D. Hawksw. - Figs. 3, $44 \mathrm{C}$

Ascomata perithecioid, partly immersed when young, with only the ostiole visible as a black spot, superficial at maturity, black, setose. Asci 43-84 × 8-20 $\mu \mathrm{m}$, mean $65.9 \times 13.6 \mu \mathrm{m}(\mathrm{n}=20$, three collections), bitunicate, spindle- to sackshaped, wide at the base, elongated internal canal, 8-spored. Ascospores 14-22.5 × 3.5-8 $\mu \mathrm{m}$, mean $17.7 \times 5.7 \mu \mathrm{m}(\mathrm{n}=30$, three collections $)$, spindle-shaped, with the other end wider than the other, 3-septate, with or without guttules. Paraphyses and periphyses absent. Outer excipulum of textura angularis, cells thick-walled. Medullary excipulum of textura globulosa, cells thinwalled, $10 \mu \mathrm{m}$ diam.

Hosts: Peltigera canina, P. didactyla, P. praetextata (Sommerf.) Zopf., P. rufescens.

Capronia peltigerae has dark, setose perithecia, which form more or less superficially on the dor- 
A

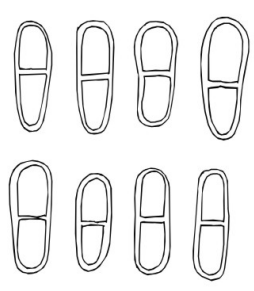

B

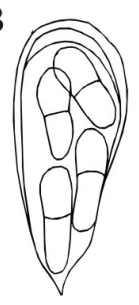

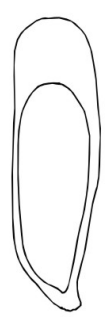
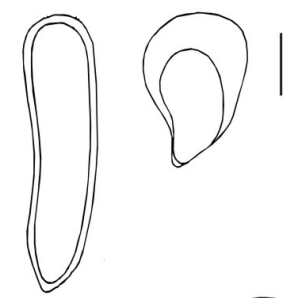

$\mathrm{C}$
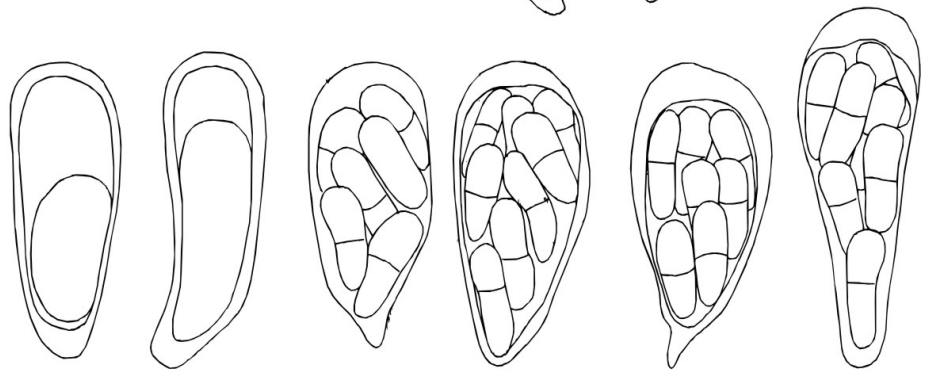

$\mathrm{D}$

$\mathrm{E}$

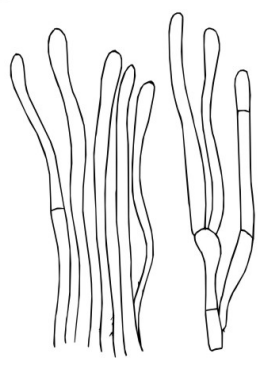

$\mathrm{F}$
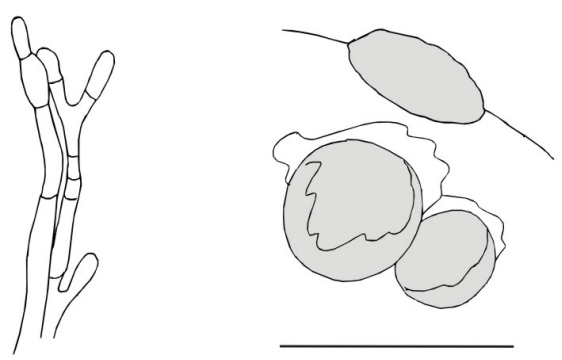

Fig. 2. Arthonia peltigerea (A, C-F $=1947$ Huuskonen; $\mathrm{B}, \mathrm{E}=1958$ Huuskonen), $\mathrm{A}=$ ascospores, $\mathrm{B}-\mathrm{C}=$ asci, $\mathrm{D}-\mathrm{E}=$ paraphyses, $\mathrm{F}=$ elevated patches on host thallus caused by A. fuscopurpurea. Bars (A-E) $10 \mu \mathrm{m},(\mathrm{F}) 1 \mathrm{~mm}$.

sal side of the host. Reported also from Norway and Sweden.

Specimens studied: Varsinais-Suomi. Kemiönsaari, Dragsfjärd, Tynglax, 22.IV.1981 Kvist (H). Lohja, Kukkumäki, 16.VII.2007 Pykälä 31459, 31460 (H); Nummenkylä, 28.IV.2007 Pykälä 30767 (H). Uusimaa. Kirkkonummi 1864 Kullhem $(\mathrm{H})$. Vantaa, Kopparberg 15.VI.1948 Lyyra (H, two specimens)*. Etelä-Karjala. Miehikkälä, Kirkonkylä, 12.IX.1967 Rintanen (H). Satakunta. Kullaa, Joutsijärvi, 23.VIII.1939 Laurila (H). Etelä-Häme. Asikkala, Viitaila, 17.V.1985 Ahti 43915 \& Daniëls (H). Hämeenlinna, Lammi, Evo, 1976 Lång (H). Kuhmoinen, Tehi, 18.X.1911 Linkola (H). Etelä-Savo. Imatra, Sienimäki, 16.IV.1988 Thurén $616(\mathrm{H})^{*}$. PohjoisSavo. Jäppilä, 18.VII.1964 Takala (H). Varkaus, Könönpelto, 9.V.2003 Haikonen $22255(\mathrm{H})^{*}$. Pohjois-Karjala. Pielisjärvi, Koli, 24.VIII.1966 Vitikainen 2153a (H). Koillismaa. Salla, Oulankajoki, 17.VII.1939 Laurila (H).
Corticifraga fuckelii (Rehm) D. Hawksw. \& R. Sant. - Figs. 4, $44 \mathrm{D}$

Ascomata apothecioid, immersed when young, emerging through cortex at maturity, round or irregular shaped, $0.3-0.5 \mathrm{~mm}$, lighter than host thallus when young, almost black at maturity. Asci 45-78 × 10-21 $\mu \mathrm{m}$, mean $59.5 \times 13.6 \mu \mathrm{m}$ $(\mathrm{n}=20$, three collections), elongate, thick-walled, thickened at the apices, 8-spored. Ascospores $12-21 \times 4-7 \mu \mathrm{m}$, mean $16.0 \times 5.5 \mu \mathrm{m}(\mathrm{n}=28$, three collections), septate, occasionally with two septa, slightly constricted, the other cell often rounded and larger than the other. Paraphyses of ascal length, ca $5 \mu \mathrm{m}$ wide, septate, sometimes branched. Excipular cells rounded, 0.5-1 $\mu \mathrm{m}$ diam, thin- and dark-walled. 
A

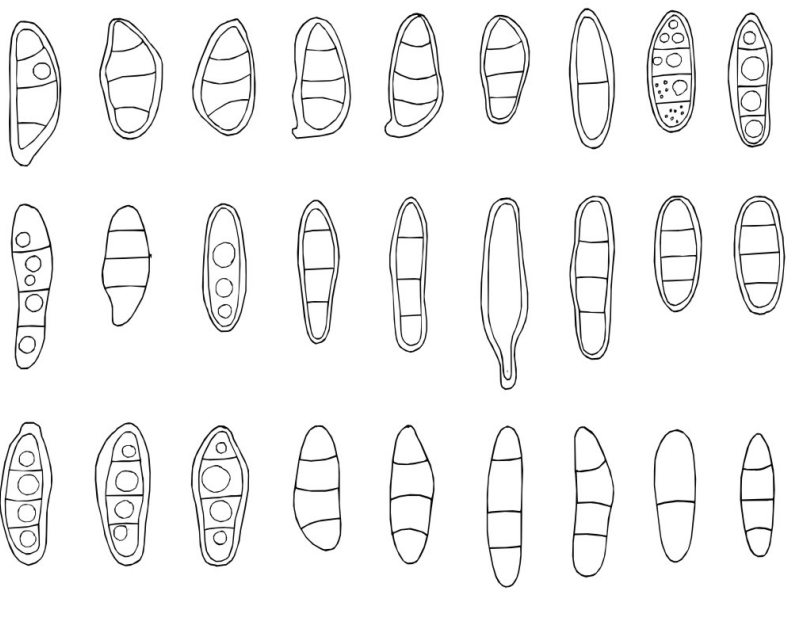

$\mathrm{B}$

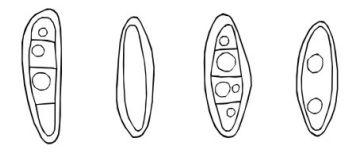

$\mathrm{F}$

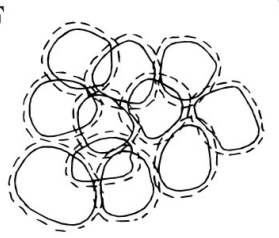

G

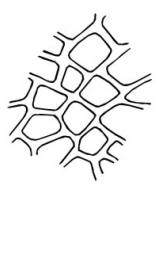

$\mathrm{D}$
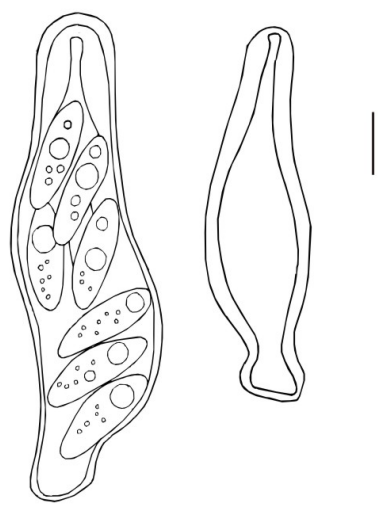

$\mathrm{E}$

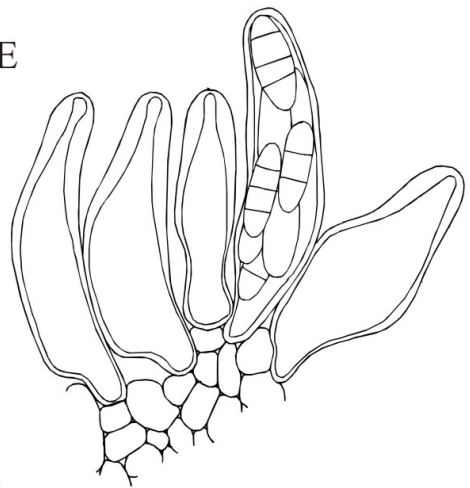

$\mathrm{C}$

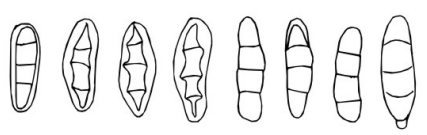

$\mathrm{H}$

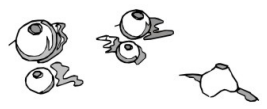

Fig. 3. Capronia peltigerae (A, D = Haikonen 22255; B, E = 1948 Lyyra; C, F-H Thurén 616), A-C = ascospores, D, $\mathrm{E}=$ asci, $\mathrm{F}, \mathrm{G}=$ excipulum, $\mathrm{H}=$ perithecia. Bars $(\mathrm{A}-\mathrm{G}) 10 \mu \mathrm{m},(\mathrm{H}) 1 \mathrm{~mm}$.

Hosts: Peltigera aphthosa (L.) Willd., P. canina, P. collina (Ach.) Schrad, P. didactyla, P. extenuata (Nyl. ex Vain.) Lojka, P. hymenina, P. lepidophora (Nyl.) Bitter, P. leucophlebia, P. neopolydactyla (Gyeln.) Gyeln., P. praetextata, P. rufescens. Reported also on P. neckeri Hepp ex Müll. Arg. (Nordin et al. 2010).

The apothecia of Corticifraga fuckelii arise scattered from the host thallus, immersed in the beginning and emerging through the dorsal host cortex, surrounded by the jagged edges of the ruptured cortex. It does not induce necrotic or bleached patches on the host. Reported also from Norway and Sweden.

Specimens studied: Varsinais-Suomi. Kustavi, Kunnarainen, 11.X.1983 Alava 20751 (TUR). Lohja, Kirkonkylä, 20.VII.2004 Pykälä 25169 (H), 13.V.2006
Pykälä 28515, 28516, 28517 (H), 16.VII.2007 Pykälä 31451 (H), 17.X.2007 Pykälä 32230, 32235 (H); Storön, Hermala, 21.VII.1890 Boldt $(\mathrm{H})^{*}$. Parainen, Houtskär, Hyppeis, 9.VII.1992 Bruun (H)*; Ersby, 7.IX.1912 Linkola (TUR-V); Sattmark, 23.IX.1978 Alava 18322 (TUR); Pyhänsuu, 29.VII.1911 Linkola (TUR). Paimio, Askala, 4.IX.1971 Alava (TUR), 5.X.1969 Alava 8404 (TUR). Turku, Katariinanlaakso, 6.VII.1934 Auer (TUR). Uusimaa. Helsinki, Munkkiniemi, 10.X.1948 Takala (TUR). Mäntsälä, Sahajärvi-SW, 12.VII.1964 Suominen (H). Pornainen, Hevonselkä, 4.VIII.2001 Ahti 61502c (H). Sipoo, Träskby, 13.X.2006 Pykälä 28850 (H). Vantaa, Korso 3.X.1915 Häyrén (TUR-V, two specimens). Satakunta. Rauma, Sorkka, 25.VII.1935 Kari (TUR). Etelä-Häme. Asikkala, Kissakallio 8.I.1863 $\operatorname{Norrlin}(\mathrm{H})$. Heinola, Lusi, 12.III.1997 Haikonen 18375 (H). Hollola, Upila, VII.1883; Vaania 4.VIII.1874 Vainio (TUR-V). Hämeenlinna, Evo,Valkjärvi, 26.VII.1909 Lång (H)*; Mustajärvi 30.VII.1909 Lång (H). Jyväskylä, Korpilahti, Vaarunvuori, 1873 Wainio (TUR-V). Kuhmoinen, Tehi, 18.X.1911 Linkola (H)*. Lempäälä, Rikala, 25.IX.1988 Kääntönen (H)*. Nokia, Siuro, 27.VII.1990 Kääntönen $(\mathrm{H})^{*}$. Pälkäne, Luopioinen, 1.VIII.1926 Linkola (H). 
A

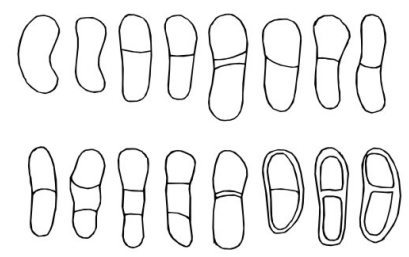

B

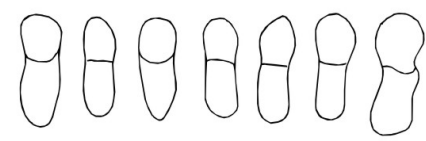

$\mathrm{C}$

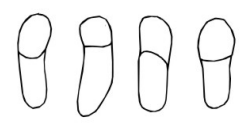

I

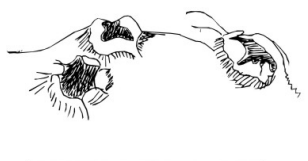

$\mathrm{D}$

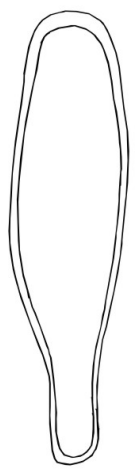

G

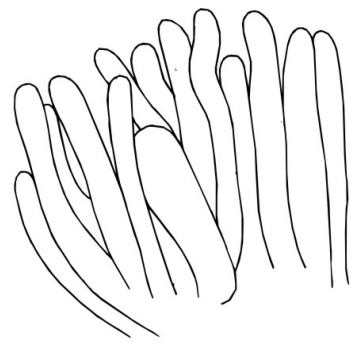

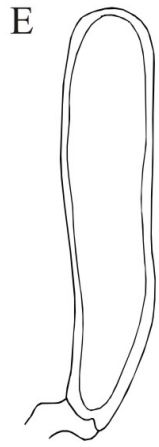
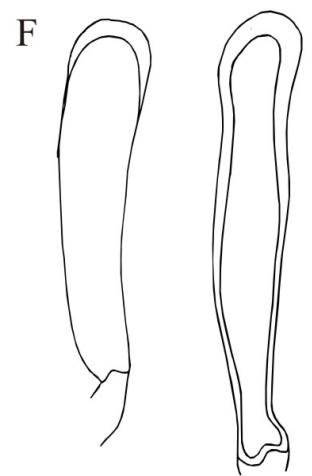

$\mathrm{H}$

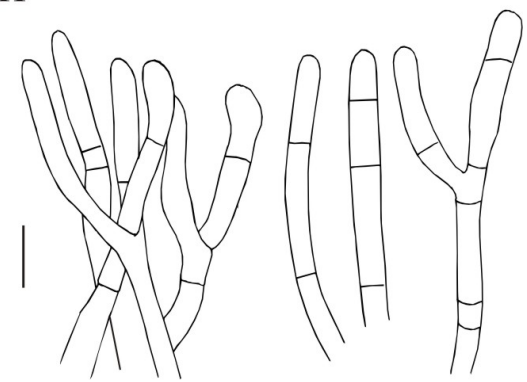

Fig. 4. Corticifraga fuckelii (A, D = 1911 Linkola; B, E = 1890 Boldt; C, F, G = 1992 Bruun; H = 1988 Kääntönen; I = 1909 Lång), A-C = ascospores, D-F = asci, G, H = paraphyses, I = apothecia. Bars (A-H) $10 \mu \mathrm{m},(\mathrm{I}) 1 \mathrm{~mm}$.

Etelä-Savo. Kangasniemi, Rutakoski, 29.VI.2003 Haikonen 2248 (H). Kerimäki, Viitamäki, 24.VIII.1991 Haikonen $13336(\mathrm{H})$. Puumala, Saha, 21.IX.2002 Vitikainen $16476(\mathrm{H})$. Mäntyharju, Parish village, 9.VIII.1964 Suominen $(\mathrm{H})^{*}$. Pohjois-Häme. Jyväskylä, Sulkula, 29.VII.1946 Hakulinen (TUR). Pohjois-Karjala. Ilomantsi, Ritovaara, 17.VII.1936 Laurila (TUR). Koillismaa. Kuusamo, Iivaara, 1877 Wainio (TUR-V); Kiutaköngäs, 30.VI.1949 Takala (TUR). Inarin Lappi. Utsjoki, Kevo, 2.VII.1967 Såltin \& Roms (TUR); Kevo, Kotkapahta, 6.VIII.1964 Hakulinen (TUR).

Corticifraga peltigerae (Fuckel) D.

Hawksw. \& R. Sant.

- Figs. 5, $44 \mathrm{E}$

Ascomata apothecioid, immersed when young, superficial and rupturing host cortex at maturity, $0.2-0.3 \mathrm{~mm}$, dark-brown, almost black. Asci $41-65 \times 7-20 \mu \mathrm{m}$, mean $53.8 \times 12.8 \mu \mathrm{m}(\mathrm{n}=20$, three collections), clavate to cylindrical, thickened at the apices, 8-spored. Ascospores 10-25 $\times$ 4-7 $\mu \mathrm{m}$, mean $15.4 \times 5.4 \mu \mathrm{m}(\mathrm{n}=30$, three collections), septate with 1-3 thick septa, end cells tapering. Paraphyses of ascal length or longer,
1-1.5 $\mu \mathrm{m}$ wide, remotely septate, the apical cell expanded, sometimes with a guttule. Excipular cells rounded, 3-5 $\mu \mathrm{m}$ diam, thin-walled, dark.

Hosts: Peltigera aphthosa, P. canina, $P$. didactyla, P. horizontalis (Huds.) Baumg., P. leucophlebia, P. malacea (Ach.) Funck, P. neopolydactyla, P. polydactylon (Neck.) Hoffm., P. praetextata, P. rufescens, $P$. scabrosa, Lobaria linita.

Corticifraga peltigerae is a parasitic fungus, which causes irregula, 1-2 mm wide, bleached or necrotic patches on the host thallus. The apothecia are formed in this patch, scattered or in circular formation, immersed in the beginning, rupturing the cortex unevenly, as they mature. Reported also from Norway and Sweden.

Selected specimens studied (out of 63): Ahvenanmaa. Sottunga, 26.VIII.1952 af Hällström (H)*. VarsinaisSuomi. Parainen, Ersby, 9.IX.1912 Linkola (H)*. Uusikaupunki, W of Käätyjärvi, 25.XII.1951 Laine (TUR). Uusimaa. Helsinki, Oulunkylä, 5.VI.1916 Rainio $(\mathrm{H})^{*}$; Orimattila, Pennala, 26.IV.2002 Haikonen $21207(\mathrm{H})^{*}$. 

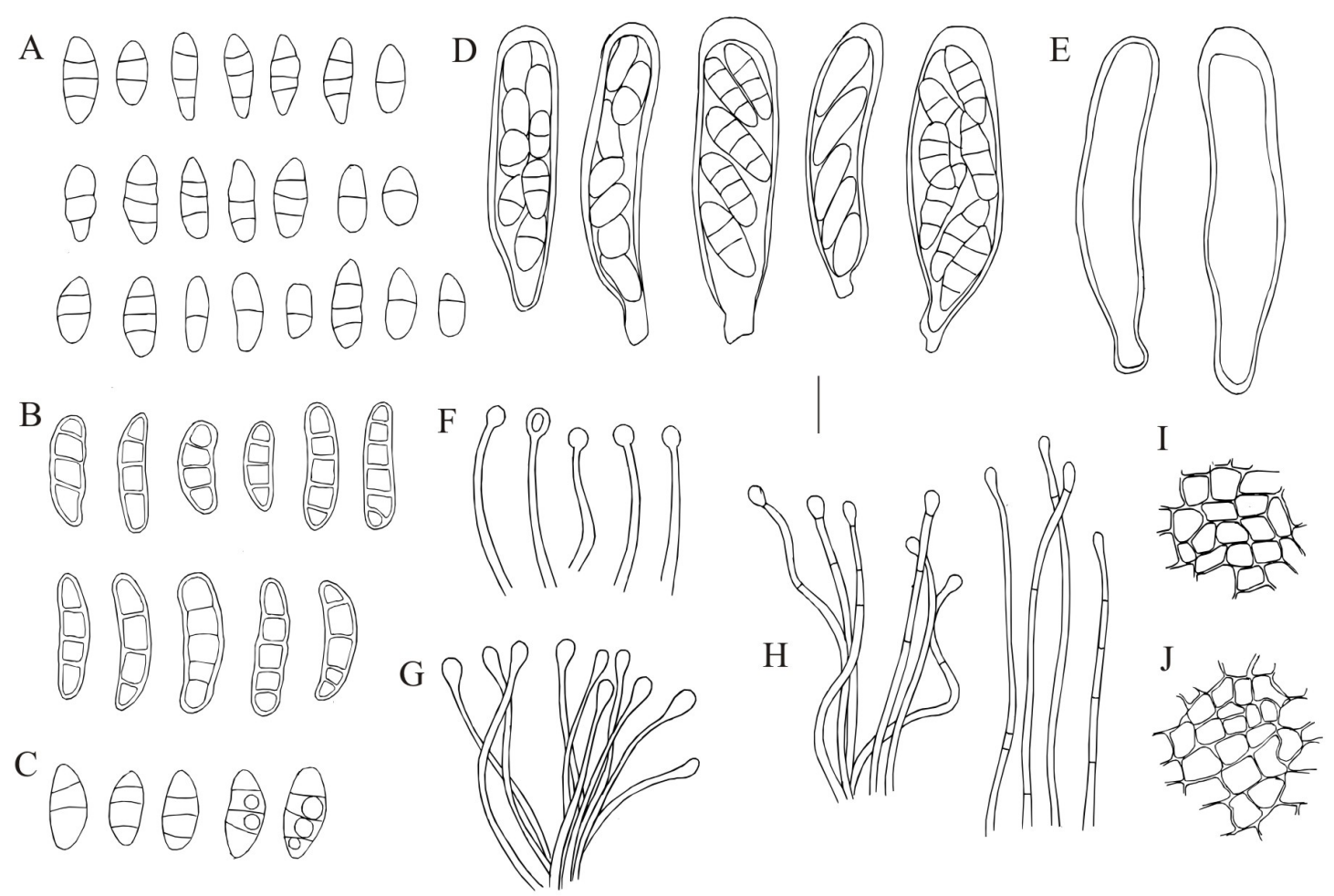

K

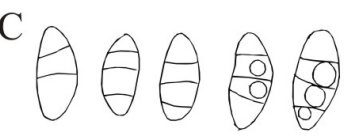

L
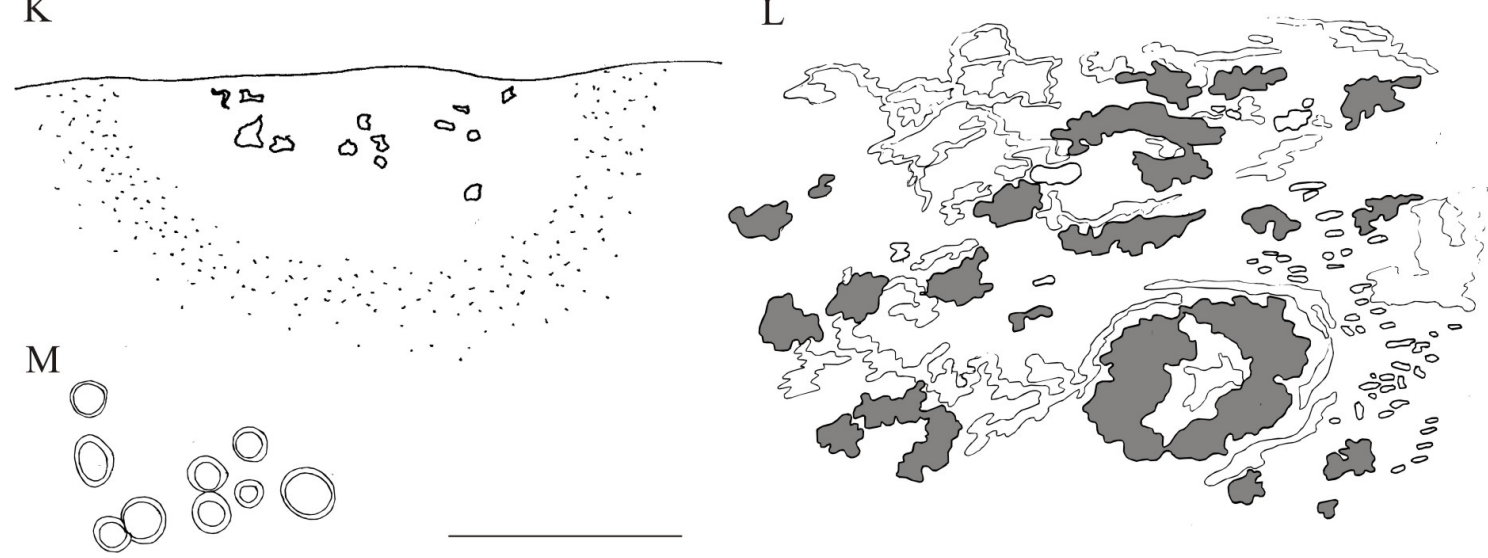

Fig. 5. Corticifraga peltigerae (A, D, F, G = 1947 Klingstedt; B, E, H, J, M = Vitikainen 9973; C=Haikonen 21207; I= 1916 Rainio; $\mathrm{L}=1912$ Linkola $; \mathrm{K}=1935$ Laurila), $\mathrm{A}-\mathrm{C}=$ ascospores, $\mathrm{D}, \mathrm{E}=$ asci, $\mathrm{F}-\mathrm{H}=$ paraphyses, I, J = excipulum, $\mathrm{K}=$ infection patch on host thallus with a cracking cortex caused by emerging apothecia, $\mathrm{L}=$ dark patches on the host thallus caused by apothecia, $\mathrm{M}=$ mature apothecia. Bars $(\mathrm{A}-\mathrm{J}) 10 \mu \mathrm{m},(\mathrm{K}-\mathrm{M}) 1 \mathrm{~mm}$.

Etelä-Karjala. Hamina, Vehkalahti, 18.VII.1914 Krohne (H). Satakunta. Kankaanpää, Luomajärvi, 29.VI.1935 Laurila $(\mathrm{H}) *$. Rauma, Lappi, Kivikylä, 1.VIII.1957 Såltin $(\mathrm{H})^{*}$. Etelä-Häme. Hollola, Upila, VII.1883 Vainio $(\mathrm{H})$. Urjala, Kivijärvi, 10.IX.1950 Fagerström (H). EteläPohjanmaa. Kristiinankaupunki, Lappfjärd, Torngrund,
1.VIII.1953 Railonsala (TUR). Pohjois-Häme. Tuomioniemi, 29.IV.1951 Valovirta (H). Äänekoski, Piilola, 3.V.1947 Klingstedt (H)*. Pohjois-Savo. Kuopio, Korsumäki, 19.V.1946 Sepponen (TUR). Pohjois-Karjala. Ilomantsi, Koitere, Laitasaari, 11.X.1948 Leppälä (TUR).

Keski-Pohjanmaa. Kruunupyy, Söderpåras, Storbacken 
13.V.1962 Krokfors (H). Oulun Pohjanmaa. Hailuoto, Marjaniemi 10.IX.1994 Vitikainen 13290 (H). Koillismaa. Kuusamo, Juuma, 12.VI.1980 Vitikainen $9973(\mathrm{H}) *$. Sodankylän Lappi. Sodankylä, Sattanen, 18.VI.1980 Kvist $(\mathrm{H})$. Enontekiön Lappi. Enontekiö, Toskalharji, 18.VII.2006 Syrjänen (TUR) on Lobaria linita. Inarin Lappi. Utsjoki, Kevo, 16.VIII.1965 Ahti $21042 a(\mathrm{H})$.

\section{Dacampia rufescentis (Vouaux) D.} Hawksw. - Figs. 6, $44 \mathrm{~F}$

Ascomata pseudoperithecioid, immersed. Asci

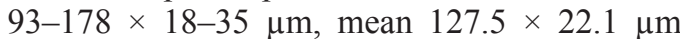
$(\mathrm{n}=17$, three collections), bitunicate, cylindrical, thick-walled, rounded at the apex, 8 -spored. $A s$ cospores $22-29(-40) \times 9-14.5 \mu \mathrm{m}$, mean $26.5 \times$ $11.8 \mu \mathrm{m}(\mathrm{n}=31$, three collections), elongate, muricate, constricted at septa, brown. Pseudoparaphyses 2-3.5 $\mu \mathrm{m}$ diam., septate, branching. Ectal excipulum composed of dark, thick-walled, elongate or cubiform cells, $6.5-15 \times 1.5-5 \mu \mathrm{m}$. Medullary excipulum composed of reddish, thinwalled cells, 4-6 $\mu \mathrm{m}$ diam.

Host: Peltigera rufescens. The species has also been reported from $P$. didactyla (Nordin et al. 2010).

Dacampia rufescentis is reported as new to Finland. It forms necrotic, decolourized, circular, 2-3 $\mathrm{mm}$ wide infection areas on the host thallus. The infected area is elevated while the margins are delimited by a flat, brown ring. The ascomata are scattered in the elevated infection area, immersed, often in concentric rings, with only the ostiolar regions visible as dark spots. D. rufescentis is a parasitic fungus (Hawksworth 1986). All of the localities from which the host species had been collected were either in the immediate vicinity of old limestone quarries or otherwise calcareous areas. Reported also from Norway and Sweden.

Specimens studied: Varsinais-Suomi. Lohja, Vappula, 20.V.2006 Pykälä 28555 (H). Parainen, Ersby, 12.X.1969 Alava $8392 a$ (TUR); 9.IX.1912 Linkola (H)*. KeskiPohjanmaa. Alajärvi, Kuparikallio, 26.VI.1907 Backman (H)*. Kainuu. Paltamo, Melalahti, 28.VII.1970 Alava (TUR)*. Perä-Pohjamaa. Rovaniemi, Taipale, 2.IX.1981 Kytövuori 811028 (H)*.

\section{Graphium aphthosae Alstrup \& D.}

Hawksw. - Figs. 7, $44 \mathrm{G}$

Synnemata small, dark, shiny, composed of an erect bunch of conidiophores that splay out at the apex. Conidia 6.5-9 × 3-4.5 $\mu \mathrm{m}$, mean $7.6 \times$ $3.7 \mu \mathrm{m}(\mathrm{n}=33$, three collections), simple, cubiform, broader at the upper end.

Hosts: Peltigera aphthosa, P. canina, P. leucophlebia. Reported also from $P$. rufescens (Nordin et al. 2010).

Species in the genus Graphium Corda are anamorphs of Ophiostoma Syd. \& P. Syd. The genus was first recorded from Finland by Toivanen (2008). Reported also from Norway and Sweden.

Specimens studied: Varsinais-Suomi. Lohja, Lylyinen, 21.VI.1947 af Hällström (H); Varola, Päivärinteenkallio, 1.X.2005 Pykälä 28096 (H); Immula, 6.IX.2008 Pykälä 33669 (H). Turku, Kakskerta, 17.VIII.1934 Kari (TUR); Ruissalo, 29.X.1933 Seppä $(\mathrm{H})^{*}$; Uusimaa. Helsinki, Oulunkylä, 26.I.1930 Häyrén $(\mathrm{H})$. Orimattila, Niemi, 2.IX.1914 Linkola $(\mathrm{H})^{*}$. Etelä-Häme. Hämeenlinna, Lammi, Evo, 28.VI.1967 Pankakoski (H)*. Koillismaa. Kuusamo, Liikasenvaara, 15.VI.1980 Vitikainen 10103 $(\mathrm{H})^{*}$; Rukajärvi, 11.VI.1980 Vitikainen 9931 b (H). Inarin Lappi. Paatsjoki, 1909 Renvall $(\mathrm{H})$.

\section{Hawksworthiana peltigericola (D. Hawksw.) U. Braun - Figs. 8, $44 \mathrm{H}$}

Hawksworthiana peltigericola induces semiglobose, gall-like deformations on the host thallus. Conidiogenous cells are located immediately on the surface of the galls, giving the surface a matt appearance. Conidia 13-21(-33) × 6-10 $\mu \mathrm{m}$, mean $17.6 \times 7.5 \mu \mathrm{m}(\mathrm{n}=32$, three collections $)$, spindle-shaped, 0-1 -septate, thin-walled, attenuated with a thickened scar at the site of attachment.

Hawksworthiana U. Braun is a monotypic genus, which accommodates the mitosporic species H. peltigericola. The positioning of the genus is unclear.

Hosts: Peltigera canina, $P$. collina, $P$. didactyla, $P$. neopolydactyla, $P$. polydactylon, P. praetextata, P. rufescens.

Hawskworthiana is reported as a new genus for Finland. Reported also from Sweden. 
A
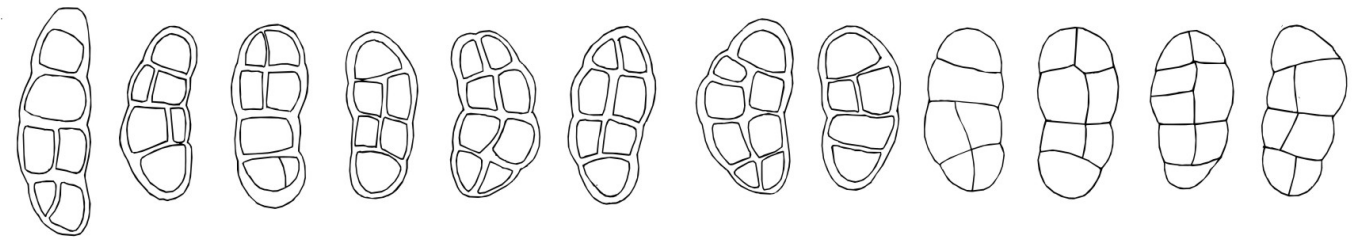

$\mathrm{B}$

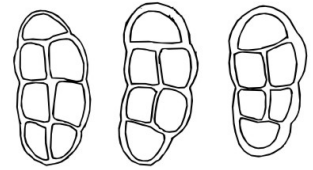

$\mathrm{D}$
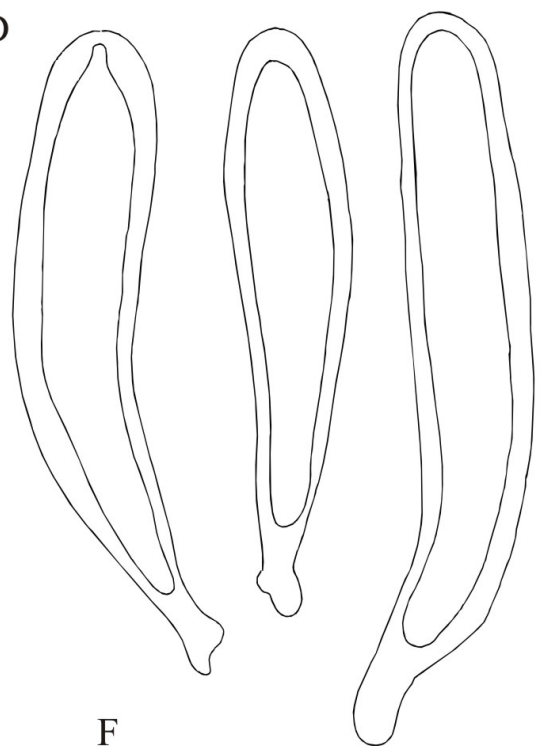

E
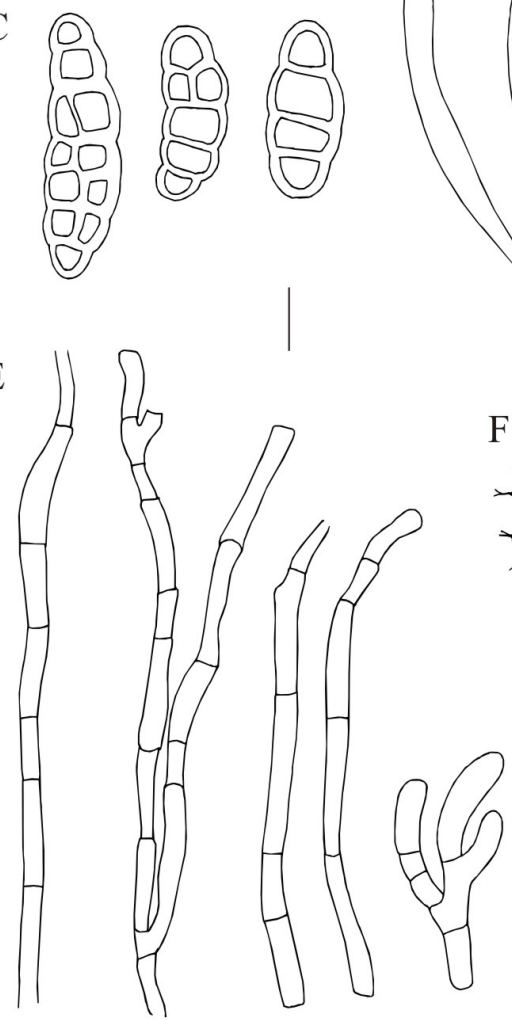

F
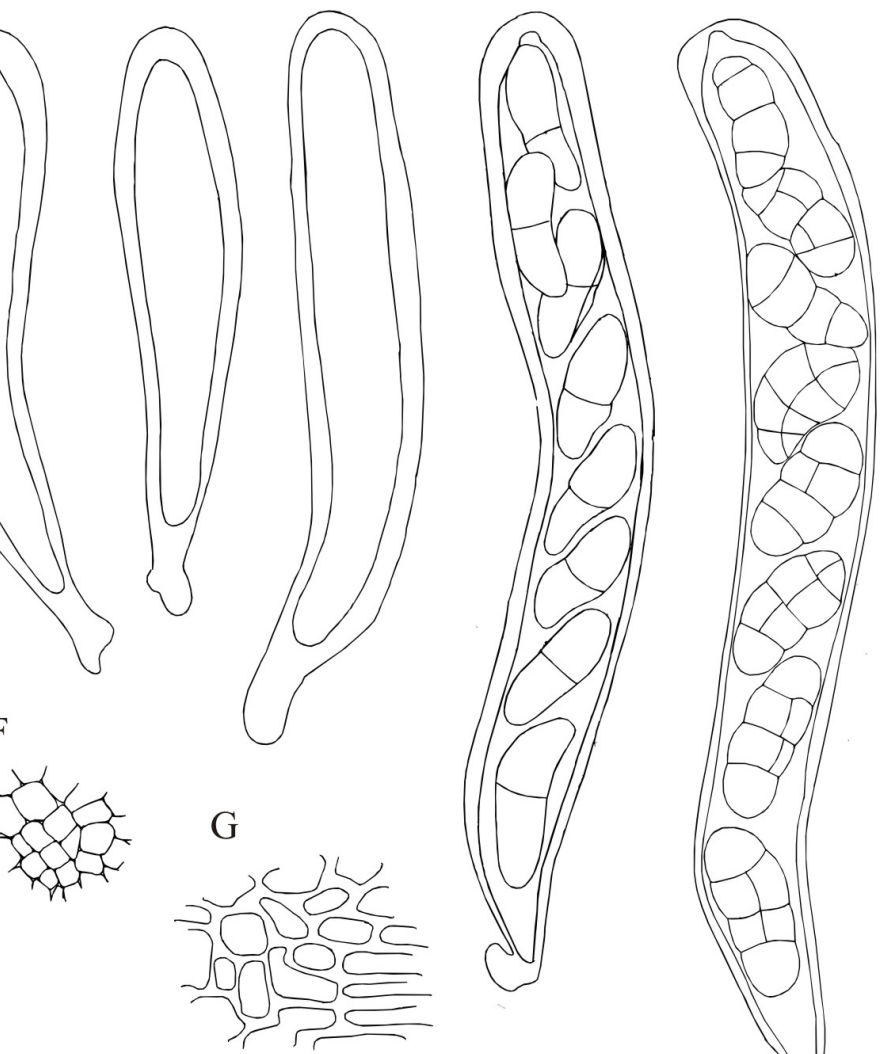

$\mathrm{H}$

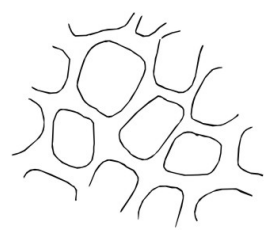

I

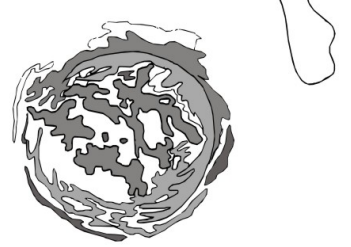

Fig. 6. Dacampia rufescentis (A, D, F, G, I = 1907 Backman; B, H = Kytövuori 811028; C, E = 1912 Linkola), A-C $=$ ascospores, $\mathrm{D}=$ asci in different stages of maturity, $\mathrm{E}=$ pseudoparaphyses, $\mathrm{F}=$ medullary excipulum, $\mathrm{G}, \mathrm{H}=$ ectal excipulum. I = elevated patch on cortex of host thallus caused by D. rufescentis. Bars (A-H) $10 \mu \mathrm{m}$, (I) $1 \mathrm{~mm}$.

Specimens studied: Varsinais-Suomi. Lohja, Ojamo, 6.X.2004 Pykälä 25983 (H); Parish village, 13.V.2006
Pykälä 28516 (H). Turku, Katariinanlaakso, 7.V.1959 Mäkinen (TUR)*, 6.VI.1934 Auer (TUR)*; Tähtitorninmäki, 26.IX.1926 Suza (TUR-V). Uusimaa. Pernaja, Hardom, 20.VIII.1912 Klingstedt (TUR)*. Pornainen, 


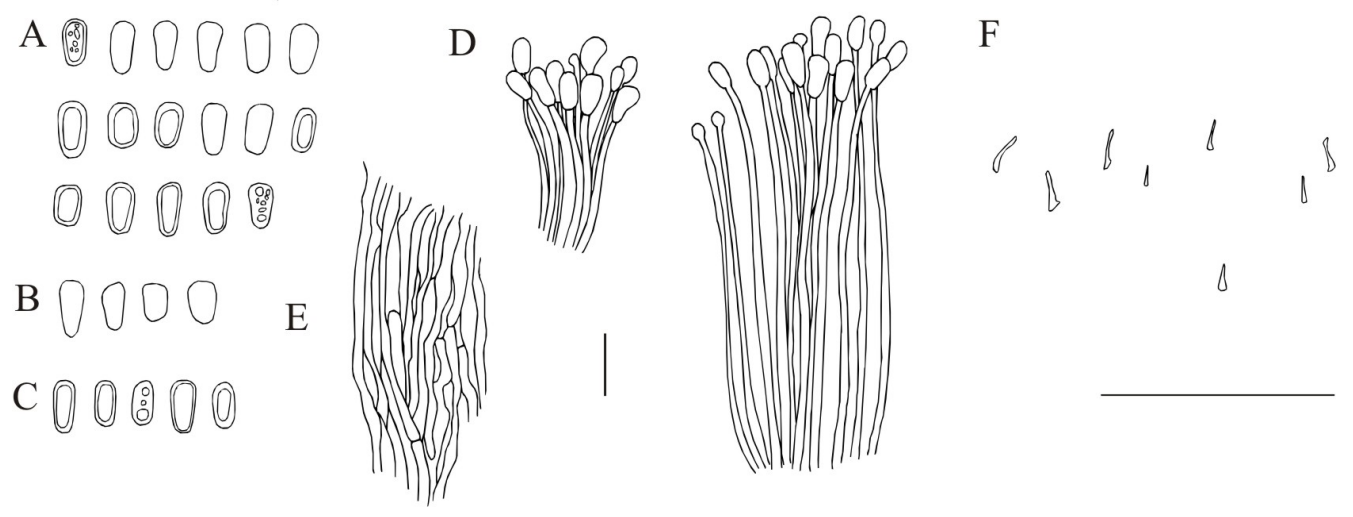

Fig. 7. Graphium aphthosae (A, E = 1914 Linkola; $\mathrm{B}, \mathrm{D}, \mathrm{F}=1967$ Pankakoski; $\mathrm{C}=1933$ Seppä), $\mathrm{A}-\mathrm{C}=\mathrm{conidia}, \mathrm{D}=$ conidiophores, $\mathrm{E}=$ detail of synnema stipe, $\mathrm{F}=$ synnemata on host thallus. Bars $(\mathrm{A}-\mathrm{E}) 10 \mu \mathrm{m},(\mathrm{F}) 1 \mathrm{~mm}$.

A

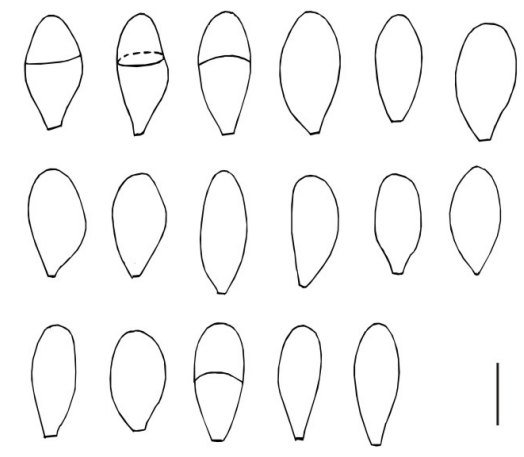

B
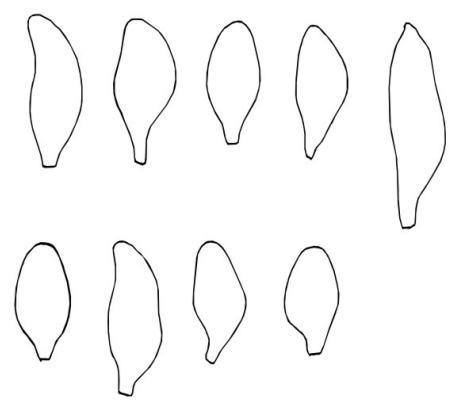

C

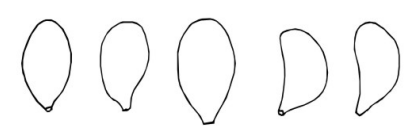

D
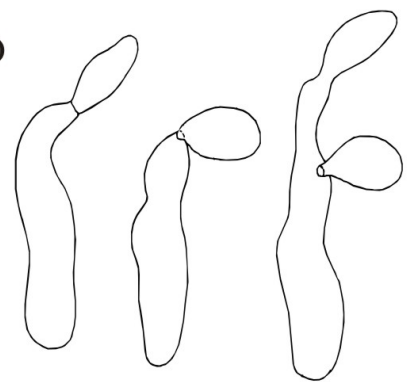

F

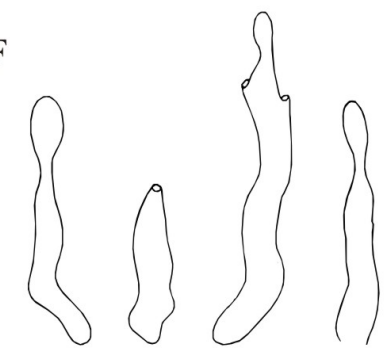

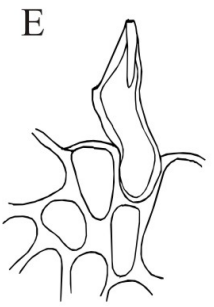

E

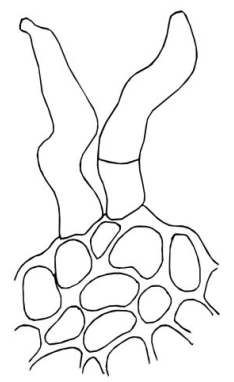

G

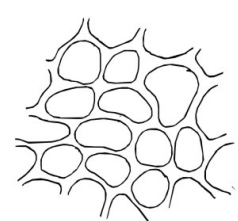

$\mathrm{H}$

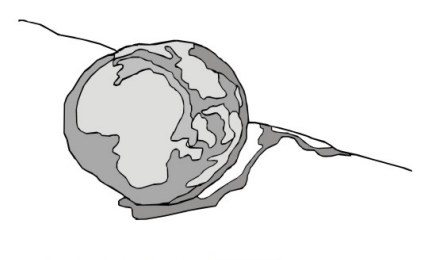

Fig. 8. Hawksworthiana peltigericola (A, D = 1959 Mäkinen; $\mathrm{B}, \mathrm{E}, \mathrm{H}=1912$ Klingstedt; $\mathrm{C}, \mathrm{F}=1934$ Auer $), \mathrm{A}-\mathrm{C}=$ conidia, $\mathrm{D}-\mathrm{F}=$ conidiophores, $\mathrm{G}=$ excipulum, $\mathrm{H}=$ gall caused by $H$. peltigericola on host thallus. Bars $(\mathrm{A}-\mathrm{G}) 10 \mu \mathrm{m}$, (H) $1 \mathrm{~mm}$. 


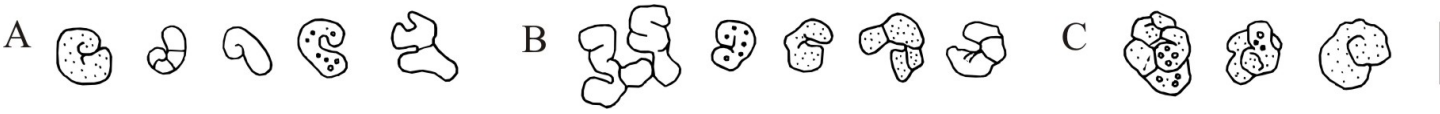

Fig. 9. Conidia of Hobsoniopsis santessonii (A = 1958 Huuskonen; $\mathrm{B}=1934$ Kari; $\mathrm{C}=1984$ Alava $)$. Bar $10 \mu \mathrm{m}$.

Hevonselkä, 4.VIII.2001 Ahti 61502c (H). Tuusula, Klemetskog, 13.VIII.1941 Häyrén (H). Vihti, Vihtijärvi, 10.VI.2003 Haikonen 22424 (H). Etelä-Savo. Kangasniemi, Rutakoski, 29.VI.2003 Haikonen 22483 (H). Kittilän Lappi. Kolari, Teuravuoma, VII.1933 Vaasio (H).

\section{Hobsoniopsis santessonii (Lowen \& D. Hawksw.) D. Hawksw. $\quad$ - Figs. 9, 44 I}

Sporodochia erumpent through the dorsal cortex of the host thallus, grey to yellowish. Conidia $7-14 \times 6-12 \mu \mathrm{m}$, mean $10.2 \times 8.5 \mu \mathrm{m}(\mathrm{n}=30$, three collections), solitary, light brown to orange, filament helicoid, multicellular, walls sparsely darkly verrucose.

\section{Host: Peltigera scabrosa.}

Hobsoniopsis D. Hawksw. is reported as a new genus for Finland. Reported also from Norway and Sweden.

Specimens studied: Varsinais-Suomi. Turku, Kakskerta, 21.VIII.1934 Kari (TUR). Uusimaa. Hanko, Tvärminne, 6.VII.1911 Linkola (H). Pyhtää, Mogenpörtö, 11.VI.1941 Fagerström (H). Etelä-Häme. Jämsä, Seppola, 3.IX.1933 Koskinen (H). Hämeenlinna, Lammi, VähäEvo, 22.VI.1986 Haikonen 7417 (H). Luhanka, Jutinsalo, 1873 Vainio (TUR-V). Pohjois-Karjala. Ilomantsi, Kuuksenvaara, 2.IX.1958 Klingstedt (H). Perä-Pohjanmaa. Kemijärvi, Jumisko, 18.VII.1966 Rintanen (H). Koillismaa. Kuusamo, parish village, 16.VI.1962 Ahti 11624 (H). Enontekiön Lappi. Enontekiö, Kaaresuvanto, 3.VII.1957 Hämet (H), 4.VII.1957 Hämet (H); Kilpisjärvi, Jehkats, 27.VII.1956 Huuskonen (H), 18.VIII.1958 Huuskonen (TUR)*. Inarin Lappi. Utsjoki, Kevo, 6.VII.1984 Alava 20924 (TUR)*, 16.VIII.1965 Ahti $21042 a(\mathrm{H}) ; \mathrm{N}$-slopes of Ailigas, 24.VIII.1974 Vitikainen $8361(\mathrm{H})$.

Illosporium carneum Fr. - Figs. 10, 44 J

Sporodochia erumpent through the dorsal cortex of the host thallus, white to pink. Conidia $5-10 \times$ 3.5-7 $\mu \mathrm{m}$ (mean $7.2 \times 4.9 \mu \mathrm{m}(\mathrm{n}=30$, four collections), $0-1$-septate, may contain guttules, a scar may be visible.
Hosts: Peltigera canina, P. didactyla, P. hymenina, P. lepidophora, P. rufescens.

Illosporium carneum is easily identified by the sporodochia it forms on the dorsal host thallus. It resembles superficially Hobsoniopsis santessonii, but their shape of conidia and choices of host differ from each other. Illosporium carneum has been usually accepted as the conidial state of Pronectria (Lawrey \& Diederich 2011), with recent molecular analyses confirming its position in the Hypocreales (Sikaroodi et al. 2001). Reported also from Norway and Sweden.

Selected specimens studied (out of 66): Ahvenanmaa. Sottunga, 8.VIII.1952 af Hällström (H). VarsinaisSuomi. Kustavi, Iso-Varestus, 25.V.1988 Mäkinen 88-65 (TUR). Turku, Kärsämäki 1.VI.1936 Auer (TUR). Uusimaa. Hanko, railway station, 23.VII.1911 Linkola (H). Raasepori, Tammisaari, Strömsö 30.V.1984 Murto 3115 (H). Etelä-Karjala. Lappeenranta, Ylämaa, 4.VII.1965 Vitikainen $317(\mathrm{H})$. Satakunta. Kankaanpää, Luomajärvi, 29.VI.1935 Laurila (H); Etelä-Häme. Orivesi, Siitama, 19.V.1974 Mikkola (H); Yliskylä, 8.VI.1982 Thuneberg $(\mathrm{H})^{*}$. Etelä-Savo. Juva, Kaihunmäki, 1.V.1983 Vitikainen 10461 (H). Etelä-Pohjanmaa. Kurikka, Mieto, 2.VII.1965 Suominen (H)*. Pohjois-Häme. Jyväskylä, Ristikivenlaakso, 18.VI.1912 Linkola (H). Pohjois-Savo. Kuopio, Suovu, 3.VI.1906 Linkola (TUR). KeskiPohjanmaa. Siikajoki, Ruukki, 19.VI.2001 Ahti 60896 (H). Kainuu. Suomussalmi, Ala-Vuokki, 5.VII.1936 Auer (TUR). Oulun Pohjanmaa. Hailuoto, Marjaniemi 10.IX.1994 Vitikainen 13290 (H). Perä-Pohjanmaa. Kemijärvi, Joutsijärvi, 30.VII.1964 Suominen (H). Koillismaa. Salla, Pieni Pyhätunturi, 4.VII.1981 leg. ? (H). Kittilän Lappi. Kolari, Äkäsjokivarsi, Kelokämppä, 20.VII.1978 Huuskonen (H). Sodankylän Lappi. Sodankylä, Peurasuvanto, 18.VI.1980 Kvist (H). Enontekiön Lappi. Enontekiö, Kuonjarvarri, 2.VIII.1947 Huuskonen (H). Inarin Lappi. Inari, Inarinjärvi, 1910? Renvall (H). Utsjoki, Niemelä, 17.VI.1980 Kvist (H).

Karsteniomyces peltigerae (P. Karst.) D. Hawksw. - Figs. 11, $44 \mathrm{~K}$

Conidiomata globose, $0.1-0.15 \mathrm{~mm}$ diam, greyish to pale or yellowish brown. Macroconidia $11.5-20 \times 3.5-5$, mean $15.9 \times 4.6 \mu \mathrm{m}(\mathrm{n}=30$, 

A : $\theta \theta$
$\mathrm{B} @ 00 \mathrm{O}$
000
$\mathrm{C} \because \frac{\circ}{\circ} \because$

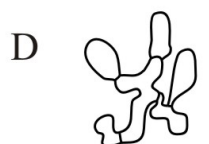<smiles>OC(O)O</smiles><smiles>C=C=O</smiles><smiles>C=O</smiles><smiles>c1ccc2ccccc2c1</smiles><smiles>C=COCC</smiles>

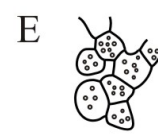

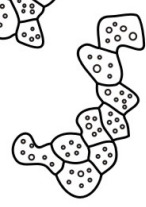

Fig. 10. Illosporium carneum (A, D = 1982 Thuneberg; $\mathrm{B}=1965$ Suominen; $\mathrm{C}, \mathrm{E}=1910$ Renvall), $\mathrm{A}-\mathrm{C}=\mathrm{conidia}$, $\mathrm{D}=$ conidiogenous cells, $\mathrm{E}=$ guttulate cells from soralia. Bar $10 \mu \mathrm{m}$.

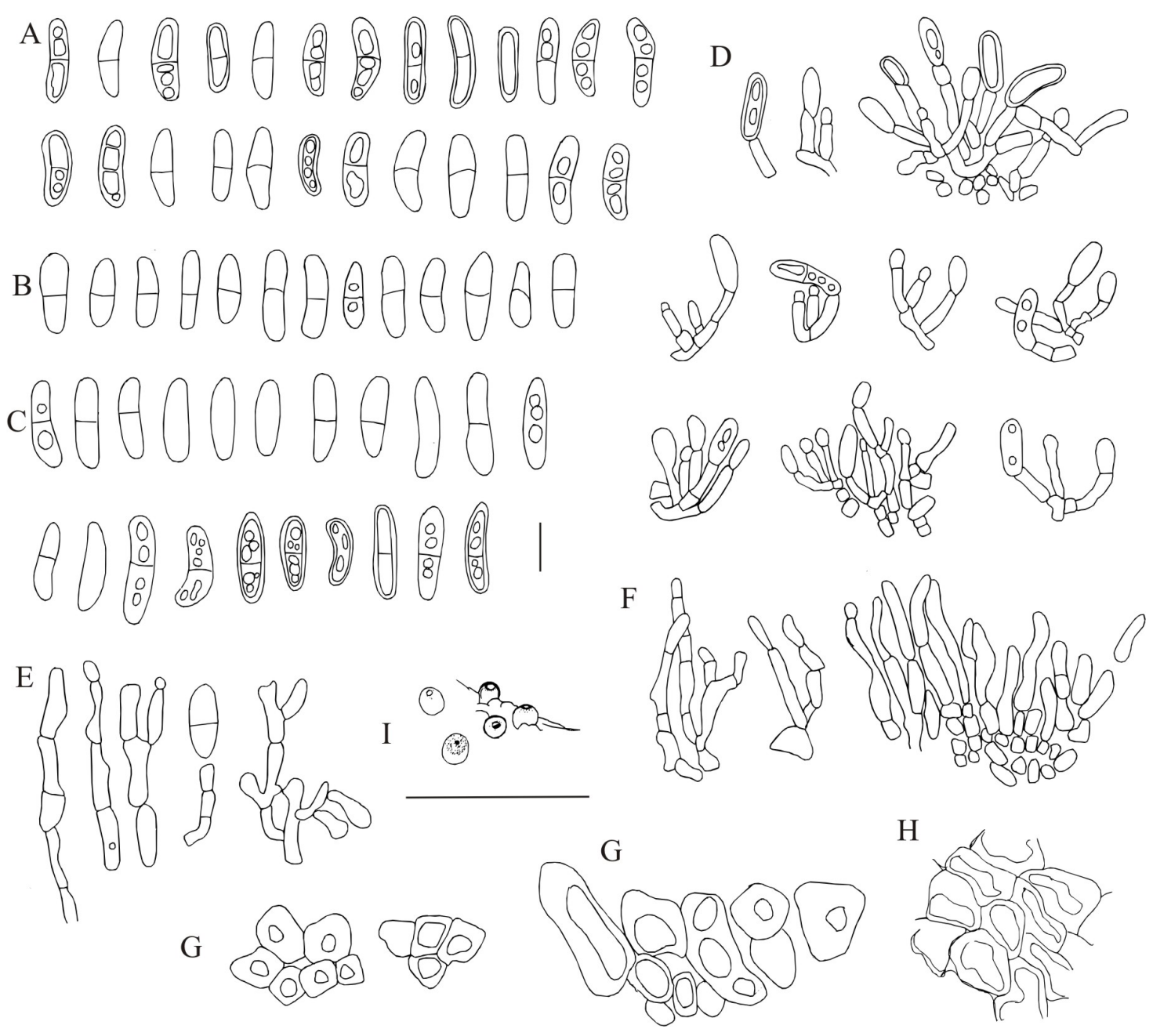

Fig. 11. Karsteniomyces peltigerae (A, D = 1965 Vitikainen; B, E = 1955 Kukkonen; C, F, G = 1911 Linkola; H, I = 1912 Linkola), A-C = conidia, D-F = conidiophores and conidiogenous cells, G, H ectal excipulum, I = pycnidia. Bars (A-H) $10 \mu \mathrm{m}$, (I) $1 \mathrm{~mm}$. 
three collections), ellipsoid-elongate, often slightly curved, 0-1 -septate. Conidiophores 2-3 $\mu \mathrm{m}$ wide, branching, septate, often constricted at septa. Ectal excipulum composed of densely packed, dark, thick-walled, cubiform cells, 7-15 $\mu \mathrm{m}$ diam. Medullary excipulum composed of thin-walled, more loosely packed cells $3.5-6.5$ $\mu \mathrm{m}$ diam.

Hosts: Peltigera canina. P. leucophlebia, P. praetextata, P. rufescens.

Karsteniomyces peltigerae is the macroconidiaproducing anamorph of Scutula miliaris (Wallr.) Trevis. It is often found without the teleomorph producing quite large amounts of aggregated pycnidia. Reported also from Norway and Sweden.

Specimens studied: Ahvenanmaa. Finström, Björkö, 28.V.1976 Alava 15890 (TUR). Varsinais-Suomi. Kemiönsaari, Västanfjärd, 29.IX.1988 Laine (TUR). Lohja, Paloniemi, 28.IV.2005 Pykälä 26717 (H). Parainen, Ersby, 3.IX.1912 Linkola (H)*; Lampis, 10.VI.1911 Linkola (H). Paimio, Hirvonpään Alitupa, 27.VI.1955 Kukkonen (H)*. Raasepori, Bromarv 20.V.1927 Linkola \& Häyrén (H); Hållonästrakten, 8.VIII.1890 Boldt. Turku, Ispoinen, 22.V.1912 Linkola (TUR-V); Kakskerta, Monnonen, 12.VII.1934 Kari (TUR); Katariinanlaakso, 23.VII.1922 Räsänen (TUR); Muhkuri, 24.IX.1945 Kallio (TUR). Uusikaupunki, 24.II.1951 Laine (TUR); Käätyjärvi-W, 25.XI.1951 Laine (TUR). Vihti, Vanjärvi, 1896 Lång (TUR). Uusimaa. Helsinki, Fredriksberg, 1874 Vainio (TUR-V); Meilahti, 7.XII.1929 Häyrén (H); Toivola, 16.VII.1874 Collin $(\mathrm{H})$. Hanko, Tvärminne, 1907 Brofeldt (TUR, two specimens); Kragen, 3.VII.1911 Linkola $(\mathrm{H})^{*}$; Långholmen, 7.VIII.1908 Rancken $(\mathrm{H})$. Espoo, Railway station, 12.XI.1911 Linkola (TUR-V); Kasaberg 31.VIII.1913 Linkola ( TUR-V). Satakunta. Sastamala, Karkku, Koski, 23.VI.1967 Suominen (H, two specimens). Etelä-Häme. Kuhmoinen, Ansiolahti, Myysälä, 10.VIII.1948 Norrlin (H); Päijälä, Rumavuori, 14.IV.1974 Oittinen 5 (H). Tammela, Mustiala 1867 Kullhem (H). Etelä-Savo. Savitaipale, Kärnäkoski, 13.VIII.1981 Vitikainen 10521, 10521 b (H). Taipalsaari, Paakkola, 5.XI.1966 Vitikainen (H)*. Etelä-Pohjanmaa. Alavus, Sapsalampi, 11.VII.1948 Leppälä (TUR, two specimens). Pohjois-Savo. Kuopio, 22.VI.1909 Heikinheimo $(\mathrm{H})$.

Lasiosphaeriopsis salisburyi D. Hawksw. \& Sivan. - Figs. 12, 44 L

Stromata superfiacial, carbonaceous, $0.4-0.6$ mm. Asci 31-62 × 15-17 $\mu \mathrm{m}$, mean $46.7 \times 15.1$ $\mu \mathrm{m}(\mathrm{n}=7$, one collection), clavate, rounded at the apex, 3-6 -spored. Ascospores 19-24 × 4.5-7 $\mu \mathrm{m}$, mean $21.5 \times 5.4 \mu \mathrm{m}(\mathrm{n}=23$, one collection $)$, 3 -septate, thick-walled, the 2 middle cells thicker walled and darker than the apical cells. Unripe spores rich with small guttules. Paraphyses 1.5-2 $\mu \mathrm{m}$ wide, branching, septate. Excipular cells $10-17 \mu \mathrm{m}$ diam., round to irregular, brown, thick-walled. In many cells a circular, ca $1.5 \mu \mathrm{m}$ diam, pore (munk pore) was observed.

\section{Host: Peltigera leucophlebia.}

Lasiosphaeriopsis was reported as a new genus to Finland by Toivanen (2008). Lasiosphaeriopsis salisburyi forms distinctive, carbonaceous, black, verrucose, erumpent and superficial stromata. It appears to be parasitical, damaging the thallus on the site of formation, but apparently not harming the host seriously as whole. Reported also from Sweden.

Specimens studied: Pohjois-Savo. Suonenjoki, Keurunmäki, 10.VII.2008 Hyvärinen. Kittilän Lappi. Kittilä, Kiistala, 24.VII.1963 Haapasaari $383(\mathrm{H})^{*}$.

\section{Libertiella curvispora D. Hawksw. \& Miądl. -Figs. 13, $45 \mathrm{M}$}

Pycnidia 0.09-0.12 mm diam, flattened-globose, pale to translucent orange, ostiole visible as a light spot. Conidia $6-8.5 \times 1.5-2 \mu \mathrm{m}$, mean 6.6 $\times 1.9 \mu \mathrm{m}(\mathrm{n}=30$, three collections), simple, often curved, rounded at both ends, thin-walled, may contain guttules. Conidiophores $2 \mu \mathrm{m}$ wide, small-celled, branched, septate. Ectal excipulum composed of dark, thick-walled cells. Medullary excipulum composed of more loosely packed angular cells.

Hosts: Peltigera canina, P. membranacea (Ach.) Nyl., P. praetextata, P. rufescens.

Libertiella curvispora does not seem to harm its host; groups of pycnidia may be find scattered on the dorsal or ventral side of the host thallus. The genus Libertiella Speg. \& Roum. is considered to be the anamorph genus of Scutula Tul. (Triebel et al. 1997). The species was first recorded from Finland by Toivanen (2008). 


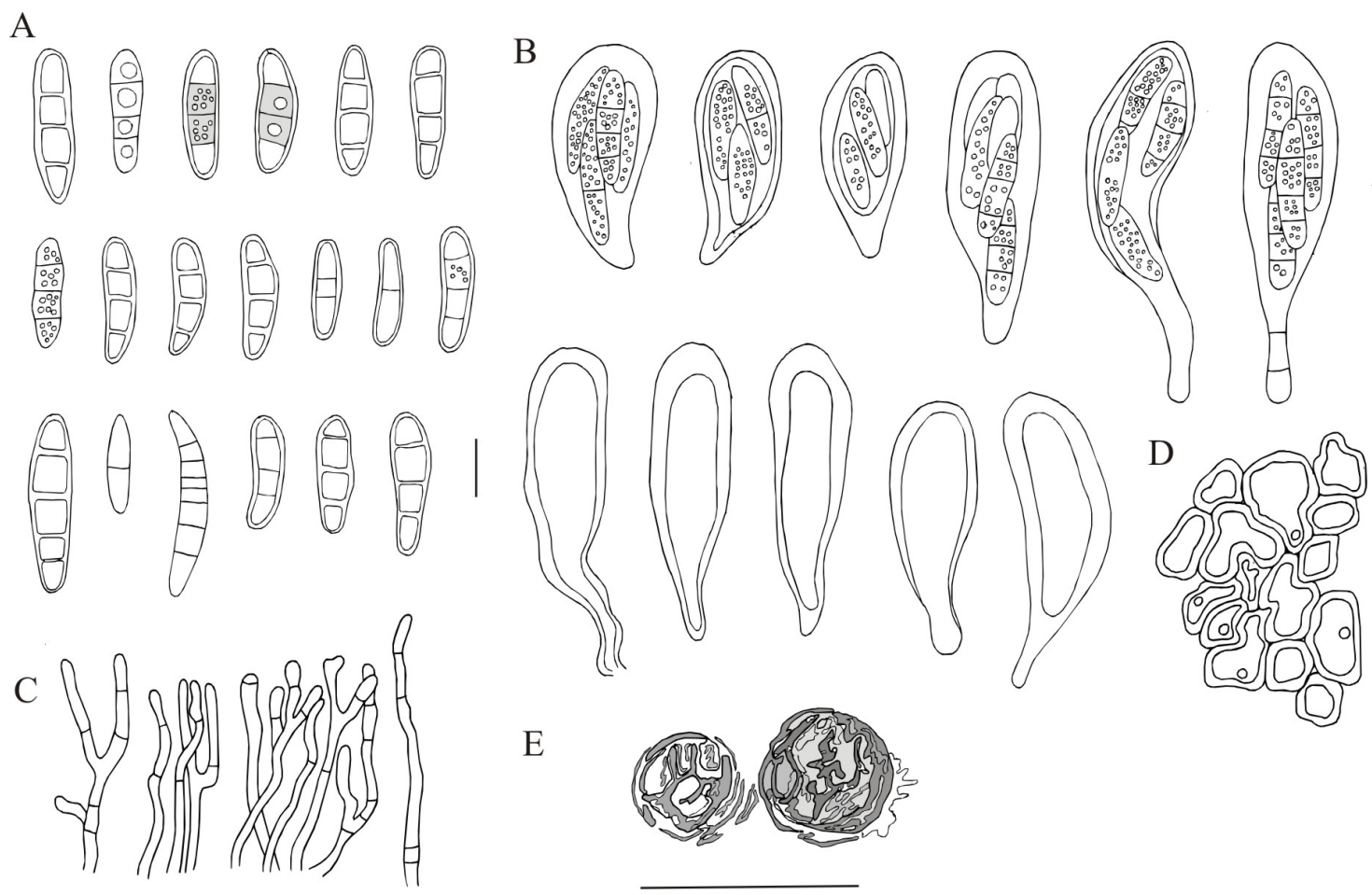

Fig. 12. Lasiosphaeriopsis salisburyi (Haapasaari 383), $\mathrm{A}=$ ascospores, $\mathrm{B}=$ asci in different stages of maturity, $\mathrm{C}=$ paraphyses, D = excipular cells with "Munk pore", E = stromata caused by L. salisburyi on host cortex. Bars (A-D) 10 $\mu \mathrm{m},(\mathrm{E}) 1 \mathrm{~mm}$.
a 00000000
B 0000800
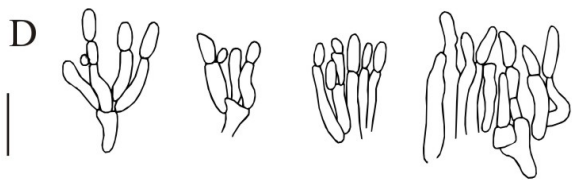
$\mathrm{C} 0000000: 0$
000080000
E 20303
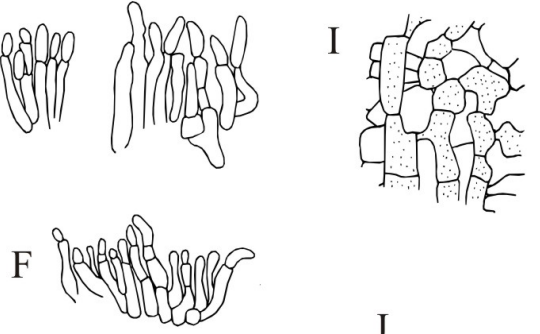

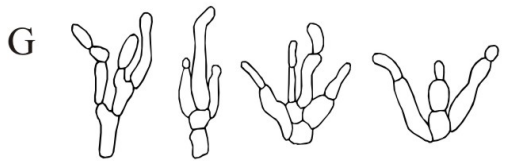

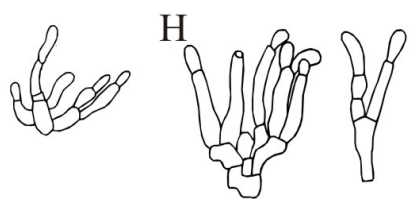
$\mathrm{J}$

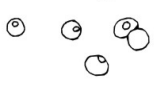

Fig. 13. Libertiella curvispora (A, D, I, J = 1964 Kytövuori \& Kytövuori; B, E= Toivonen \& Uotila 23449; $\mathrm{C}, \mathrm{G}=1937$ Hiitonen; $\mathrm{F}=$ Kuusinen 2502; $\mathrm{H}=$ Vitikainen 6070), $\mathrm{A}-\mathrm{C}=$ conidia, $\mathrm{D}-\mathrm{H}=$ conidiophores and conidiogenous cells, $\mathrm{I}=$ medullary excipulum, $\mathrm{J}=$ pycnidia. Bars (A-I) $10 \mu \mathrm{m},(\mathrm{J}) 1 \mathrm{~mm}$. 
Selected specimens studied (out of 75): Ahvenanmaa. Finström, Björkö, 30.V.1976 Alava 16033 (TUR); Grelsby, Mangelbo, 17.V.1989 Alava 22546 (TUR). VarsinaisSuomi. Karjalohja, Karkali, 14.V.1962 Koponen 3613 (H). Turku, Muhkuri, 6.X.1951 Lindgren (TUR). Uusimaa. Pernaja, Tervik, 25.VII.1992 Piirainen \& Piirainen $2398(\mathrm{H})$. Vantaa, Kårböle, 1.V.1942 Marklund $(\mathrm{H})$ Etelä-Karjala. Hamina, Vehkalahti, Pyhältö, 12.VI.1947 Fagerström (H). Satakunta. Karkku, Koski, 23.VI.1967 Suominen (H). Pomarkku, Sulkjärvi, 9.VI.1937 Laurila (H). Etelä-Häme. Kuhmoinen, Tapiola, 7.VIII.1937 Norrlin $(\mathrm{H})^{*}$; S of Isojärvi, 5.VIII.1949 Hiitonen $(\mathrm{H})^{*}$; Ruovesi, Haukkamaa, 9.VI.1964 Kytövuori \& Kytövuori (H).* Valkeakoski, Sääksmäki, Kärsä, 31.VIII.1917 Norrlin (H). Etelä-Savo. Juva, Kaihunmäki, 8.X.1978 Vitikainen 8658 (H). Etelä-Pohjanmaa. Kristiinankaupunki, Lappfjärd, 25.VI.1946 Railonsala (TUR)*. Mustasaari, Hospital, 1.IV.1953 Suominen (H). PohjoisHäme. Jyväskylä, Tuomioniemi, 29.IV.1951 Valovirta (H). Pohjois-Savo. Pieksämäki, Jäppilä, 18.VII.1964 Takala (H). Vieremä, Karankamäki, 10.-12.VIII.1989 Kuusinen $2502(\mathrm{H})^{*}$. Pohjois-Karjala. Juankoski, Säyneinen, 29.VII.1970 Vitikainen $6076(\mathrm{H})^{*}$. Keski-Pohjanmaa. Evijärvi, Järvelä, 21.VI.1907 Backman (H). Vimpeli Västerbacka, 25.IX.2003 Haikonen 22976 (H). Kainuu. Hyrynsalmi, Väisälä, 18.IX.2000 Vitikainen 16001 (H). Oulun Pohjanmaa. Haukipudas, Niemeläntörmä, 28.VII.1974 Toivonen \& Uotila $23449(\mathrm{H})^{*}$. PeräPohjamaa. Simo, Pahnila, 4.VI.1931 Räsänen (H, two specimens). Koillismaa. Kuusamo, Juuma, 6.VII.1981 Vitikainen $10137 a(\mathrm{H})$.

\section{Libertiella fennica Alstrup - Figs. 14, $45 \mathrm{~N}$}

Pycnidia $0.1-0.12 \mathrm{~mm}$ diam, globose, yellowish brown to dark brown, dark around the ostiolar area. Thallus light coloured, grainy, visible on the host thallus. Conidia 3.5-6 $\times 2.5-4.5 \mu \mathrm{m}$, mean $4.8 \times 3.2 \mu \mathrm{m}(\mathrm{n}=30$, three collections $)$, rounded, simple, may contain a guttule, scar conspicuous. Conidiophores $2 \mu \mathrm{m}$ wide, branched, septate. Conidiogenous cells cylindrical, with a collarette. Excipular cells small and rounded, cells $2-3.5 \mu \mathrm{m}$ diam.

Host: Peltigera didactyla.

Libertiella fennica appears to be commensalistic (Hawksworth \& Miadlikowska 1997). Its pycnidia form on the dorsal side of the host thallus. Reported also from Norway.

Specimens studied: Etelä-Häme. Nastola, Immilä, 15.XI.2003 Haikonen $23113(\mathrm{H})^{*}$. Etelä-Savo. Kouvola, by the railway, 20.VIII.1949 Klingstedt (H). Mikkeli, Häppälä, 19.IX.2004 Haikonen 23669 (H)*.
Libertiella malmedyensis Speg. \& Roum. - Figs. 15, $45 \mathrm{O}$

Pycnidia superficial, $0.12-0.2 \mathrm{~mm}$ diam, globose, pale yellowish to darker, ostiole dark. $\mathrm{Co}$ nidia $4-7 \times 2-4.5 \mu \mathrm{m}$, mean $5.8 \times 4.5 \mu \mathrm{m}(\mathrm{n}=30$, three collections), rounded to elongate, may contain guttules. Conidiophores 1.5-2 $\mu \mathrm{m}$ wide, sometimes branched. Ectal excipulum composed of dark- and thick-walled cells, 3.5-6 $\mu \mathrm{m}$ diam. Medullary excipulum composed of rounded, thin-walled cells, 4-4.5 $\mu \mathrm{m}$ diam.

\section{Hosts: Peltigera didactyla, P. rufescens.}

Libertiella malmedyensis may be found either on the dorsal or the ventral side of its host. It does not seem to cause any apparent harm to its host.

The species was reported as new to Finland by Alstrup (2004) and is reported also from Sweden.

Specimens studied: Uusimaa. Hanko, Tvärminne, 3.VI.1929 Pohjala (H)*. Vantaa, Backas, 14.V.1905 Sola $(\mathrm{H})^{*}$; Kårböle, Kopparberget, 1.V.1942 Marklund (H)*. Satakunta. Kokemäki, 1859 Malmgren (H). EteläHäme. Hollola, Kalliola, 7.IV.1985 Haikonen 5532 (H). Orivesi, Längelmäki, 24.VIII.1987 Miekk-oja (H). Pohjois-Häme. Saarijärvi, Mahlu, 17.VIII.1933 Koskinen $(\mathrm{H})^{*}$.

\section{Lichenopeltella peltigericola (D. Hawksw.) R. Sant. - Figs 16, $45 \mathrm{P}$}

Ascomata catathecioid, superficial, $40 \mu \mathrm{m}$ diam, almost black, with setae around the ostiole. Asci 24-35 × 9-13 $\mu \mathrm{m}$, mean $30.8 \times 11.1 \mu \mathrm{m}(\mathrm{n}=16$, three collections), bitunicate, thin-walled, sometimes thickened at the apex, 4-spored. Ascospores $14-22 \times 3.5-5 \mu \mathrm{m}$, mean $18.3 \times 4.4 \mu \mathrm{m}(\mathrm{n}=30$, three collections), allantoid to almost straight, one end tapering, septate, slightly constricted at septum, with or without guttules. Paraphyses or periphyses not observed. Setae surrounding the ostiole, 18-26 × 5-9 $\mu \mathrm{m}$, dark-coloured, thickwalled.

Hosts: Peltigera canina, P. didactyla, P. leucophlebia, $P$. membranacea, $P$. praetextata, $P$. scabrosa. Records were made during this study also on Lobaria linita and Nephroma arcticum 

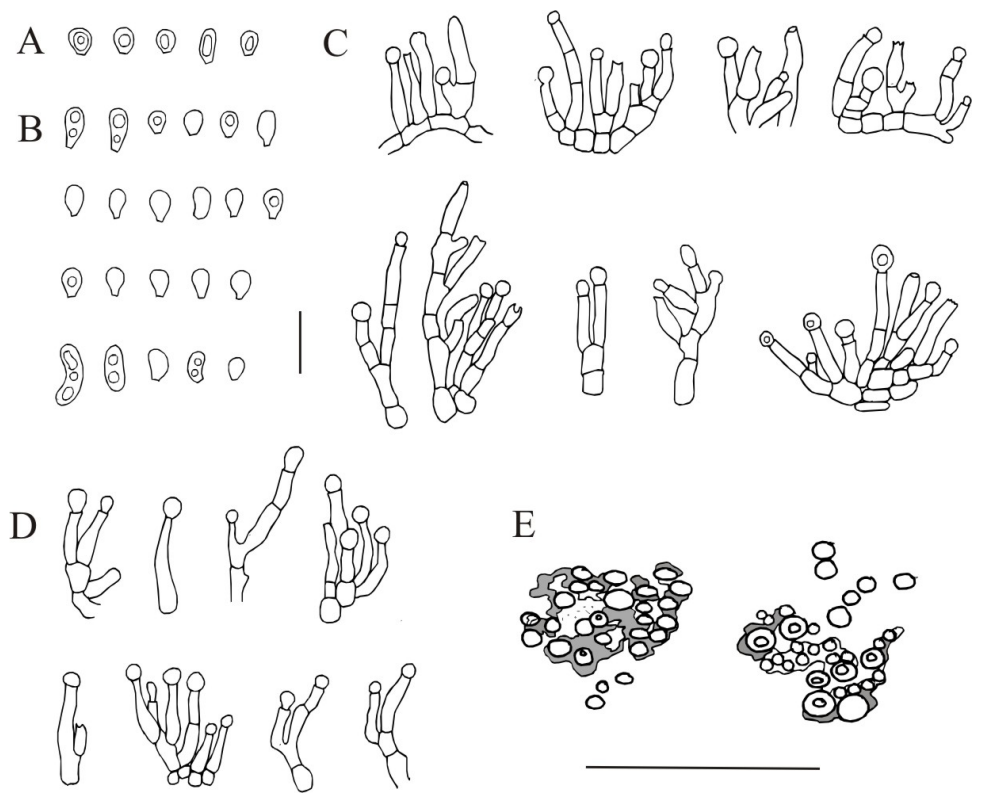

Fig. 14. Libertiella fennica (A, C, E = Haikonen 23113; B, D = Haikonen 23669), $\mathrm{A}, \mathrm{B}=$ conidia, $\mathrm{C}, \mathrm{D}=$ conidiophores and conidiogenous cells, $\mathrm{E}=$ pycnidia and thallus on dorsal cortex of host thallus. Bars (A-D) $10 \mu \mathrm{m},(\mathrm{E}) 1 \mathrm{~mm}$.
A 000000000000

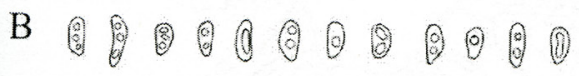
D andy
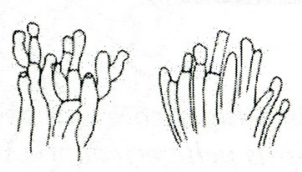

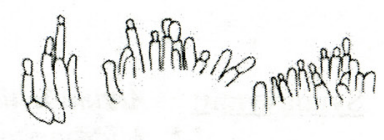
9000000000

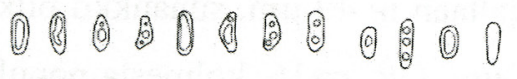
C 00000000
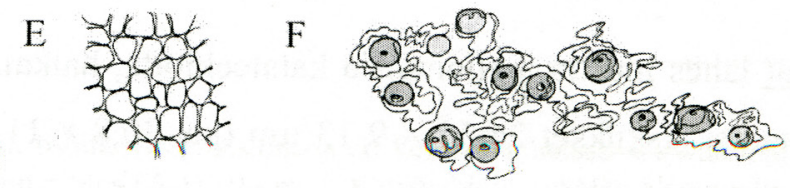

Fig. 15. Libertiella malmedyensis ( $\mathrm{A}=1905$ Sola; $\mathrm{B}, \mathrm{D}, \mathrm{E}=1942$ Marklund; $\mathrm{C}, \mathrm{F}=1929$ Pohjala $), \mathrm{A}-\mathrm{C}=$ conidia, $\mathrm{D}$ $=$ conidiophores and conidiogenous cells, $\mathrm{E}=$ excipulum, $\mathrm{F}=$ pycnidia on host thallus. Bars $(\mathrm{A}-\mathrm{E}) 10 \mu \mathrm{m},(\mathrm{F}) 1 \mathrm{~mm}$. 


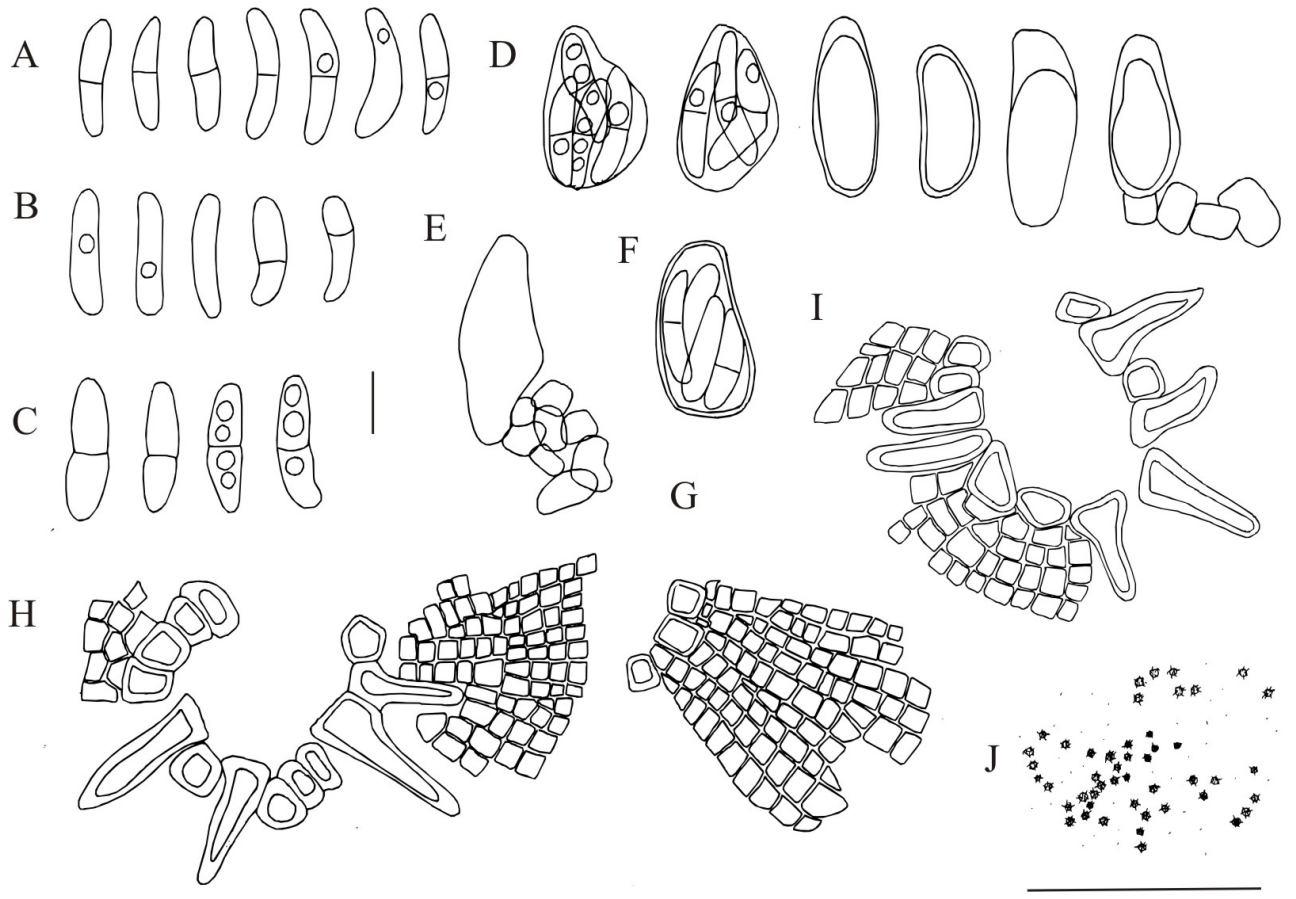

Fig. 16. Lichenopeltella peltigericola (A, D, H = 1967 Pankakoski; B, E, G = 1944 Klingstedt; C, F = Haikonen 13629; I = 1981 Kvist; J = 1946 Kukkonen), A-C = ascospores, D-F = asci in different stages of maturity, $\mathrm{G}=$ ectal excipulum, $\mathrm{H}, \mathrm{I}=$ setae and cells surrounding the ostiole, $\mathrm{J}=$ catathecia on ventral side of host thallus. Bars (A-I) $10 \mu \mathrm{m},(\mathrm{J}) 1 \mathrm{~mm}$.

(L.) Torss. Reported also on Peltigera rufescens (Spooner \& Kirk 1990).

Lichenopeltella peltigericola forms ascomata on the older thalli of several Peltigera species, usually in groups on the veins of the underside thallus lobes, but occasionally also on the upper surface. May be confused with Lichenopeltella santessonii. The species was first recorded from Finland by Toivanen (2008). Reported also from Sweden and Norway.

Selected specimens studied (out of 105): Ahvenanmaa. Finström, Grelsby, 26.IX.1992 Bruun (H). VarsinaisSuomi. Kemiönsaari, Dragsfjärd, 21.IV.1981 Kvist $(\mathrm{H})^{*}$. Masku, Karevanrahka, 18.V.1946 Kukkonen $(\mathrm{H})^{*}$. Uusimaa. Espoo, Vällskog, 3.IV.1964 Takala (TUR). EteläKarjala. Hamina, Vehkalahti, Kannusjärvi, 14.VIII.1968 Fagerström (H). Satakunta. Ikaalinen, Uuraslahti 31.VIII.1935 Laurila (H, two specimens). Etelä-Häme. Lammi, Kannaila, 12.VII.1967 Pankakoski (H)*. Sysmä, Mynnilä, 19.X.1991 Haikonen 13629 (H)*. Etelä-Savo. Mikkeli, Anttola, 12.VIII.1983 Vitikainen $10877(\mathrm{H})$ Pohjois-Häme. Jyväskylä, 12.XI.1944 Klingstedt (H)*.
Pohjois-Karjala. Lieksa, Pielisjärvi 24.VIII.1966 Vitikainen 2153 a (H). Ilomantsi, Ilaja, 17.VIII.1925 Waris (TUR, on Nephroma arcticum). Pohjois-Savo. Kuopio, Levänen, 5.V.1946 Leppälä (TUR, on Nephroma arcticum). Etelä-Pohjanmaa. Laihia, Pappila, 27.VI.1960 Takala (TUR). Perä-Pohjanmaa. Keminmaa, Kemi rural commune, 23.VII.1964 Suominen (H). Koillismaa. Kuusamo, Liikanen, 23.VII.1949 Kari (TUR, on Nephroma arcticum); Rukajärvi, 19.VII.1949 Koskinen (TUR, on Nephroma arcticum). Kittilän Lappi. Kittilä, Isovaara, 8.VIII.1877 Hjelt \& Hult (H). Enontekiön Lappi. Enontekiö, Jollonoaivi, 25.VII.1957 Huuskonen (TUR, on Lobaria linita). Inarin Lappi. Utsjoki, Kevojoki valley, 20.VIII.1965 Ahti 20775 (H).

\section{Lichenopeltella santessonii (P.M. Kirk \&} Spooner) R. Sant. - Figs. 17, 45 Q

Ascomata catathecioid, superficial, 100-120 $\mu \mathrm{m}$ diam, dark brown, sometimes with short setae around the ostiole. Asci 34-50 × 11-12 $\mu \mathrm{m}$, mean $41.9 \times 11.4 \mu \mathrm{m}(\mathrm{n}=14$, two collections $)$, bitunicate, wall CR-, 8-spored. Ascospores 12-17 $\times 3-5 \mu \mathrm{m}$, mean $14.1 \times 3.5 \mu \mathrm{m}(\mathrm{n}=33$, two col- 

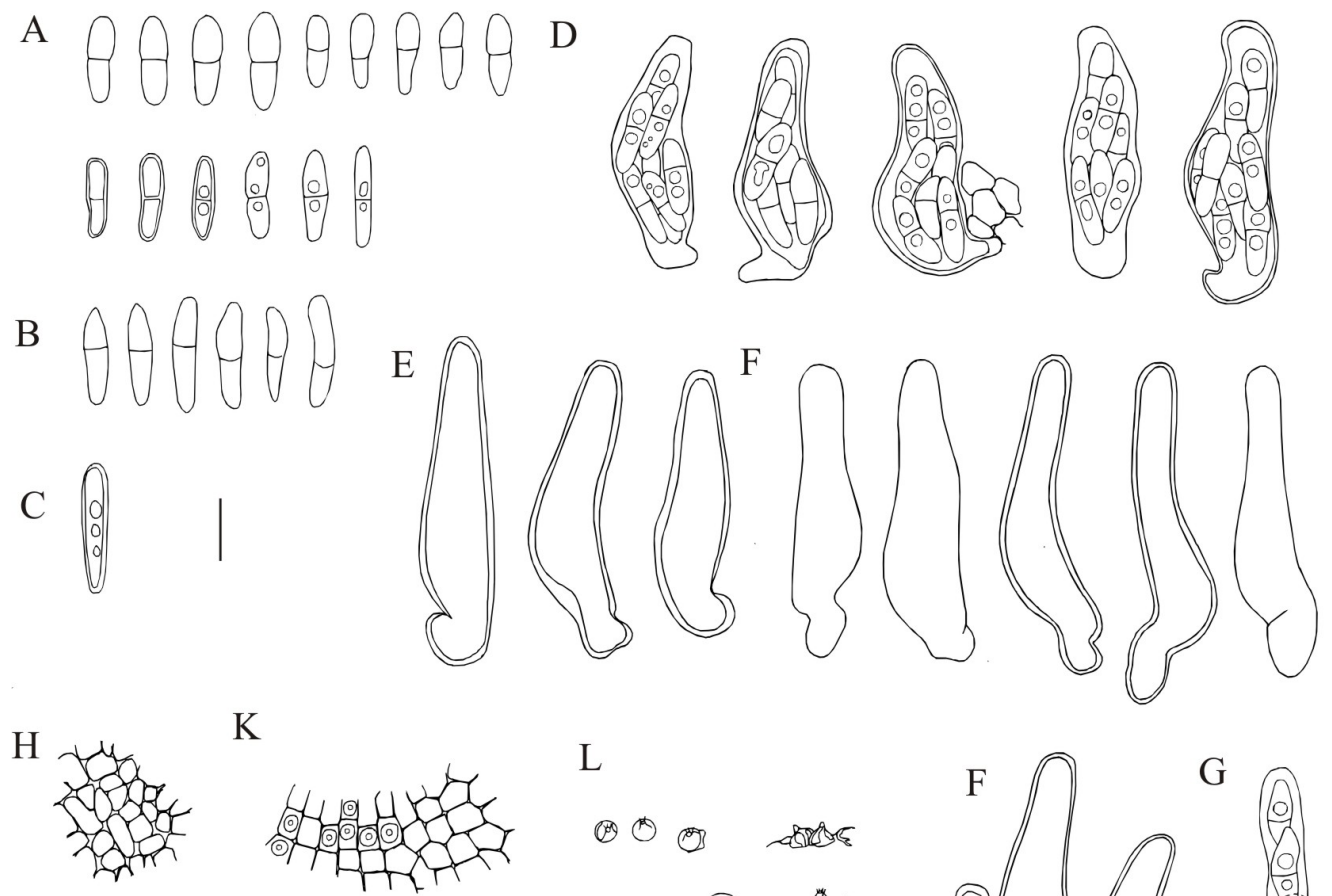

K
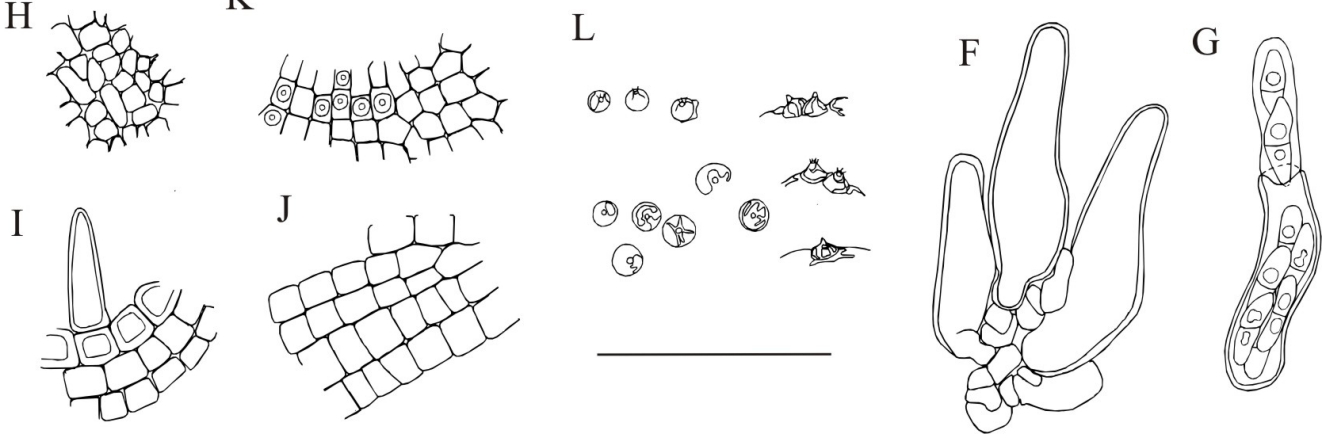

Fig. 17. Lichenopeltella santessonii (A, D, G-I, K = 1915 Räsänen; B, E = 1917 Lindberg; F = 1967 Fagerström; C, $\mathrm{J}=1965$ Huuskonen; $\mathrm{L}=1933$ Häyrén), $\mathrm{A}-\mathrm{C}=$ ascospores, $\mathrm{D}=$ mature asci with ascospores, $\mathrm{E}, \mathrm{F}=\mathrm{empty}$ asci, $\mathrm{G}$ = opening, bitunicate ascus, $\mathrm{H}=$ medullary excipulum, $\mathrm{I}=$ seta, margin of ostiole, $\mathrm{J}=$ ectal excipulum, $\mathrm{K}=\mathrm{detail}$ of catathecium, $\mathrm{L}=$ catathecia on ventral side of host thallus. Bars (A-K) $10 \mu \mathrm{m},(\mathrm{L}) 1 \mathrm{~mm}$.

lections), septate, slightly constricted at septum, may contain guttules. Paraphyses or periphyses not observed. Setae surrounding the ostiole, $15 \times$ $4 \mu \mathrm{m}$, thick-walled.

Hosts: Peltigera aphthosa, P. canina, P. leucophlebia, P. praetextata, P. rufescens, P. scabrosa. Also found on Lobaria linita, L. pulmonaria (L.) Hoffm., and Nephroma expallidum (Nyl.) Nyl. during this study.

Lichenopeltella santessonii appears to be widespread and frequent. The catathecioid ascomata form on the older thalli of several Peltigera species, usually on the veins of the underside thallus lobes, but occasionally also on the upper surface. Distinguished from L. peltigericola by larger ascomata, asci and ascospores. The species was first recorded from Finland by Toivanen (2008). Reported also from Sweden.

Selected specimens studied (out of 37): Ahvenanmaa. Jomala, Kungsö, 14.VIII.1945 Fagerström (H). Varsinais-Suomi. Lohja, Jalassaari, 10.IX.1917 Lindberg (H)*. Parainen, Ålö, 7.1916 Pesola $(\mathrm{H})^{*}$. Uusimaa. Espoo, Nuuksio, 18.XI.1934 Puolanne (H, two specimens). Etelä-Karjala. Miehikkälä, Virokoski, 29.VIII.1967 Fagerström (H)*. Satakunta. Eura, Kauttua, 16.XI.1946 Klingstedt (H). Etelä-Häme. Hollola, Upila, 1876 Norrlin (H). Tampere, Teisko, 3.VIII.1967 Laine (TUR, on Lobaria pulmonaria). Etelä-Savo. Mäntyharju, Haarala railway stop, 9.VIII.1964 Suominen (H). Pohjois-Häme. 
A

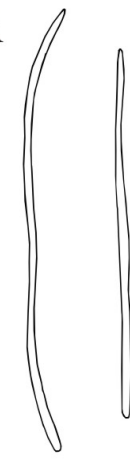

B

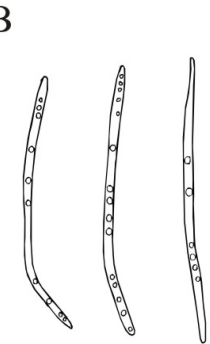

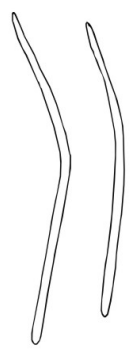

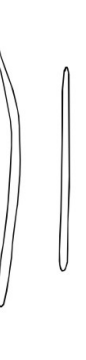

$\mathrm{D}$
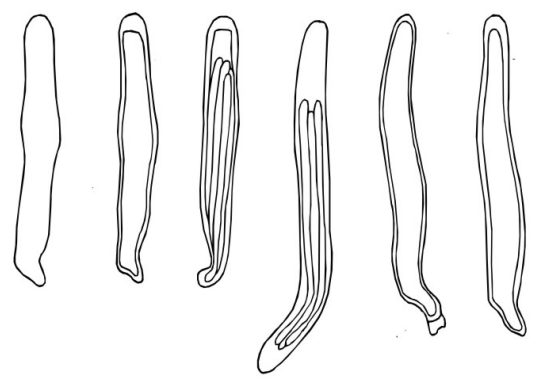

E

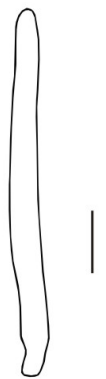

F

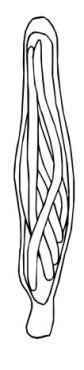

G

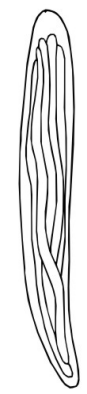

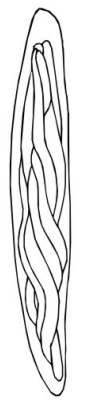

$\mathrm{H}$

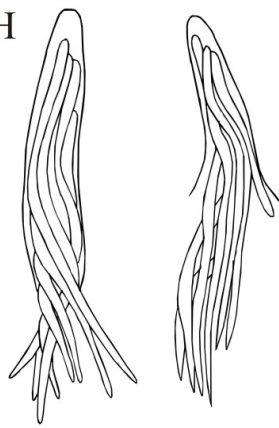

L

K

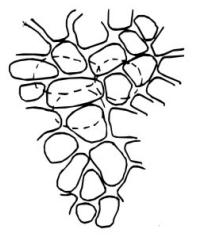

$\mathrm{M}$

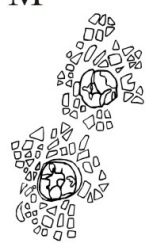

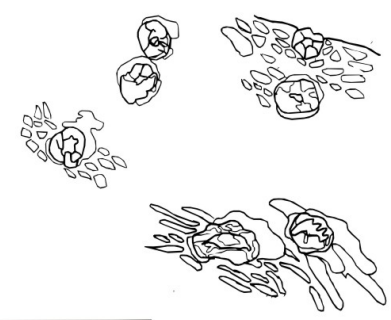

Fig. 18. Nanostictis peltigerae (A, D, I, L = Kytövuori \& Suominen 916; B, E = 1979 Ervi; C, G, H, K = 1948 af Hällström; $\mathrm{F}=$ Vänskä 3389; $\mathrm{M}=1917$ Lindberg), $\mathrm{A}-\mathrm{C}=$ ascospores, $\mathrm{D}-\mathrm{G}=$ asci in different stages of maturity, $\mathrm{H}=$ broken asci with ascospores, commonly seen in squash mounts, $\mathrm{I}, \mathrm{J}=$ paraphyses, $\mathrm{K}=$ setae, $\mathrm{L}=$ excipulum, $\mathrm{M}=$ apothecia. Bars (A-L) $10 \mu \mathrm{m},(\mathrm{M}) 1 \mathrm{~mm}$.

Saarijärvi, Parish village, 15.VII.1933 Häyrén (H)*. Pohjois-Savo. Juankoski, Säyneinen, 8.1965 Huuskonen (H). Perä-Pohjanmaa. Simo, Syvälahti, 2.VIII.1915 Räsänen $(\mathrm{H})^{*}$. Koillismaa. Kuusamo, Juuma, 12.VI.1980 Vitikainen 9973 (H). Kittilän Lappi. Kolari, Teuravuoma, 7.1933 Vaasio (H). Enontekiön Lappi. Enontekiö, Kilpisjärvi, SE-Saana 31.VII.1949 Huuskonen (TUR, on Nephroma expallidum); Porojärvet, Anjelonji, 28.VII.1955 Henssen Le 169 (TUR, on Nephroma expallidum). Inarin Lappi. Utsjoki, Linkkapahta, 12.VII.1964 Laine (TUR, on Nephroma expallidum).
Nanostictis peltigerae M.S. Christ.

- Figs. 18, 45 R

Ascomata apothecioid, $0.15-0.25 \mathrm{~mm}$, superficial, disc-shaped, margin prominent, cracked, white. Asci 39-59 × 4-6.5(-10) $\mu \mathrm{m}$, mean 50.5 $\times 5.6 \mu \mathrm{m}(\mathrm{n}=20$, three collections $)$, cylindrical, thin-walled, thickened at the apex. 8-spored. $A s$ cospores $32-69 \times 1-2 \mu \mathrm{m}$, mean $49.9 \times 1.5 \mu \mathrm{m}$ $(\mathrm{n}=30$, three collections), hyaline, thread-like, twisted together in a bundle. Paraphyses 1.5-2 $\mu \mathrm{m}$ thick, septate, branched, with the tips often 
A

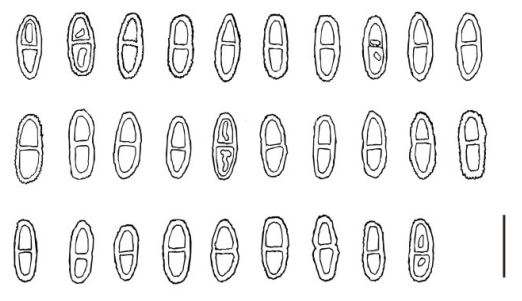

B

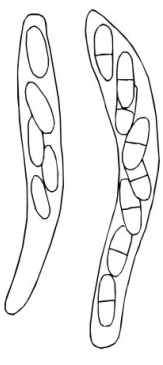

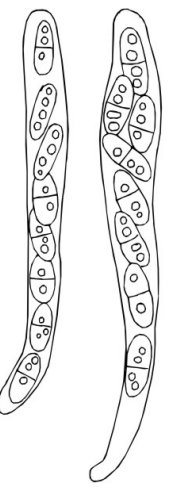

$\mathrm{C}$
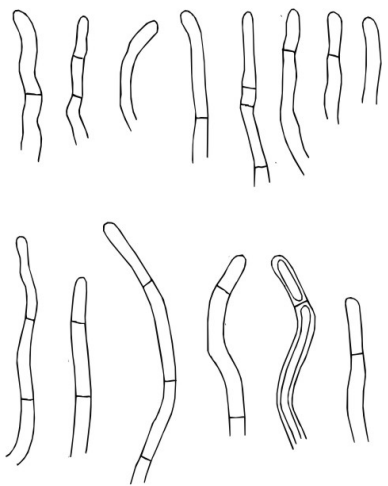

$\mathrm{D}$

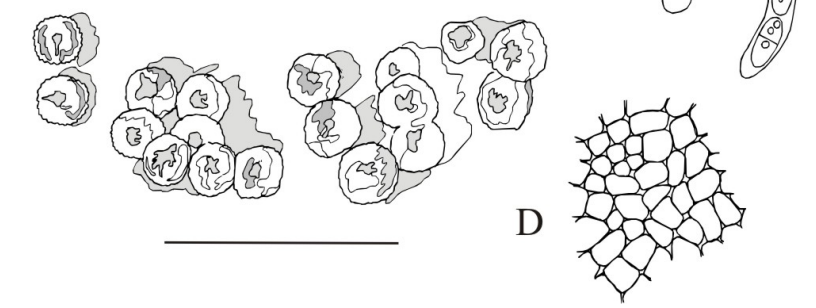

Fig. 19. Nectriopsis lecanodes $(\mathrm{A}=1951$ Klingstedt $\mathrm{B}, \mathrm{E}=$ Vitikainen 8680; $\mathrm{C}, \mathrm{D}=1945$ af Hällström $)$, $\mathrm{A}=$ ascospores, $\mathrm{B}=$ asci with unripe ascospores, $\mathrm{C}=$ hairs, $\mathrm{D}=$ excipulum, $\mathrm{E}=$ perithecia. Bars $(\mathrm{A}-\mathrm{D}) 10 \mu \mathrm{m},(\mathrm{E}) 1 \mathrm{~mm}$.

somewhat swollen. Excipular cells rounded, ca $5 \mu \mathrm{m}$ diam.

Hosts: Peltigera aphthosa, P. canina, P. leucophlebia, P. neckeri, P. neopolydactyla, P. polydactylon, $P$. scabrosa, $P$. praetextata, $P$. rufescens. Reported also from Peltigera malacea.

The white, thick-rimmed apothecia of Nanostictis peltigerae are usually crowded on the ventral side of the host thallus, partly immersed in the hyphae. Occasionally the apothecia may form on the dorsal side, partly immersed when young, superficial at maturity. Microscopically easily identified by the vermiform ascospores. Reported also from Norway and Sweden.

Selected specimen studied (out of 77): Varsinais-Suomi. Lohja, Jalassaari, 19.IX.1917 Lindberg (H, two specimens)*. Uusimaa. Kirkkonummi, Porkkala, 3.V.1970 Alanko 14709 (H)*. Kouvola, Elimäki, 23.IX.1958 Klingstedt (H). Mäntsälä, Ohkola, 13.X.1963 Kytövuori \& Suominen $916(\mathrm{H})^{*}$. Sipoo, Mårtensby, 24.VII.1948 af Hällström (H, two specimens)*. Siuntio, Övitsby, 27.VIII.1968 Vänskä 3389 (H)*. Etelä-Karjala. Miehikkälä, Hauhia, 8.VII.1968 Fagerström (H). Satakunta. Kankaanpää, Venesjärvi , 2.VII.1934 Laurila (H). EteläHäme. Jyväskylä, Korpilahti, Putkilahti, 15.VIII.1979 Ervi $(\mathrm{H})^{*}$. Etelä-Savo. Hirvensalmi, Kilkinkylä, 22.VI.1958 Räsänen (TUR). Etelä-Pohjanmaa. Alavus, Keskikylä, 2.VI.1947 Leppälä (H). Pohjois-Häme. Kannonkoski, Lakomäki, VI.1894 Kihlman (H). Äänekoski, Kuhnamojärvi-W, 11.V.1947 Klingstedt (H). Pohjois-
Savo. Heinävesi, Tyvi, 7.VI.2002 Haikonen 21373 (H). Pieksämäki, Jäppilä, 18.VII.1964 Takala (H). PohjoisKarjala. Joensuu, Tuupovaara, Rekivaara, Takala 3650 (H). Polvijärvi, Sotkuma, 11.X.1964 Lehväslaiho (H). Keski-Pohjanmaa. Kokkola, Kälviä, Peitso, 1.VIII.1923 Kujala (H). Kainuu. Kajaani, Nuasjärvi, 6.VIII.1921 Huuskonen (H). Perä-Pohjanmaa. Simo, Syvälahti, 23.IX.1922 Räsänen (H). Koillismaa. Kuusamo, Paljakka, 8.VII.1981 Alava 19635, 19636, 19638 (TUR). Enontekiön Lappi. Enontekiö, between Palojoensuu and Muotkajärvi, 22.VII.1956 Huuskonen (H). Inarin Lappi. Inari, Sarviniemi, 7.VII.1910 Renvall (H).

\section{Nectriopsis lecanodes (Ces.) Diederich \& Schroers - Figs. 19, $45 \mathrm{~S}$}

Ascomata perithecioid, $0.18-0.26 \mathrm{~mm}$, globose to subglobose, white, hairy or pruinose. Asci 39$70 \times 4-8 \mu \mathrm{m}$, mean $53.4 \times 6.0 \mu \mathrm{m}(\mathrm{n}=14$, three collections), cylindrical, very thin-walled but slightly thickened at apex, 8-spored. Ascospores 8-11 × 2.5-4 $\mu \mathrm{m}$, mean $9.6 \times 3.5 \mu \mathrm{m}(\mathrm{n}=30$, three collections), ellipsoid, slightly verruculose, septate, sometimes slightly constricted at septum, may contain guttules. Setae $2 \mu \mathrm{m}$ diam, septate. Excipular cells rounded, thin-walled, 4-8 $\mu \mathrm{m}$ diam.

Hosts: Peltigera aphthosa, P. canina, P. collina, P. malacea, P. neopolydactyla, P. praetextata, $P$. rufescens. Also found during this study on Neph- 


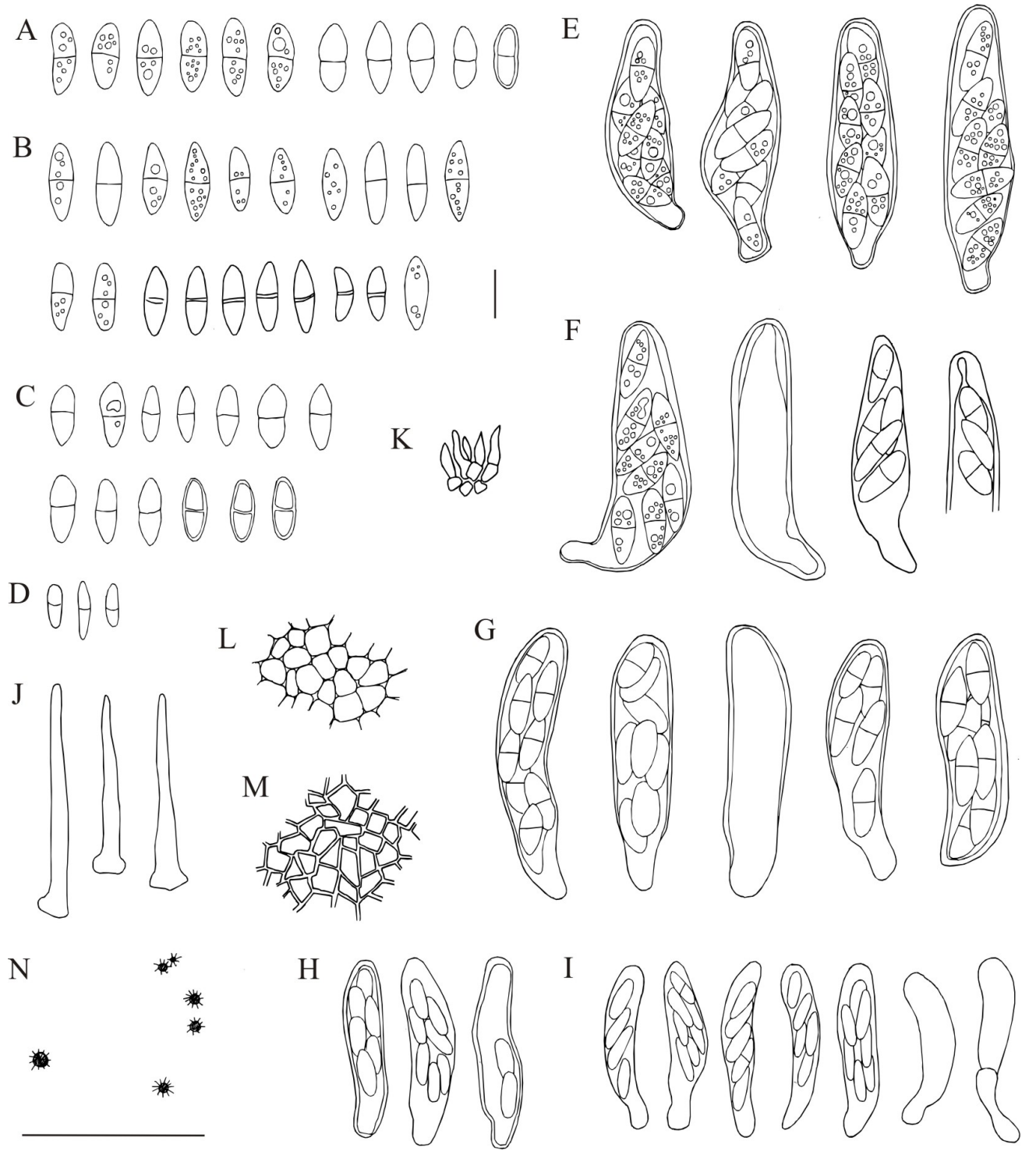

Fig. 20. Niesslia peltigericola (A, E, L, N = 1958 Huuskonen; B, F = Takala 1271; C, G = 1936 Auer; D, H, J, M = 1873 Lang; I = 1981 Kvist K = 1955 Henssen $), A-D=$ ascospores, E-I = asci in different stages of maturity, J = setae, $\mathrm{K}=$ cells on excipulum, $\mathrm{L}=$ medullary excipulum, $\mathrm{M}=$ ectal excipulum, $\mathrm{N}=$ perithecia. Bars $(\mathrm{A}-\mathrm{M}) 10 \mu \mathrm{m},(\mathrm{N}) 1 \mathrm{~mm}$.

roma resupinatum (L.) Ach. and Lobaria scrobiculata (Scop.) DC.

The ascomata of Nectriopsis lecanodes are superficial and scattered on the dorsal cortex of the host thallus. Reported also from Norway and Sweden.
Specimens studied: Ahvenanmaa. Kökar, 15.VI.1934 Kari, on Lobaria scrobiculata (TUR). Varsinais-Suomi. Lohja, 6.IX.2008 Pykälä 33671 (H). Salo, Särkisalo, Förby, 1.VIII.1985 Alava 21256 (TUR). Turku, 15.X.1938 Laurila (H); Ispoinen, 8.IX.1908 Linkola (H); Kakskerta, 17.VIII.1934 Kari (TUR), 15.VII.1934 Kari (TUR); Ruissalo, 11.IX.1932 Kari (TUR). Vihti, Olkkala, 2.IV.1897 Lång (H). Uusimaa. Hanko, Tvärminne, 9.VIII.1978 Vitikainen $8680(\mathrm{H})^{*}$. Tuusula 12.X.1941 Häyrén $(\mathrm{H})$. Etelä-Häme. Hartola, 23.VII.1945 af Hällström (H)*. 
Jyväskylä, Korpilahti, 1873 Vainio, on Nephroma resupinatum (TUR). Koski 1871 Vainio (TUR). Etelä-Savo. Kouvola, 14.X.1951 Klingstedt $(\mathrm{H})^{*}$.

\section{Niesslia peltigericola (D. Hawksw.) Etayo - Figs. 20, $45 \mathrm{~T}$}

Ascomata perithecioid, superficial, globose, black, $40-80 \mu \mathrm{m}$ diam, setose. Setae prominent, 20-48 $\mu \mathrm{m}$ long, usually in the upper part of the perithecium. Asci $40-58 \times 10-14 \mu \mathrm{m}$, mean 49.7 $\times 12.7 \mu \mathrm{m}(\mathrm{n}=20$, three collections $)$, bitunicate, cylindrical or sack-shaped, hyaline, $\mathrm{CR}-. . A s-$ cospores $10-15 \times 4-4.5 \mu \mathrm{m}$, mean $13 \times 4.8 \mu \mathrm{m}$ $(\mathrm{n}=30$, three collections), spindle-shaped, thinwalled, septate, sometimes slightly constricted at septum, with or without guttules. Paraphyses not present. Ectal excipulum of textura angularis, cells thick-walled, 4-6 $\mu \mathrm{m}$ diam. Medullary excipulum of textura globosa, cells 4-6 $\mu \mathrm{m}$ diam.

Hosts: Peltigera aphthosa, P. leucophlebia, P. malacea, $P$. scabrosa. Reported also on $P$. britannica (Gyeln.) Holt.-Hartw. \& Tønsberg (Nordin et al. 2010).

Niesslia peltigericola has a typical pyrenomycetous appearance, with its dark, setose, perithecia, which form in abundance both on the dorsal and ventral sides on older, dying or dead lobes of the host thalli. The species is common and widespread in Finland. It was first recorded from Finland by Toivanen (2008).

Selected specimens studied (out of 113): Ahvenanmaa. Hammarland, Signilskär, 15.VI.1969 Björkwall (H)*. Varsinais-Suomi. Karjalohja, Karkali, 31.V.1962 Suominen \& Koponen $4148(\mathrm{H})$. Uusikaupunki, Arvassalo, 8.IV.1981 Laine (TUR). Uusimaa. Askola, Monninkylä, 25.VII.1940 Tynni (H). Raasepori, Tammisaari, Österby, 23.XI.1929 Häyrén (H). Etelä-Karjala. Kouvola, Anjalankoski, 21.VII.1969 Fagerström (H). Ylämaa, Hujakkala, 29.IV.1941 Laurila (H). Satakunta. Kankaanpää, Venesjärvi, 8.VII.1934 Laurila (H). EteläHäme. Luhanka, Parish village, 1873 Lang $(\mathrm{H})^{*}$. Ypäjä, Vähäsuo, 4.XII.1966 Kantee (H). Etelä-Savo. Luumäki, Harattalanjärvi-N, 4.VII.1965 Takala 1271 (H)*. Suomenniemi, Kiesilä, 8.VIII.1983 Vitikainen 10725 (H). Laatokan Karjala. Parikkala, Kolmikanta, 18.IV.1987 von Bach 139 (H). Etelä-Pohjanmaa. Isokyrö, Orisberg, 12.VI.1903 Rancken (H). Kristiinankaupunki, Lappfjärd, Pyhävuori, 3.V.1953 Railonsala (TUR). Pohjois-Häme. Jyväskylä, 21.VI.1912 Leino (H); Saarijärvi, Parish village, 23.IX.1959 Ahti 9011 (H). Pohjois-Savo. Kuopio,
Neulamäki, 11.V.1947 Huuskonen (TUR). PohjoisKarjala. Ilomantsi, Hattu, Ahopelto, 5.VIII.1968 Maksimainen (H). Keski-Pohjanmaa. Kokkola, Kaarlela, 23.V.1967 Takala 3197 (H). Kainuu. Ristijärvi, Mustavaara, 27.VI.1936 Auer (H*, TUR). Oulun Pohjanmaa. Oulunsalo, Sanginjoki, 8.X.1973 Ulvinen (H). PeräPohjanmaa. Pello, Juoksenjoki, 19.VIII.1970 Vitikainen 6622 (H). Koillismaa. Salla, NE of church, 31.VII.1964 Suominen (H); Ruuhijoki, 5.VII.1981 Kvist (H)*. Kittilän Lappi. Kittilä, Alakylä, 20.IX.1956 Ahti (H); Isovaara, 17.VI.1908 Lång (H). Sodankylän Lappi. Sodankylä, Nattastunturit, 10.VI.1959 Ahti 10156 (H). Enontekiön Lappi. Kilpisjärvi, Saana, 18.VI.1955 Henssen (H, two specimens)*; Ropinsalmi, 17.VIII.1958 Huuskonen $(\mathrm{H})^{*}$. Inarin Lappi. Utsjoki, Sujala, 11.VIII.1964 Hakulinen (TUR).

\section{Pezizella epithallina (W. Phillips \& Plowr.) Sacc. - Figs. 21, $45 \mathrm{U}$}

Ascomata apothecioid, superficial, disc-shaped, plane, $0.2-0.34 \mathrm{~mm}$ diam, colour varies from very pale to darker orange, translucent, margins often paler than the disc, very shortly stipitate, often appearing sessile. Asci cylindrical-clavate, unitunicate, $63-105 \times 10-15 \mu \mathrm{m}$, mean $84.7 \times$ $12.4 \mu \mathrm{m}(\mathrm{n}=20$, one collection), thickened at the apex, 8-spored. Ascospores 10-14 × 4-7 $\mu \mathrm{m}$, mean $11.3 \times 4.6 \mu \mathrm{m}(\mathrm{n}=30$, one collection), elongate-ellipsoid, simple, occasionally septate, slightly attenuated at the other end. Paraphyses of ascal length, $2 \mu \mathrm{m}$ wide, septate, slightly swollen at the apices. Ectal excipulum parenchymatous, composed of thin-walled cells, 5-7 $\mu \mathrm{m}$ diam.

Hosts: Peltigera rufescens. Reported also on $P$. lepidophora and P. membranacea.

The superficial orange apothecia of Pezizella epithallina on the dorsal cortex of the host make this lichenicolous microfungus easily visible. This rare species was first recorded from Finland by Toivanen (2008). Reported also from Norway and Sweden.

Specimens studied: Varsinais-Suomi. Parainen, 9.X.1969 Alava (TUR). Etelä-Häme. Kuhmoinen, Puukkostenkylä, 21.X.1911 Linkola $(\mathrm{H})^{*}$. 


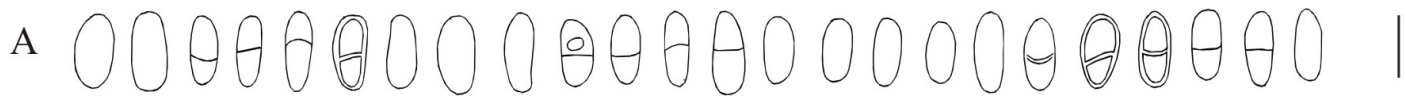
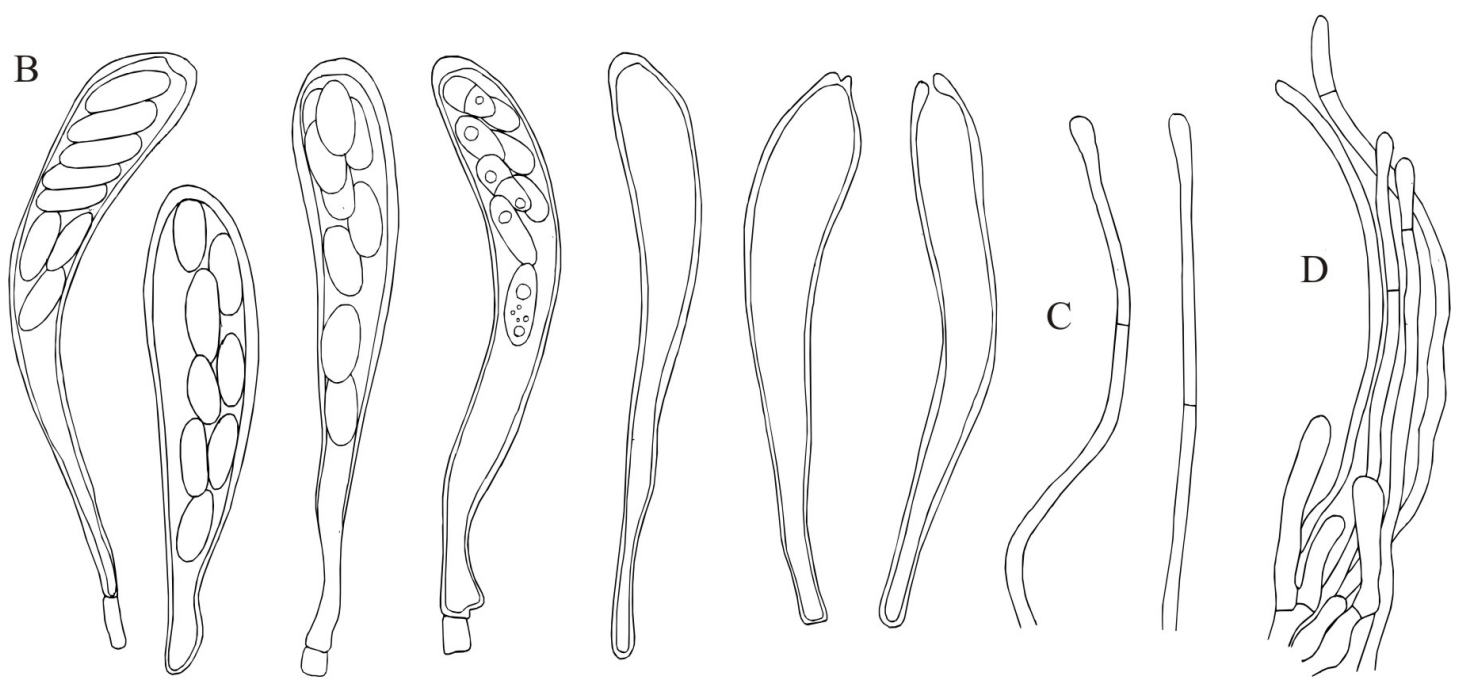

B
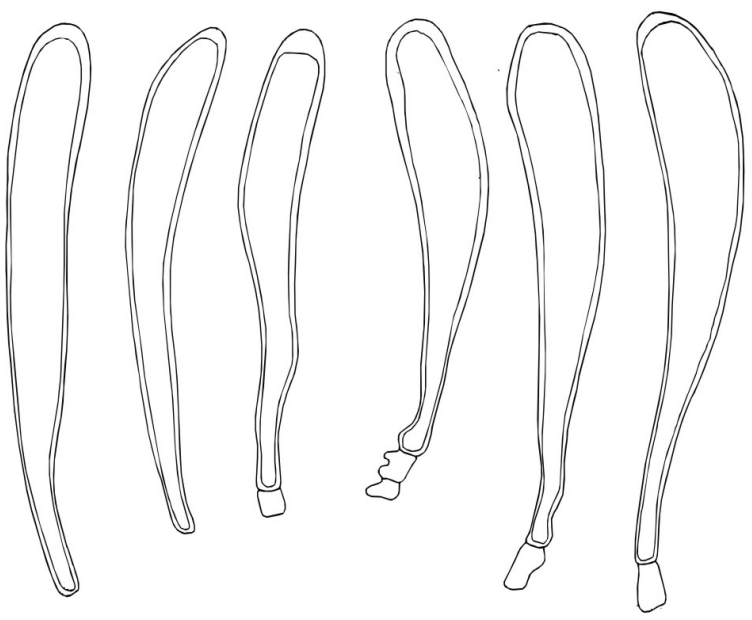

$\mathrm{E}$

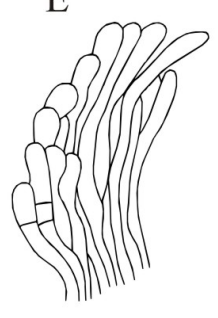

F

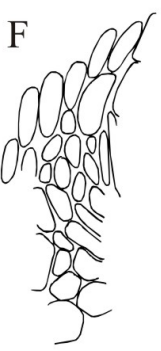

$\mathrm{F}$
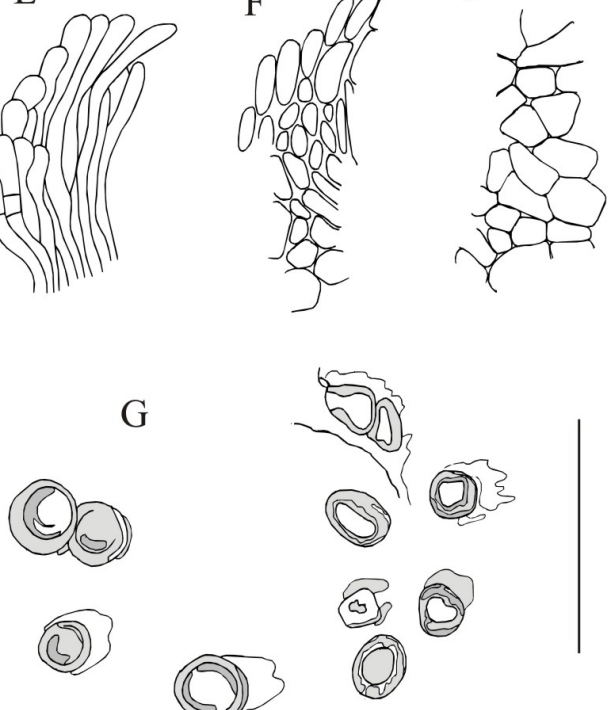

Fig. 21. Pezizella epithallina (1911 Linkola), $\mathrm{A}=$ ascospores, $\mathrm{B}=$ asci in different stages of maturity, $\mathrm{C}=$ paraphyses, $\mathrm{D}=$ paraphyses and unripe asci, $\mathrm{E}=$ detail of apothecial margin, $\mathrm{F}=$ excipulum, $\mathrm{G}=$ apothecia. $\mathrm{Bars}(\mathrm{A}-\mathrm{F}) 10 \mu \mathrm{m},(\mathrm{G})$ $1 \mathrm{~mm}$.

Phoma epiparmelia Vouaux - Figs. 22, $45 \mathrm{~V}$ Pycnidia globose, black, immersed, with only the ostiole visible. Conidia $4-6.5 \times 2-4 \mu \mathrm{m}$, mean $5.2 \times 2.9 \mu \mathrm{m}(\mathrm{n}=30$, one collection), glo- bose-ellipsoid. Pycnidial wall pseudoparenchymatous, cells $4-8 \mu \mathrm{m}$ diam.

Hosts: Peltigera aphthosa, P. leucophlebia. 
A

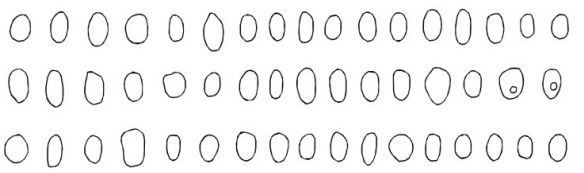

B

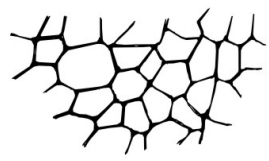

$\mathrm{C}$

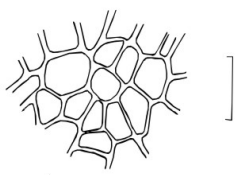

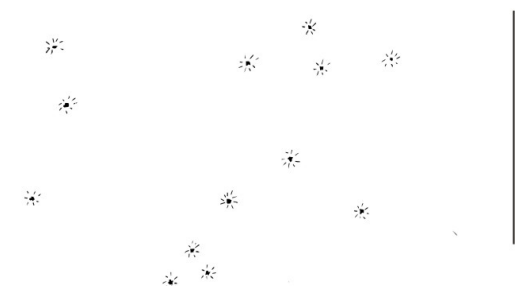

Fig. 22. Phoma epiparmelia (1925 Linkola $), \mathrm{A}=$ conidia, $\mathrm{B}=$ detail of host cortex cells, $\mathrm{C}=$ openings of pycnidia on dorsal side of host cortex. Bars (A, B) $10 \mu \mathrm{m}$, (C) $1 \mathrm{~mm}$.

A

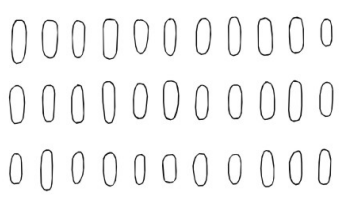

B

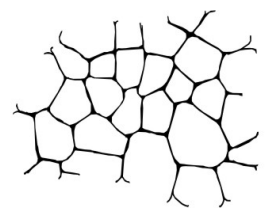

Fig. 23 Phoma peltigerae (1950 Fagerström), A = conidia, B = detail of host cortex cells. Bar $10 \mu \mathrm{m}$.

Phoma epiparmelia lives on the dorsal host thallus and does not harm its host. May be confused with Phoma peltigerae. The species is reported as new to Finland.

Specimens studied: Ahvenanmaa. Jomala, Kungsö, 13.V.1940 Fagerström (H). Uusimaa. Pernaja, Hardom, 3.VIII.1956 Klingstedt (H). Koillismaa. Salla, Kaunisharju, 18.VII.1981 Kvist (H).

Phoma peltigerae (P. Karst.) D. Hawksw. - Figs. 23, $45 \mathrm{~W}$

Pycnidia globose, black, immersed, only the ostiole visible. Conidia 3.5-6.5 × 1.5-2 $\mu \mathrm{m}$, mean $5.1 \times 1.7 \mu \mathrm{m}(\mathrm{n}=30$, three collections), elongate, hyaline. Pycnidial wall pseudoparenchymatous, cells 6-9 $\mu \mathrm{m}$ diam.

The pycnidia of Phoma peltigerae form mostly on the dorsal host thallus either scattered or in groups. The infected area is darker than the normal colour of the host thallus. Phoma peltigerae differs from Phoma epiparmelia by its more elongate conidia and larger cells.
Hosts: Peltigera aphthosa, P. canina, $P$. didactyla, $P$. leucophlebia, $P$. praetextata, $P$. rufescens.

Specimens studied: Ahvenanmaa. Lemland, Nåtö, 30.VIII.1968 Hoeggström (H). Lohja, Jantoniemi 28.V.1951 Pusa (H); Varola, 1.X.2005 Pykälä 28096 (H); Immula, 6.IX.2008 Pykälä 33666 (H). Turku, Ispoinen 8.IX.1908 Linkola $(\mathrm{H})$; Ruissalo 11.IX.1932 Kari (TUR): Uusimaa. Espoo, Westend 11.XI.1936 Malmström (H). Helsinki, X.1896 Lång (H). Nurmijärvi, Kiljava railway stop, 15.VI.1964 Suominen (H). Orimattila, Niemi, 2.IX.1914 Linkola (H). Sipoo, Råberget 23.VIII.1944 af Hällström (H). Vantaa, Kårböle, 1.V.1942 Marklund (H). Satakunta. Pori, Toukari, 12.V.1950 Isoviita (H). Etelä-Häme. Hämeenlinna, Aulangonvuori, 6.VIII.1933 Häyrén (H); Lammi, Evo, 1874 Norrlin $248 b(\mathrm{H})$; Evo, Vahtervehmas, 25.X.1964 Koponen \& Suominen $(\mathrm{H})$. Orivesi, Längelmäki, 18.VIII.1952 Pusa (H). Nokia, Siuro, 27.7.1990 Kääntönen (H). Urjala, Kivijärvi, 10.IX.1950 Fagerström (H). Etelä-Savo. Kouvola, Valkeala, 16.VI.1990 Kuusinen 2700 (H). Etelä-Pohjanmaa. Alavus, Keskikylä, 2.VI.1947 Leppälä (H). Pohjois-Häme. Ähtäri 5.VII.1940 Tynni (H). Pohjois-Savo. Mikkeli, Haukivuori, 6.VI.1965 Takala 954 (H). Iisalmi 20.VI.1945 Huuskonen (H). Pohjois-Karjala. Juuka, Polvela, 7.VIII.1971 Takala 7511 (H). Lieksa, Paha-Koli, 19.VIII.1983 Kvist (H). Ruunaa, Tienpää 31.V.1938 Lömfors (H). Juankoski, Säyneinen, 29.VII.1970 Vitikainen $6076(\mathrm{H})$. Joensuu, Tuupovaara, 29.VIII.1967 Takala 3591 (H); Tuupovaara, Öllölä, 29.X.1967 Takala 3738 (H). Tohmajärvi, Värtsilä, 17.VI.1915 Linkola (H). PeräPohjanmaa. Simo, Pahnila, 24.VII.1951 Hakulinen (H). 
A

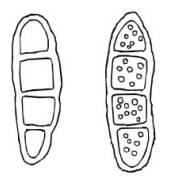

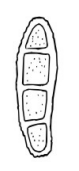

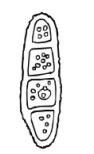

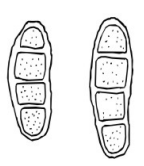
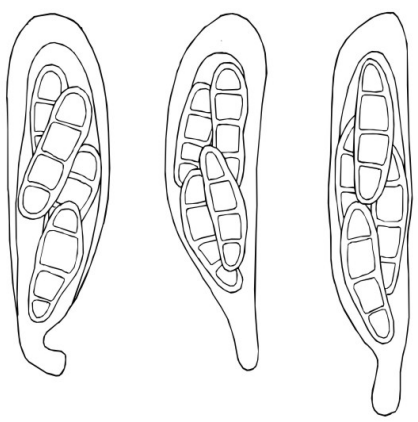

C
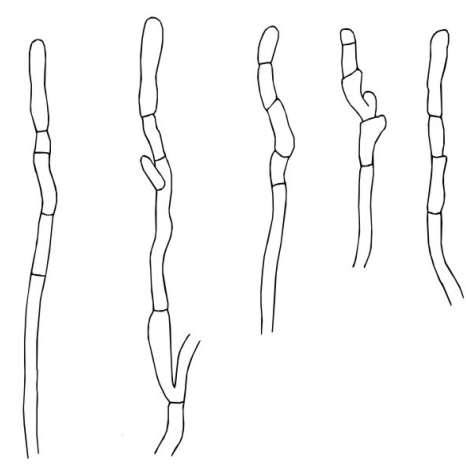
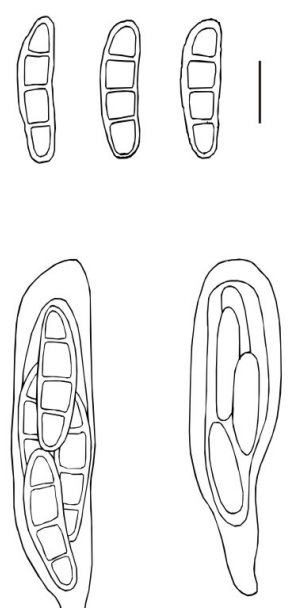

E

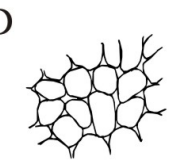

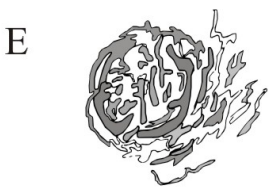
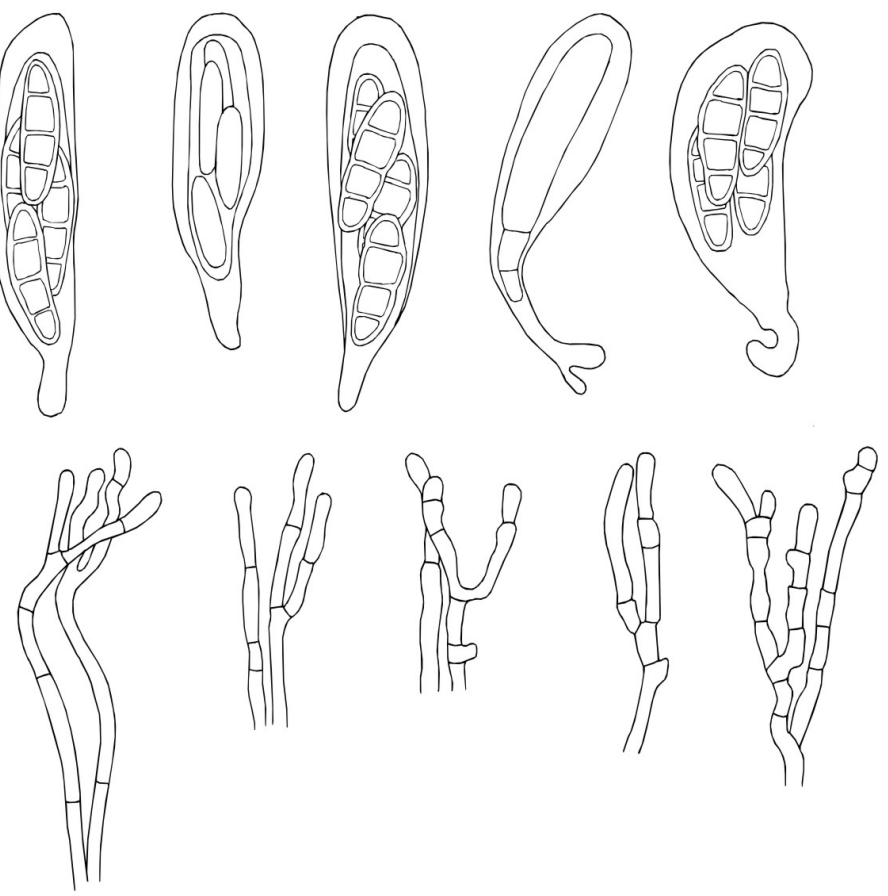

Fig. 24. Plectocarpon peltigerae (Haikonen 21623), $\mathrm{A}=$ ascospores, $\mathrm{B}=$ asci, $\mathrm{C}=$ paraphyses, $\mathrm{D}=$ excipulum, $\mathrm{E}=$ elevated patch on host thallus caused by $P$. peltigerae. Bars (A-D) $10 \mu \mathrm{m}$, (E) $1 \mathrm{~mm}$.

Koillismaa. Kuusamo, Paljakka, 14.VI.1980 Vitikainen $10072(\mathrm{H})$. Inarin Lappi. Inari, E of Sevettijärvi road, 22.VII.1974 Kvist (H). Utsjoki, Kevo, Könkäänpahta, 21.VIII.1974 Ahti \& Vitikainen $8284(\mathrm{H})$.

Plectocarpon peltigerae Zhurb., Ertz, Diederich \& Miądl. - Figs. 24, 45 X

Ascomata stromatic, gall-forming, $0.5 \mathrm{~mm}$ diam. Asci 44-66 × 13-16 $\mu \mathrm{m}$, mean $55.8 \times 14.5 \mu \mathrm{m}$ $(\mathrm{n}=12$, one collection), clavate with thick and hyaline walls, thickened at the apex, 4-spored. Ascospores 19-24 × 4.5-7.5 $\mu \mathrm{m}$, mean $21.2 \times$ $5.9 \mu \mathrm{m}(\mathrm{n}=30$, one collection), 3-septate, slightly constricted at septa, cell walls thick and hyaline
(CR-), slightly verrucose at surface, young spores smooth, with or without guttules. Paraphyses 2 $\mu \mathrm{m}$ diam, longer than asci, apices slightly swollen. Ectal excipulum composed of dark, almost black, thin-walled cells, 3-5 $\mu \mathrm{m}$ diam.

Host: Peltigera leucophlebia. The species has also been reported from Peltigera aphthosa (Nordin et al. 2010).

Plectocarpon peltigerae forms black, stromatic, elevated ascomata on the dorsal cortex of its host. The ascomata are surrounded by a circular depression and a flat, brown, external ring. Superficially this species may be confused with Arthonia fuscopurpurea or A. peltigerea which 

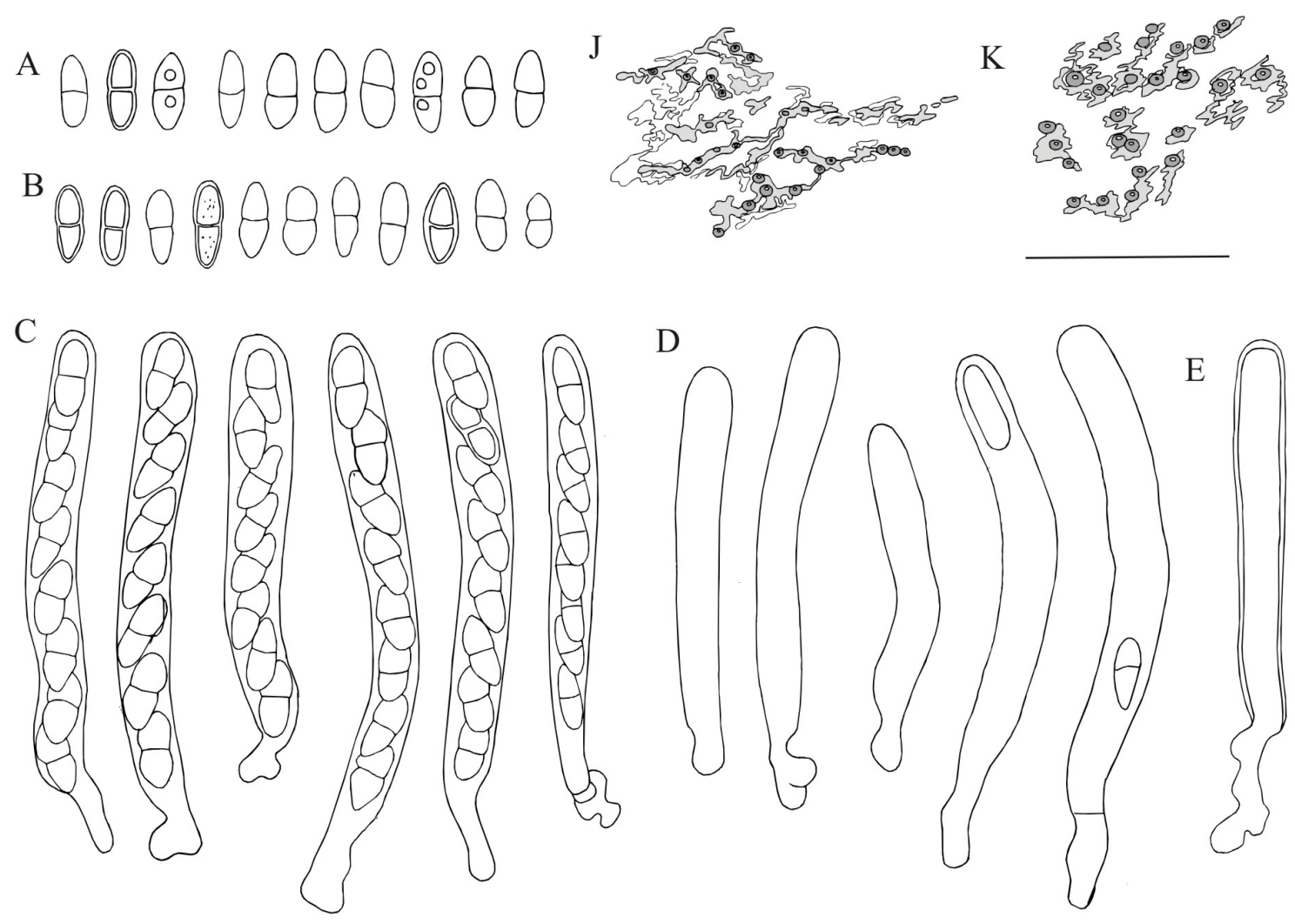

$\mathrm{E}$
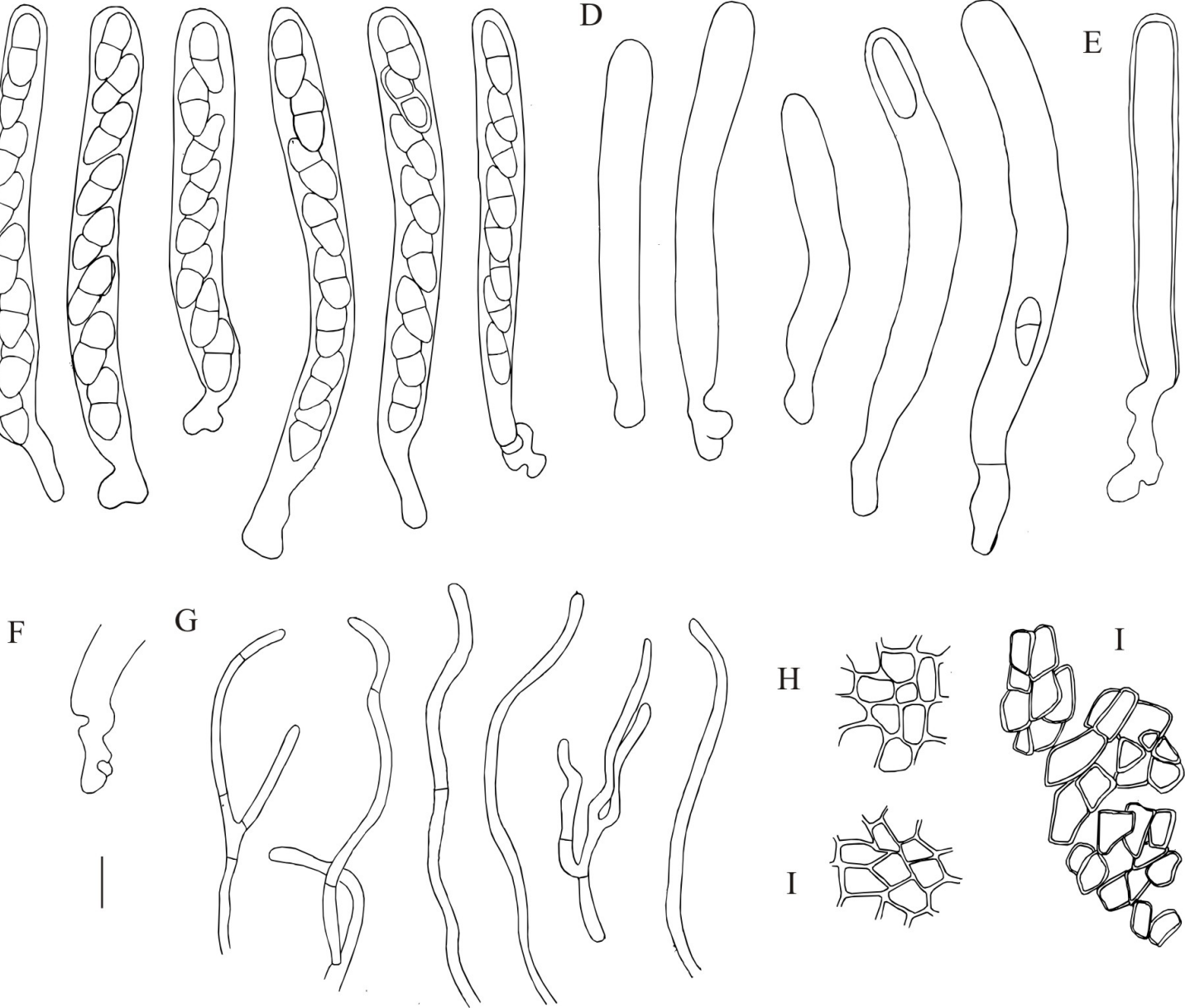

Fig. 25. Polycoccum peltigerae (A, C = 1915 Räsänen; B, D, I = 1935 Laurila; E-H, J = 1937 Häyrén; K = 1966 Roivainen), $\mathrm{A}, \mathrm{B}=$ ascospores, $\mathrm{C}=$ mature asci, $\mathrm{D}, \mathrm{E}=$ young asci, $\mathrm{F}=$ ascus base, $\mathrm{G}=$ pseudoparaphyses, $\mathrm{H}=$ medullary excipulum, I = ectal excipulum, $\mathrm{J}, \mathrm{K}=$ ostioles of perithecia visible in host cortex. Bars (A-I) $10 \mu \mathrm{m},(\mathrm{J}, \mathrm{K}) 1 \mathrm{~mm}$.

have a somewhat similar growth manner also on Peltigera. However, its ascomata are more gall-like and in the presence of mature asci, it is easily distinguished by its 3 -septate ascospores. The species was first recorded from Finland by
Toivanen (2008). Reported also from Norway and Sweden.

Specimen studied: Pohjois-Karjala. Juuka, Pääkylä, 13.VIII.2002 Haikonen $21623(\mathrm{H})^{*}$. 
Polycoccum peltigerae (Fuckel) Vězda - Figs. 25, $46 \mathrm{Y}$

Ascomata immersed, globose, dark-brown to black, ostiolar area erumpent. Asci 65-111 $\times$ $8-11 \mu \mathrm{m}$, mean $87.5 \times 9.5 \mu \mathrm{m}(\mathrm{n}=20$, three collections), bitunicate, elongate-clavate. 8 -spored. Ascospores 10-16 × 4.5-6 $\mu \mathrm{m}$, mean $13.5 \times 5.2$ $\mu \mathrm{m}$ ( $\mathrm{n}=30$, three collections), ellipsoid, thinwalled, septate, slightly constricted at septum. Pseudoparaphyses branched, septate, $2 \mu \mathrm{m}$ diam. Ectal excipulum of textura angularis, cells thick-walled, $10 \mu \mathrm{m}$ diam. Medullary excipulum of textura globulosa, cells 4-10 $\mu \mathrm{m}$ diam.

Hosts: Peltigera didactyla, $P$. praetextata, $P$. rufescens, $P$. polydactyla. Reported also from $P$. canina (Hawksworth 1978).

Polycoccum peltigerae causes necrotic, $2-3 \mathrm{~mm}$ wide, gall-like swellings on the dorsal thallus of the host. The ascomata are immersed but the papillate ostioles break through the cortex and are visible either in a scattered fashion or in circular formations. Polycoccum peltigerae has a Cyclothyrium-type anamorph (Kirk et al. 2001). Reported also from Sweden.

Specimens studied: Varsinais-Suomi. Lohja, Jalassaari, 19.IX.1917 Lindberg (H); Muijala, 18.V.2003 Pykälä 22765, 22769 (H), 28.IV.2007 Pykälä 30831 (H); Ojamo, 18.IV.2005 Pykälä 26582, 26584, 26600 (H). Paimio, Huso, 9.XI.1972 Alava 11422 (TUR). Parainen, Ersby, 12.X.1969 Alava 8379a, 8392a (TUR). Raasepori, Pohja, Ekerö, 12.IX.1937 Häyrén (H)*. Turku, Ispoinen, 29.IV.1923 Vainio (TUR); Muhkuri, 8.VI.1936 Auer (TUR); Ruissalo, 22.VII.1922 Kari (TUR). Kemiönsaari, Västanfjärd, Västerillo, 5.X.1966 Roivainen $(\mathrm{H}) *$. Uusimaa. Helsinki, Laajasalo, 5.X.1924 Häyrén (H). Lapinjärvi, Käkikoski, 23.IX.1989 Haikonen 10952 (H). Vantaa, Korso, 3.X.1915 Räsänen (H)*. Satakunta. Kankaanpää, Luomajärvi, 29.VI.1935 Laurila (H*, TUR). Etelä-Häme. Hattula, Ellilä, 22.VIII.1933 Linkola (H). Hollola, Harsala, 1872 Vainio (TUR). Etelä-Savo. Imatra, Linnankoski, 24.IV.1991 Thurén 1473 (H). Pohjois-Häme. Jyväskylä, Tourujoki, 21.VI.1913 Linkola (H). Pohjois-Savo. Kuopio, Särkilahti, 30.VII.1935 Linkola $(\mathrm{H})$.

Polycoccum superficiale D. Hawksw. \& Miądl. -Fig. $46 \mathrm{Z}$

Ascomata perithecioid, superficial, dark-brown to blackish. Asci bitunicate, 8-spored. Ascospores elongate-ellipsoid, septate, constricted at septum, brown, smooth. Pseudoparaphyses branched and septate.

Host: Peltigera canina. Reported also from Peltigera malacea.

Polycoccum superficiale forms superficial darkcoloured perithecia on the dorsal side of the host thallus. The species was first recorded from Finland by Toivanen (2008). Reported also from Sweden.

Specimens studied: Varsinais-Suomi. Parainen, Houtskär, Hyppeis, 1.VII.1991 Bruun (H). Uusimaa. Tammisaari, Alglo 2.VIII.1978 Vitikainen $9706(\mathrm{H})$.

\section{Polydesmia lichenis Huhtinen \& R. Sant.} - Figs. 26, 46 AA

Ascomata apothecioid, superficial, 0.16-0.34 $\mathrm{mm}$ diam. from light yellow to light brown, margins often paler than the disc, pruinose, margin and flanks hairy, sessile. Asci 83-120 ×9-13 $\mu \mathrm{m}$, mean $101.7 \times 10.2 \mu \mathrm{m}(\mathrm{n}=31$, two collections), cylindric-clavate, abundant. Ascospores 10-25 $\times$ 3-5 $\mu \mathrm{m}$, mean $15.9 \times 4.1 \mu \mathrm{m}(\mathrm{n}=31$, two collections), ellipsoid to elongate, length varies, 0-3 -septate, may contain greenish guttules. Paraphyses ca $2 \mu \mathrm{m}$ wide, thin, undulating, septate, branching. Ectal excipulum of textura angularis, cells $2-5 \mu \mathrm{m}$ diam. Hairs thin, undulating.

\section{Hosts: Peltigera aphthosa, P. leucophlebia.}

Polydesmia lichenis has a very characteristic apperance, with its superficial, white, pruinose apothecia, that usually occur in groups on the older parts of the host, usually on the dorsal side, but occasionally also ventrally. The species was first recorded from Finland by Toivanen (2008). Reported also from Norway and Sweden.

Specimens studied: Varsinais-Suomi. Lohja, Immula, 6.IX.2008 Pykälä 33668 (H). Uusimaa. Helsinki, Huopalahti, 8.X.1911 Kivenheimo (H). Kirkkonummi, Porkkala, 13.XII.1987 Heino 170 (H)*. Etelä-Häme. Hattula, Pekola, 20.IX.1931 Häyrén $(\mathrm{H})^{*}$. Kuhmoinen, Tehi, 18.X.1911 Linkola (H)*. Hämeenlinna, Lammi, Evo, 25.X.1964 Koponen \& Suominen (H)*. Etelä-Savo. Suomenniemi, Kiesilä, 8.VIII.1983 Vitikainen 10712 (H)*. Pohjois-Karjala. Juuka, Tahkovaara, 22.VIII.1960 Huuskonen $(\mathrm{H})^{*}$. Joensuu, Tuupovaara, Töppyniemi, 13.X.1967 Takala $3710(\mathrm{H})^{*}$. 


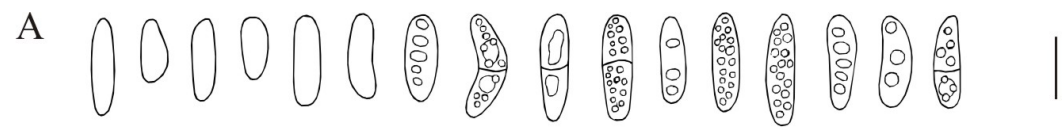

B

HAHABHAB

$\mathrm{D}$

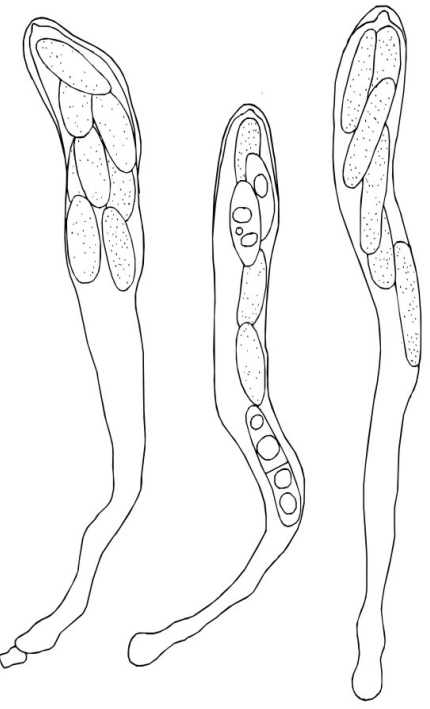

$\mathrm{J}$

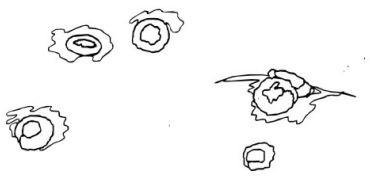

E
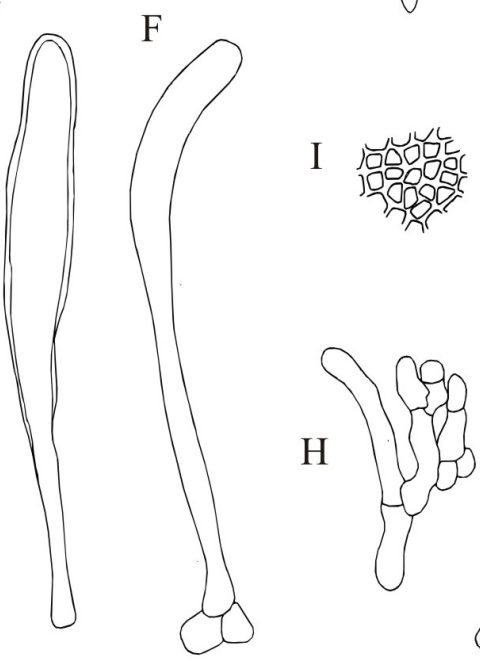

$H$ H

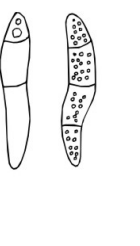

$\mathrm{C}$
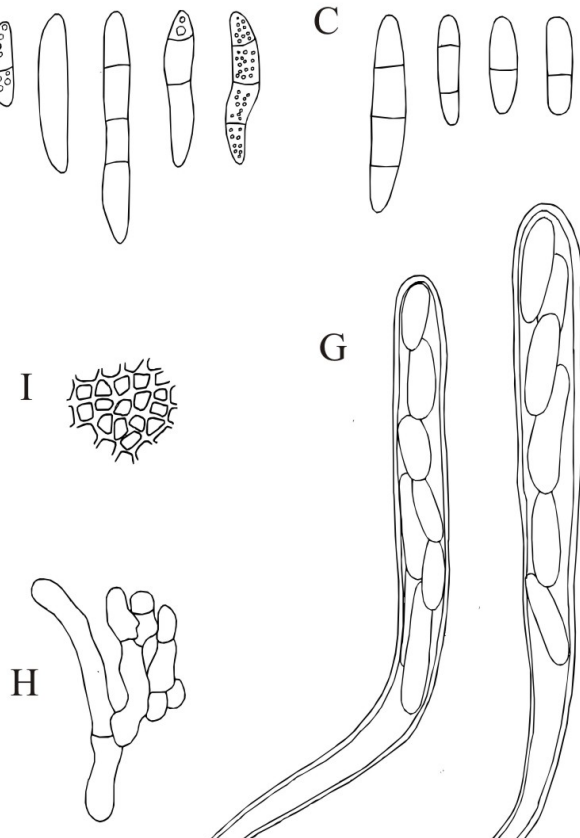

L

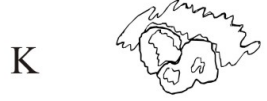

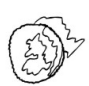
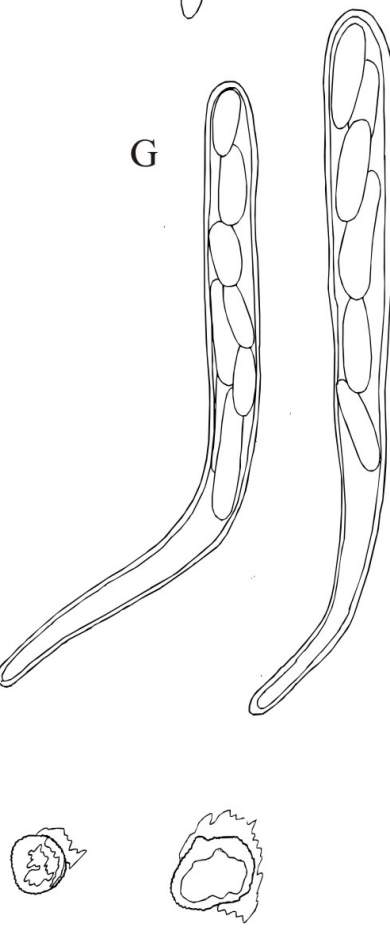

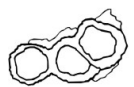

Fig. 26. Polydesmia lichenis (A, D, F, L $=1960$ Huuskonen; B, E, H, I = Heino 170; C, G, K = 1911 Linkola; J = 1931 Häyrén $), \mathrm{A}-\mathrm{C}=$ ascospores, $\mathrm{D}-\mathrm{G}=$ asci in different stages of maturity, $\mathrm{H}=$ ascogenous cells with croziers, $\mathrm{J}-\mathrm{L}=$ apothecia, I = excipulum. Bars (A-I) $10 \mu \mathrm{m},(\mathrm{J}-\mathrm{L}) 1 \mathrm{~mm}$.

\section{Pronectria erythrinella (Nyl.) Lowen}

-Figs. 27, 46 BB

Ascomata perithecioid, immersed in the host thallus, with only the neck and ostiole erumpent, white to yellowish, the exposed part ca $0.2 \mathrm{~mm}$ diam. Asci $52-84 \times 7.5-10 \mu \mathrm{m}$, mean $62.5 \times 8.8$ $\mu \mathrm{m}$ ( $\mathrm{n}=20$, three collections), cylindrical, thickened at the apices, 8-spored. Ascospores 13-22 $\times$ 4-7 $\mu \mathrm{m}$, mean $17.7 \times 5.4 \mu \mathrm{m}(\mathrm{n}=30$, three collections), roundly ellipsoid, smooth, thinwalled, septate, sometimes slightly constricted at septum, may contain guttules. Periphyses thin, short.

Hosts: Peltigera canina, P. didactyla, P. hymenina, P. leucophlebia.

The ascomata of Pronectria erythrinella are immersed in the dorsal host thallus in dense groups, only the erumpent necks are visible through 


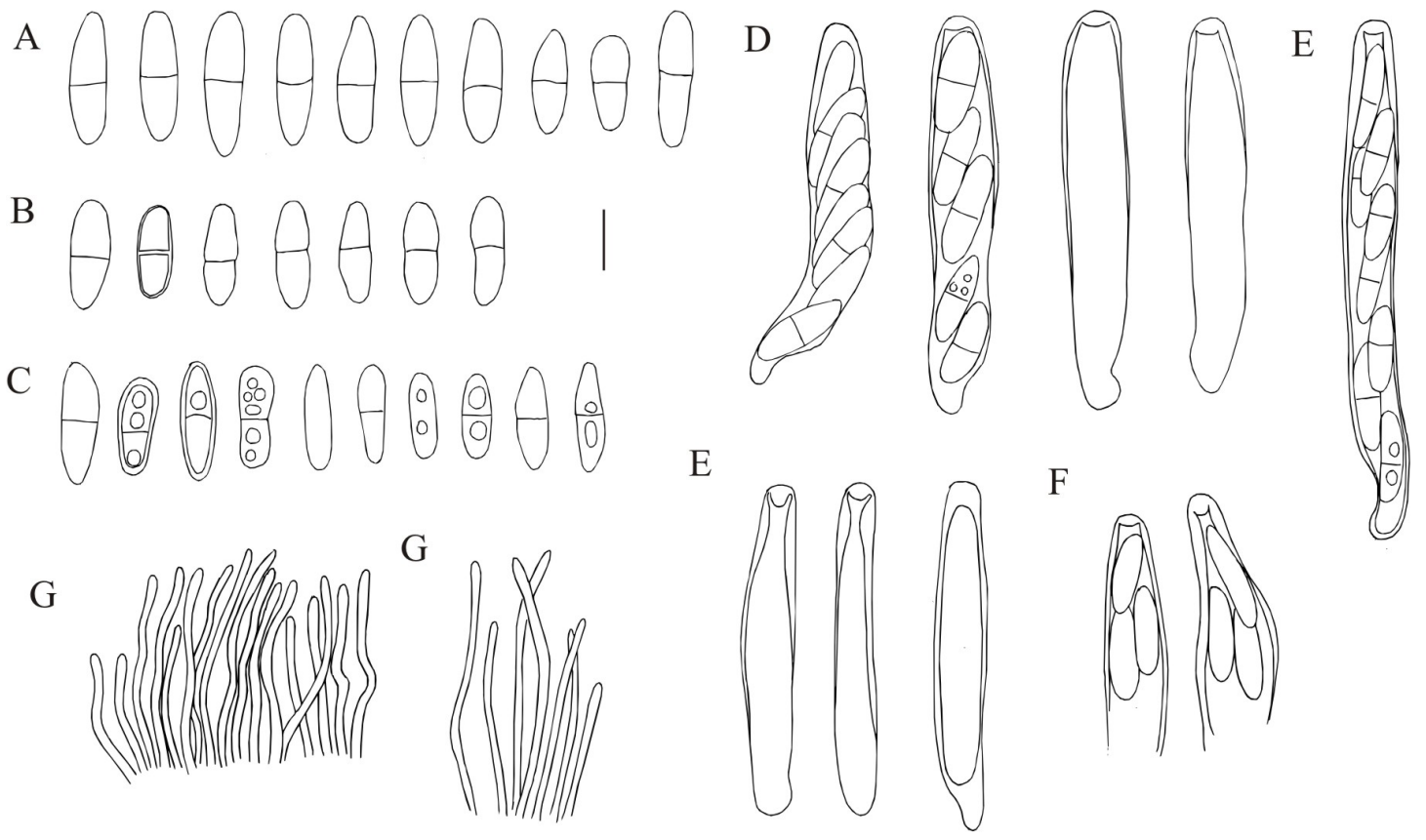

$\mathrm{H}$
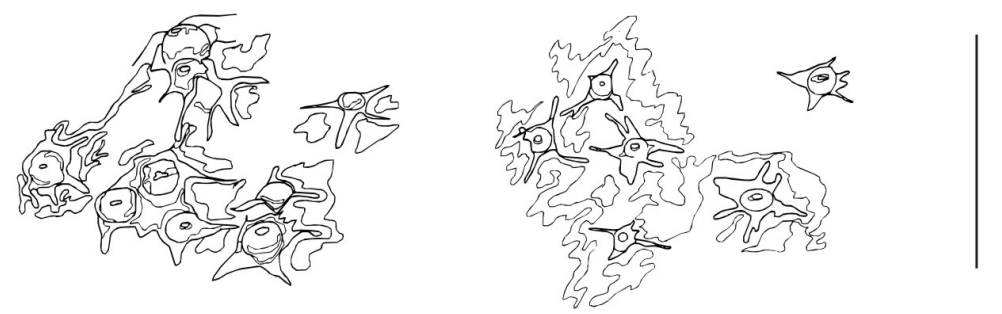

Fig. 27. Pronectria erythrinella $(\mathrm{A}=1956$ Klingstedt; $\mathrm{B}, \mathrm{D}, \mathrm{G}=1926$ Peltomaa; $\mathrm{C}, \mathrm{E}, \mathrm{F}=1964$ Suominen; $\mathrm{H}=1911$ Linkola $), \mathrm{A}-\mathrm{C}=$ ascospores, $\mathrm{D}, \mathrm{E}=$ asci, $\mathrm{F}=$ tips of asci, $\mathrm{G}=$ periphyses, $\mathrm{H}=$ necks of ostioles rupturing the host cortex. Bars (A-G) $10 \mu \mathrm{m},(\mathrm{H}) 1 \mathrm{~mm}$.

cracks in the host cortex. The infection sites are grayish indicating that the species may be harmful to its host. P. erythrinella has an Illosporiumtype anamorph.

Specimens studied: Varsinais-Suomi. Turku, Kärsämäki, 1.VI.1936 Auer (TUR); Kaarinan hautausmaa, 29.VI.1950 Merisuo (TUR). Uusimaa. Espoo, railway station, 12.XI.1911 Linkola (H). Sipoo, Träsk, 13.X.2006 Pykälä 29824 (H). Loviisa, Ruotsinpyhtää, Strömfors industrial area, 11.X.1956 Klingstedt $(\mathrm{H})$. Hanko, Tvärminne, 7.VIII.1907 Koponen (H); Långskär 11.VIII.1907 Brofeldt (TUR). Etelä-Häme. Kuhmoinen, Savi-Hukki 21.X.1911 Linkola (H). Kärkölä, Järvelä, 30.VII.1926 Peltomaa (H); Järvelä, Pappila, 30.VII.1926 Peltomaa (H). Etelä-Savo. Imatra, Vuoksenniska, 19.VI.1922 Linkola (H). Etelä-Pohjanmaa. Kurikka, Mieto,
2.VII.1965 Suominen (H). Pohjois-Häme. Laukaa, Karlvik 6.VII.1913 Linkola (H); Nurmijärvi, Saviniemi 17.VII.1962 Hakulinen (TUR). Pohjois-Savo. Kuopio, Suovu, 3.VI.1906 Linkola (TUR). Kainuu. Suomussalmi, Ala-Vuokki, 5.VII.1936 Auer (TUR). Perä-Pohjanmaa. Kemijärvi, Joutsijärvi, 30.VII.1964 Suominen (H); Joutsijärvi railway yard, 30.VII.1964 Suominen (H). Rovaniemi, Muurola, 27.VII.1964 Suominen (H). Kuusamo. Salla, Kuoppasoja, 31.VII.1964 Suominen (H); Pieni Pyhätunturi 4.VII.1981? (H). Kittilän Lappi. Kittilä, Tepasto, 25.VII.1977 Ulvinen (TUR). Inarin Lappi. Utsjoki, Nuorgam, 12.VIII.1962 Hakulinen (TUR); Vetsikko, 17.VI.1980 Kvist (H). 


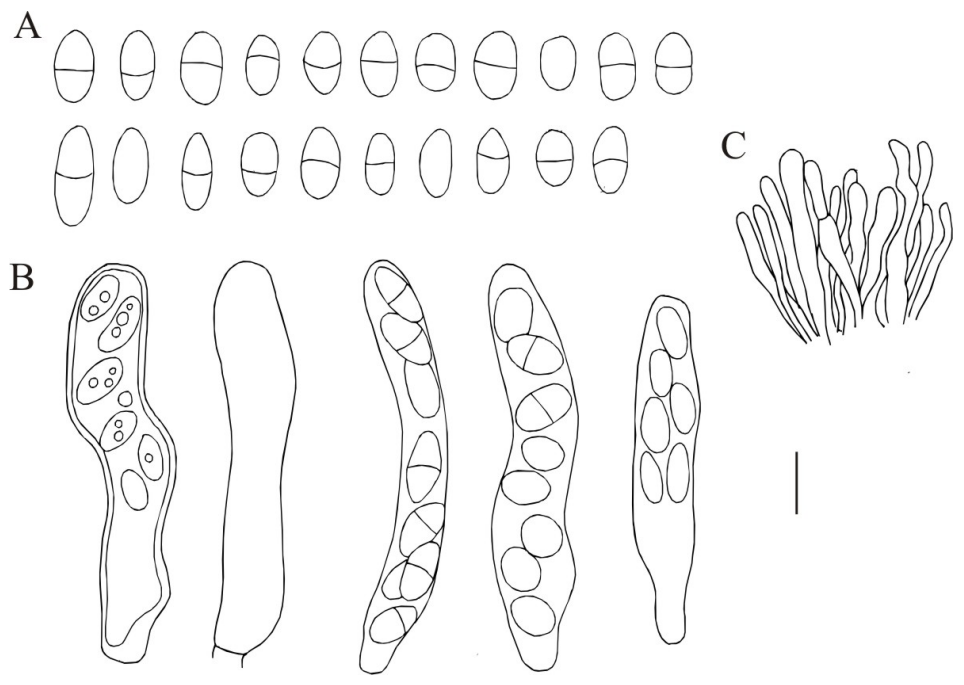

Fig. 28. Pronectria robergei (1939 Fagerström), A = ascospores, $\mathrm{B}=$ asci in different stages of maturity, $\mathrm{C}=$ periphyses. Bar $10 \mu \mathrm{m}$.

\section{Pronectria robergei (Mont. \& Desm.)} Lowen - Figs. 28, 46 DD

Ascomata perithecioid, immersed in the host thallus, with only the neck and ostiole erumpent, yellowish, the exposed part $0.15-0.2 \mathrm{~mm}$ diam. Asci $42-67 \times 7-12 \mu \mathrm{m}$, mean $59.1 \times 9.4$ $\mu \mathrm{m} \quad(\mathrm{n}=12$, one collection $)$, cylindrical, thinwalled, 8-spored. Ascospores 6.5-11.5 × 3-6.5 $\mu \mathrm{m}$, mean $9.7 \times 5.2 \mu \mathrm{m}(\mathrm{n}=30$, one collection $)$, roundly ellipsoid, smooth, thin-walled, septate, sometimes slightly constricted at septum, may contain guttules when young. Periphyses thin, thread-like.

Hosts: Peltigera rufescens, $P$. didactyla. Reported also from several other Peltigera species.

The ascomata of Pronectria robergei are immersed in the host thallus in dense groups. The infection sites are greyish, indicating that the species may be harmful to its host. Reported also from Norway and Sweden.

Specimens studied: Uusimaa. Helsinki, Pukinmäki, 5.V.1939 Fagerström (H)*; Santahamina, Österudden, 2.X.1979 Pekanpalo 349 (H). Etelä-Karjala. Lappeenranta, Ylämaa, 4.VII.1965 Vitikainen $317(\mathrm{H})^{*}$. Satakunta. Eura, Kauttua, 27.X.1946 Klingstedt (H). PohjoisHäme. Jyväskylä, Tourujoki, 21.VI.1913 Linkola (H)*.

\section{Pronectria tenuispora (D. Hawksw.) Lowen - Figs. 29, 46 EE}

Ascomata perithecioid, immersed in the host thallus, with only the neck and ostiole erumpent, yellowish to orange, visible part $0.12-0.22 \mathrm{~mm}$ diam. Asci 68-105 × 8-12 $\mu \mathrm{m}$, mean $83.9 \times 9.9$ $\mu \mathrm{m}(\mathrm{n}=16$, two collections), cylindrical, somewhat cubical and thickened at apex, 8-spored. Ascospores 16-22 × 4.5-7 $\mu \mathrm{m}$, mean $18.6 \times 5.9$ $\mu \mathrm{m}(\mathrm{n}=19$, two collections), ellipsoid, hyaline (CR-), septate, septum may be thicker than cell wall, may contain grayish guttules. Paraphyses absent. Periphyses 1-1.5 $\mu \mathrm{m}$ diam. Ectal excipulum of textura angularis, cells thick-walled. Medullary excipulum of thin-walled cells, 4-9 $\mu \mathrm{m}$ diam.

Hosts: Peltigera didactyla, P. rufescens.

The ascomata of Pronectria tenuispora are immersed in the host thallus with only the protruding neck and ostiole visible. The ascomata of are usually found in the cracking cortex of the dorsal side on older parts of the thallus. The species was recorded as new to Finland by Alstrup (2004).

Specimens studied: Varsinais-Suomi. Lohja, 4.VIII.2006 Pykälä 29194 \& Jääskeläinen (H); Kutsila, 


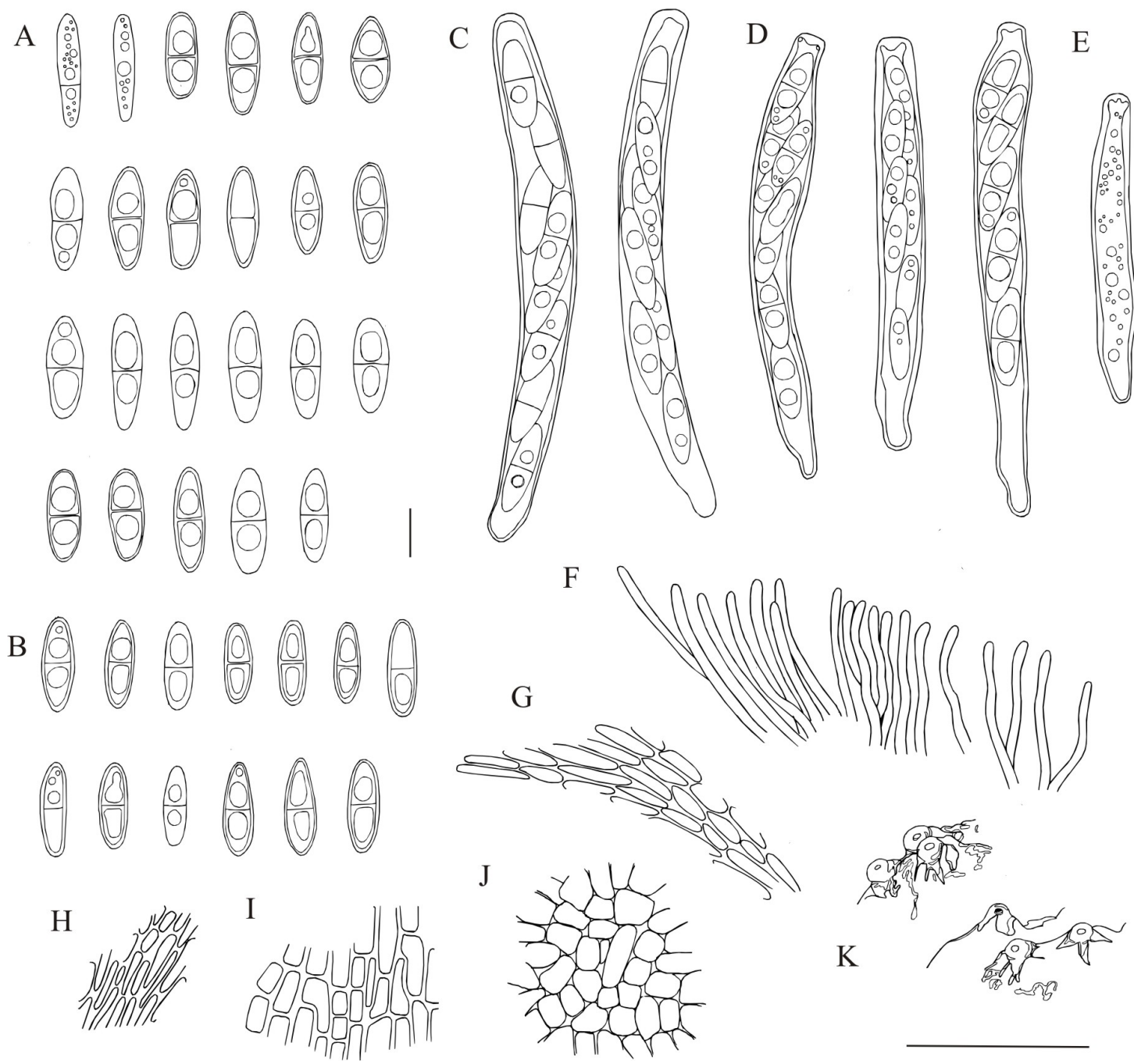

Fig. 29. Pronectria tenuispora (A, C, E-G, K = Haikonen 23669; B, D, H-J = Haikonen 24487), A, B = ascospores, $\mathrm{C}, \mathrm{D}=$ mature asci, $\mathrm{E}=$ unripe asci, $\mathrm{F}=$ periphyses, $\mathrm{G}, \mathrm{H}=$ detail from neck of perithecium, $\mathrm{I}=$ ectal excipulum, $\mathrm{J}=$ medullary excipulum, $\mathrm{K}=$ perithecia. Bars $(\mathrm{A}-\mathrm{J}) 10 \mu \mathrm{m},(\mathrm{K}) 1 \mathrm{~mm}$.

9.VII.2004 Pykälä 25023, 27670, 27661, 26584, 27135 (H); Ojamo, 18.IV.2005 Pykälä 26584 (H), 22.VI.2005 Pykälä $27135(\mathrm{H})$; Pitkäniemi industrial area, 22.VI.2005 Pykälä 27670, 27661 (H). Parainen, 12.X.1969 Alava 8378 (TUR). Uusimaa. Sipoo, 13.X.2006 Pykälä 29863, 29864, 29865 (H). Etelä-Häme. Kärkölä, Järvelä, 9.X.2005 Haikonen 24487*, 24487 (H). Nastola, Immilä, 15.XI.2003 Haikonen $23113(\mathrm{H})^{*}$. Etelä-Savo. Mikkeli, Häppälä, 19.IX.2004 Haikonen 23669 (H)*. Pohjois-Savo. Pieksämäki, Virtasalmi, Ankele, 18.VIII.2003 Haikonen 22641 (H). Kittilän Lappi. Kolari, Äkäsjokisuu, 13.VII.2003 Haikonen $22557(\mathrm{H})$.

\section{Pyrenidium actinellum Nyl. - Figs. 30, 46 FF}

Ascomata perithecioid, immersed to partly erumpent, subglobose to obpyriform, dark-brown, rough-surfaced, glabrous. Asci 63-99 × 12-16 $\mu \mathrm{m}$, mean $83.2 \times 13.7 \mu \mathrm{m}(\mathrm{n}=6$, one collection), bitunicate, cylindrical, thick-walled, bent and tapering towards the base, 4-spored. Ascospores $18-26 \times 7-10 \mu \mathrm{m}$, mean $21.6 \times 8.3 \mu \mathrm{m}(\mathrm{n}=30$, two collections), elongate-ellipsoid, 3-septate, constricted at septa, middle cells thick-walled 


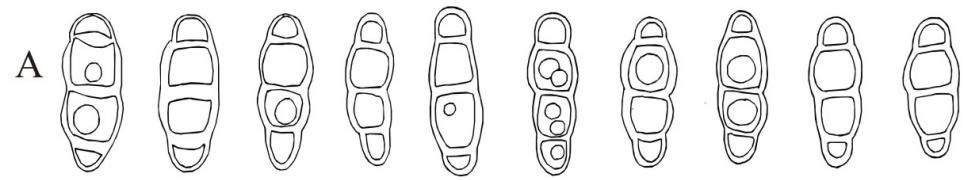

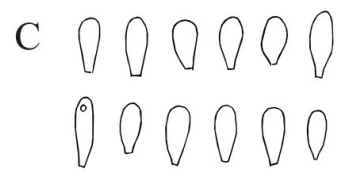
$B\left(\begin{array}{ll}0 \\ 0 \\ 0 \\ 0\end{array}\right.$
$\left(\begin{array}{ll}0 \\ 0 \\ 0\end{array}\right)\left(\begin{array}{l}0 \\ 0 \\ 0 \\ 0 \\ 0 \\ 0 \\ 0\end{array}\right.$
$\left(\begin{array}{lll}0 & 0 \\ 0 & 0 & 0 \\ 0 & 0 \\ 0 & 0 \\ 0 & 0 \\ 0 & 0 \\ 0 & 0\end{array}\right.$
$\cap \cap \cap 1$

$\mathrm{D}$
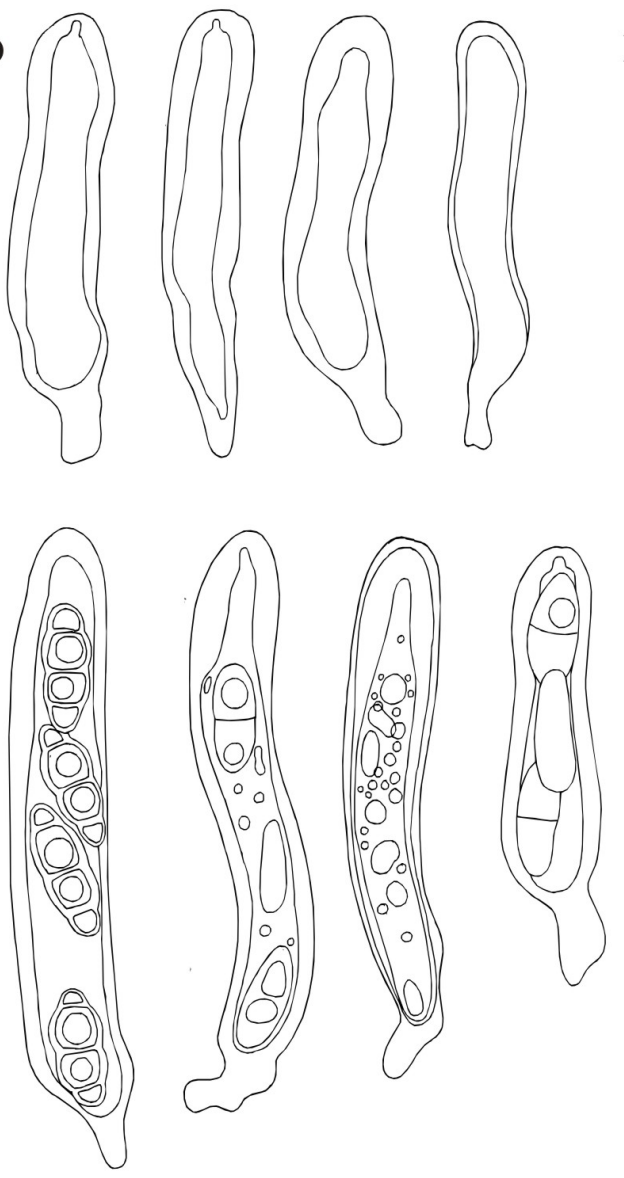

$\mathrm{E}$
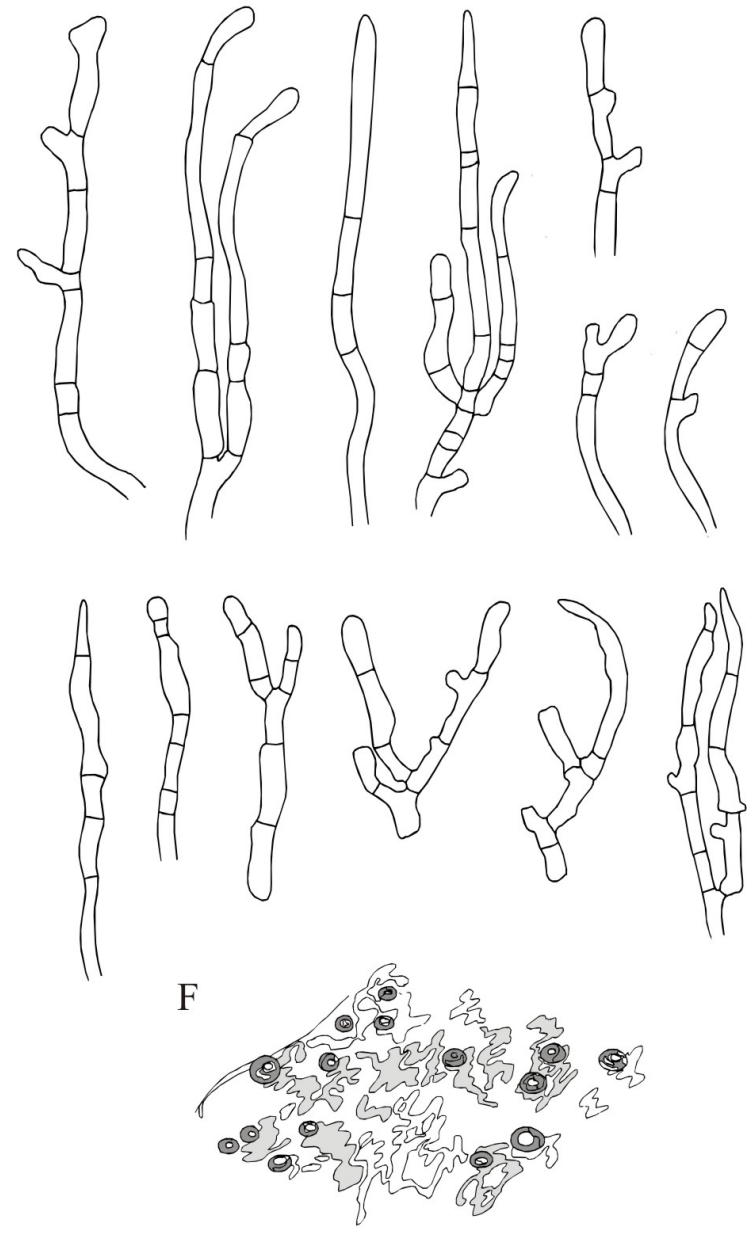

Fig. 30. Pyrenidium actinellum ( $\mathrm{A}=1964$ Kytövuori \& Kytövuori; $\mathrm{B}-\mathrm{F}=1986$ Alava $), \mathrm{A}, \mathrm{B}=$ ascospores, $\mathrm{C}=$ conidia, $\mathrm{D}=$ asci in different stages of maturity, $\mathrm{E}=$ paraphyses, $\mathrm{F}=$ necks of ostioles in host cortex. Bars (A-E) $10 \mu \mathrm{m},(\mathrm{F}) 1$ $\mathrm{mm}$. 
and dark, apical cells thin-walled and lighter, with or without guttules. Pseudoparaphyses abundant, of ascal length, 2-3 $\mu \mathrm{m}$ diam., branched, septate. Conidia 7.5-11 × 3-4.5 $\mu \mathrm{m}$, drop-shaped, thin-walled, with a thickening at the site of attachment.

Hosts: Peltigera collina, $P$. rufescens, $P$. venosa (L.) Hoffm. Also found during this study on $\mathrm{Ne}$ phroma expallidum. Pyrenidium actinellum occurs also on several other Peltigera species, as well as the lichens Aspicilia calcarea (L.) Körb. var. calcarea, Baeomyces rufus (Huds.) Rebent, Diploschistes caesioplumbeus (Nyl.) Vain., Massalongia carnosa (Dicks.) Körb., Solorina crocea (L.) Ach., S. saccata and Toninia squalida (Ach.) A.Massal. (Hawksworth 1980).

Pyrenidium actinellum forms dark swellings, 1-2 $\mathrm{mm}$ in diam, on the dorsal side of the host thallus, in which the ascomata are crowded. The black perithecia are from immersed to partly erumpent. Reported also from Norway and Sweden.

Specimens studied: Ahvenanmaa. Finström, Grelsby, 9.VI.1986 Alava 21566 (TUR)*. Etelä-Häme. Ruovesi, SE of Helvetinkolu, 9.VI.1964 Kytövuori \& Kytövuori (H)*. Pohjois-Savo. Kuopio, Korsumäki, 19.V.1946 Räsänen (TUR). Koillismaa. Salla, Jyrhämä, 6.VIII.1937 Lehtonen \& Pankakoski (H). Enontekiön Lappi. Enontekiö, Porojärvet, 21.VII.1955 Henssen (H); Kaaresuvanto 7,5 km N, Ikäjärvi-Laivaara, 2.VII.1974 Laine (TUR, on Nephroma expallidum). Inarin Lappi. Utsjoki, Kotkapahta, 6.VII.1964 Laine (H).

\section{Rhagadostoma brevisporum (Nav.-Ros. \&} Hladún) Nav.-Ros. - - Figs. 31, 46 GG

Ascomata perithecioid. Asci 93-134 × 13-21 $\mu \mathrm{m}$, mean $111.3 \times 16.8 \mu \mathrm{m}(\mathrm{n}=20$, three collections), unitunicate, clavate, thin-walled, 4-celled. Ascospores 26-40 × 6-9.5 $\mu \mathrm{m}$, mean $30.8 \times 7.3$ $\mu \mathrm{m}$ ( $\mathrm{n}=30$, three collections), elongate-cylindrical, thin-walled, 0-1 septate, may contain dark or hyaline guttules. Paraphyses length of asci or shorter, septate, constricted at septa, branching.

Host: Peltigera rufescens. Reported also from $P$. lepidophora.
Rhagadostoma brevisporum forms dark-brown, subglobose to globose, irregular-surfaced infection areas, in which the perithecia are situated. The species was first recorded from Finland by Toivanen (2008). Reported also from Sweden.

Specimens studied: Ahvenanmaa. Kökar, Finnö NW, 3.VII.1979 Kvist (H)*. Kainuu. Paltamo, Melalahti, 28.VII.1970 Alava (TUR)*. Oulun Pohjanmaa. Kiiminki, 25.VII.1952 Bäck (H)*. Enontekiön Lappi. SEMalla, 9.VIII.2009 Rämä.

\section{Scutula dedicata Triebel, Wedin \& Rambold _ - Figs. 32, 33, 34, $46 \mathrm{HH}$}

Thallus epikapylic. Ascomata apothecioid, superficial, $0.2 \mathrm{~mm}$ diam., disc yellowish-brown to black, the margin distinctively black. Asci $30-45 \times 8-15 \mu \mathrm{m}$, mean $37.7 \times 10.4 \mu \mathrm{m}(\mathrm{n}=15$, three collections), ellipsoid-cylindrical, thickwalled, strongly thickened at apex, abundant. Ascospores 8-14 × 2.5-4 $\mu \mathrm{m}$, mean $10.1 \times 3.0 \mu \mathrm{m}$ $(\mathrm{n}=30$, three collections), ellipsoid, 1-septate, may contain guttules. Paraphyses of ascal length or longer, 2-2.5 $\mu \mathrm{m}$ diam, septate, branching, sometimes constricted and swollen at apices. Macroconidia 5.5-9.5 × 2-3 $\mu \mathrm{m}$, mean $7.2 \times 2.2$ $\mu \mathrm{m}(\mathrm{n}=30$, one collection), elongate-ellipsoid, may contain guttules. Mesoconidia 5-7 $\times 2-3$ $\mu \mathrm{m}$, mean $6.2 \times 2.5 \mu \mathrm{m}(\mathrm{n}=30$, three collections $)$ ellipsoid, may contain greenish guttules.

Hosts: Peltigera didactyla, P. neckeri, P. rufescens.

Scutula dedicata forms an epikapylic thallus on its host, which is visible as a somewhat grainy, lighter area on which the brownish to dark apothecia are formed. It may be present on either the dorsal or ventral sides of the host thallus. Scutula dedicata has three different pycnidial mitosporic states of which the microconidial state has been found only once (Triebel et al. 1997) while the macroconidia producing Karsteniomyces state and the mesoconidia producing Libertiella states are more common. May be confused with $\mathrm{Scu}$ tula heeri. The species was first recorded from Finland by Toivanen (2008). Reported also from Sweden. 


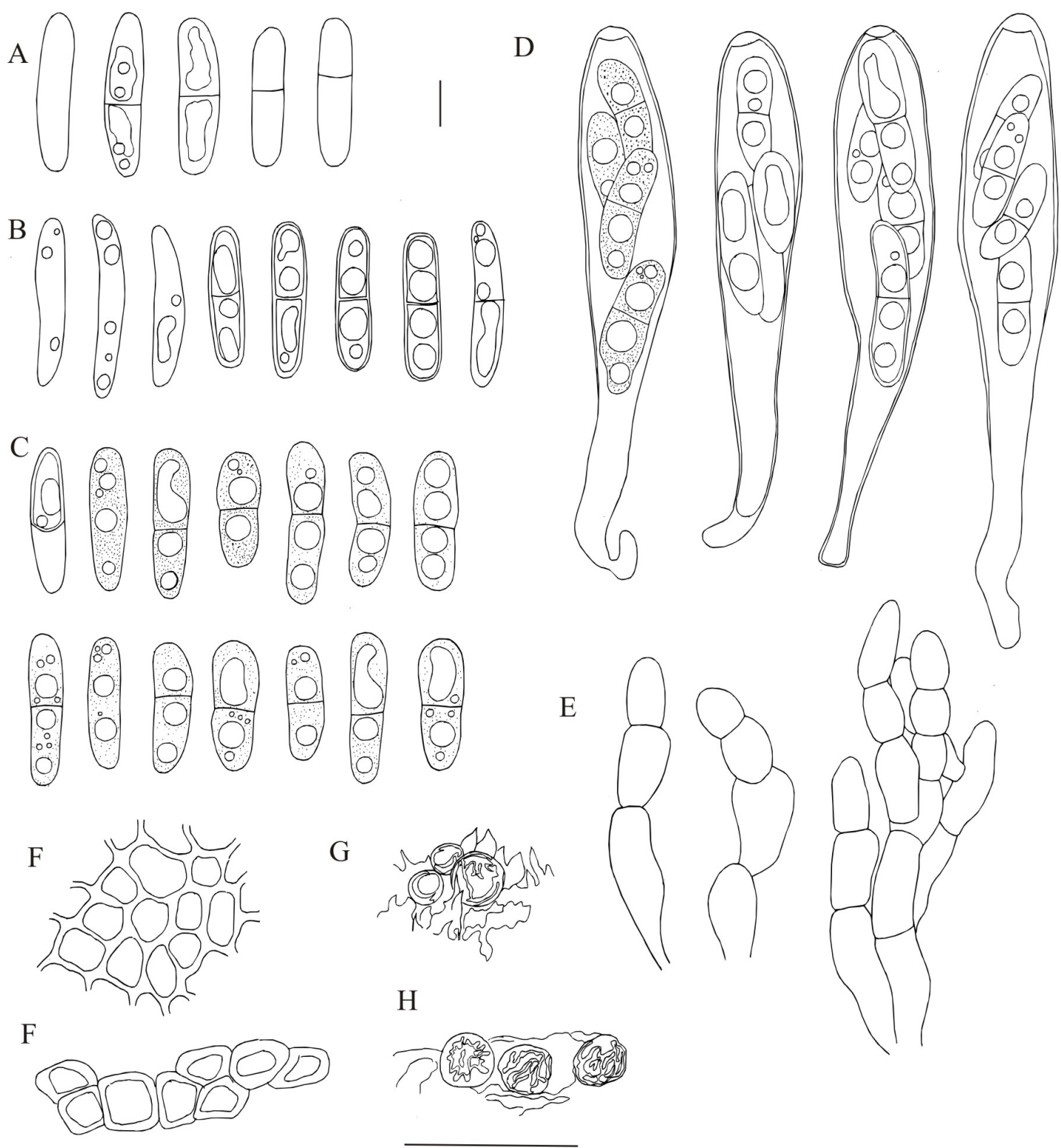

Fig. 31. Rhagadostoma brevisporum (A = 1952 Bäck; $\mathrm{B}, \mathrm{F}, \mathrm{G}=1979$ Kvist; $\mathrm{C}-\mathrm{E}, \mathrm{H}=1972$ Alava $)$, A-C = ascospores, $\mathrm{D}=$ asci, $\mathrm{E}=$ paraphyses, $\mathrm{F}=$ excipulum, $\mathrm{G}, \mathrm{H}=$ perithecia on host thallus. Bar $(\mathrm{A}-\mathrm{F}) 10 \mu \mathrm{m},(\mathrm{G}-\mathrm{H}) 1 \mathrm{~mm}$.

Specimens studied: Varsinais-Suomi. Parainen, Houtskär, Hyppeis, 30.III.1991 Bruun (H); Parainen, Ålö, 9.X.1969 Alava (TUR). Lohja, Laakspohja, 18.IX.2004 Pykälä 25665, 25666 (H). Uusikaupunki, Käätyjärvi W-side, 25.XII.1951 Laine (TUR). Uusimaa. Hanko, Tvärminne, 14.VII.1929 Häyrén $(\mathrm{H})^{*}$. Pornainen, Niinikoski, 3.VIII.1976 Kvist (H)*. Raasepori, Tammisaari, 6.I.1937 Häyrén (H). Etelä-Karjala. Hamina, Vehkalahti, 15.VIII.1948 Fagerström (H, two specimens)*, (TUR). Satakunta. Lappi, Kivikylä, 1.VIII.1957 Såltin
(H). Etelä-Häme. Hollola, Herala, 1874 leg.? (TURV)*. Padasjoki, Nyystölä, 1872 leg.? (TUR-V)*; Saksala, 1872 Lang (TUR-V)*. Pohjois-Häme. Saarijärvi, Mahlu, 29.VI.1946 Koskinen (TUR). Pohjois-Savo. Leppävirta, Kirkonkylä, 20.VIII.1927 Linkola (H). Oulun Pohjanmaa. Ylikiiminki, Jokikokko, 22.VIII.1968 Uotila $(\mathrm{H})$. Koillismaa. Salla, Pieni Pyhätunturi, 4.VII.1981 leg.? (H). Sodankylän Lappi. Sodankylä, Sattanen, 18.VI.1980 Kvist (H)*. 


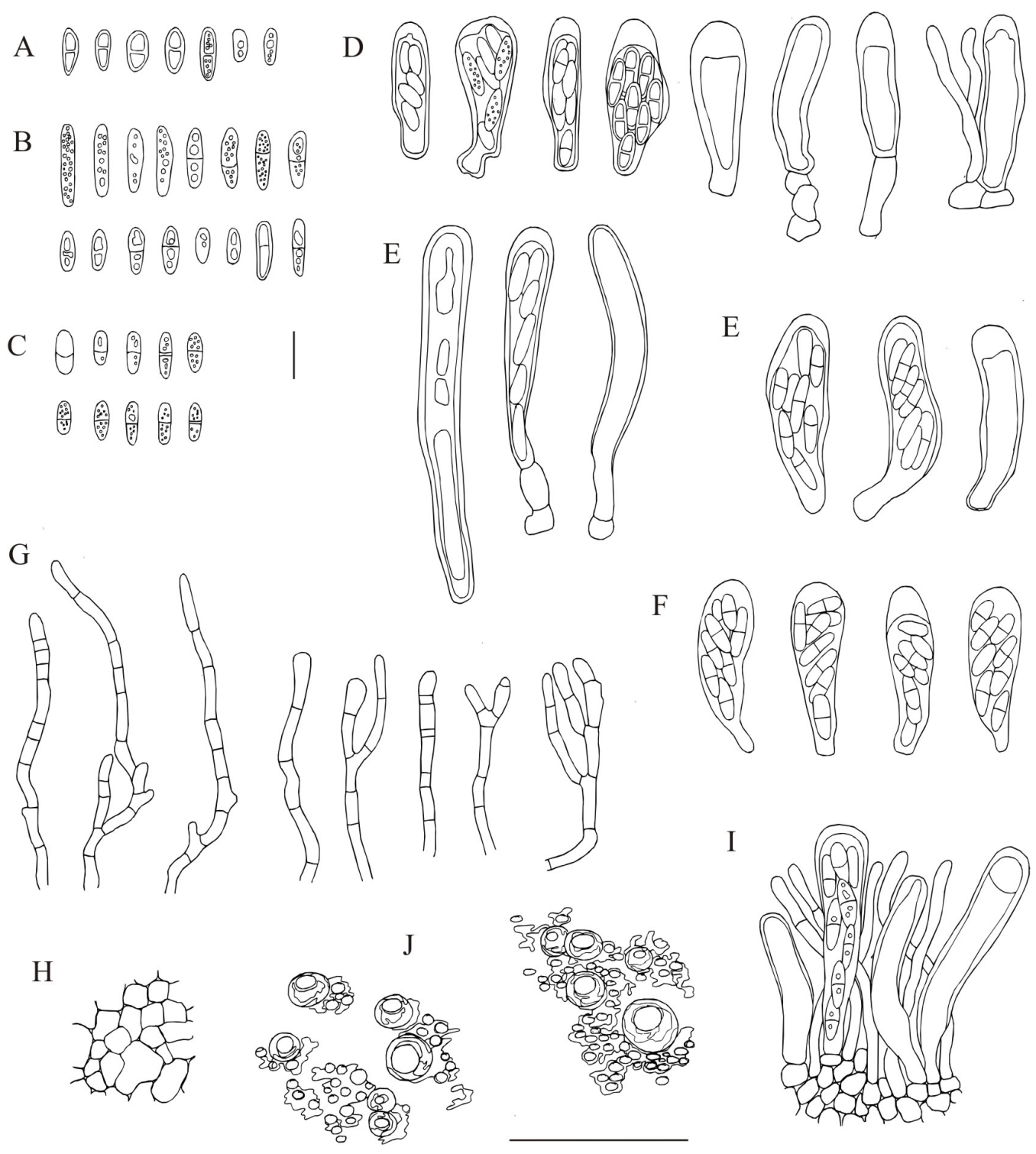

Fig. 32. Scutula dedicata (A, D, J =1872 Lang; B, E, G, I = TUR-V 22518; C, F, H = TUR-V 22514), A-C = ascospores, $\mathrm{D}-\mathrm{F}=$ asci in different stages of maturity, $\mathrm{G}=$ paraphyses, $\mathrm{H}=$ excipulum, $\mathrm{I}=$ asci, paraphyses and excipular cells, $\mathrm{J}=$ apothecia and thallus on dorsal side of host cortex. Bars (A-I) $10 \mu \mathrm{m},(\mathrm{J}) 1 \mathrm{~mm}$.

\section{Scutula epiblastematica (Wallr.) Rehm}

- Figs. 35, 46 II

Thallus endokapylic. Ascomata apothecioid, from light-brown to black; round, almost globose when young, superficially on the host thallus. Asci 21-43 × 6-13(-17) $\mu \mathrm{m}$, mean $29.7 \times$ $9.1 \mu \mathrm{m}$ ( $\mathrm{n}=20$, three collections), ellipsoid to cy- lindrical, sometimes very thick-walled, strongly thickened at apex, hyaline, CR-, 8-spored. Ascospores 6-10 × 3-5 $\mu \mathrm{m}$, mean $7.9 \times 4.0 \mu \mathrm{m}$ $(n=30$, three collections), aseptate or with $1-2$ septa, slightly constricted at septa, usually thickwalled. Paraphyses longer than asci, $3 \mu \mathrm{m}$ diam, sometimes thickened at apex, branching, septate, and sometimes slightly constricted at septa. Ex- 

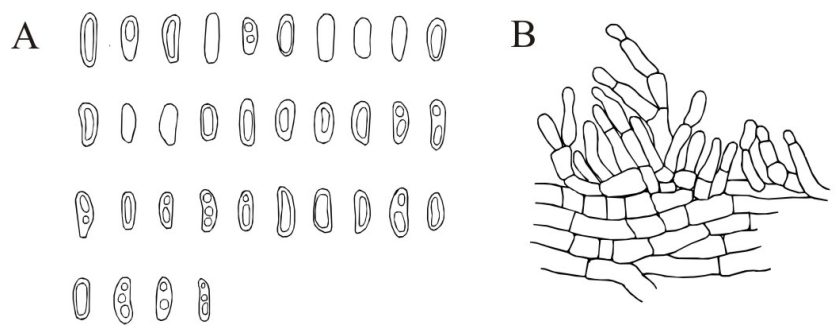

$\mathrm{C}$
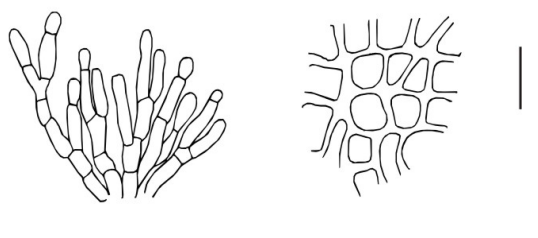

Fig. 33. Macroconidial state of Scutula dedicata (1976 Kvist), A = macroconidia, B = conidiophores and conidiogenous cells, $\mathrm{C}=$ ectal excipulum. Bar $10 \mu \mathrm{m}$.

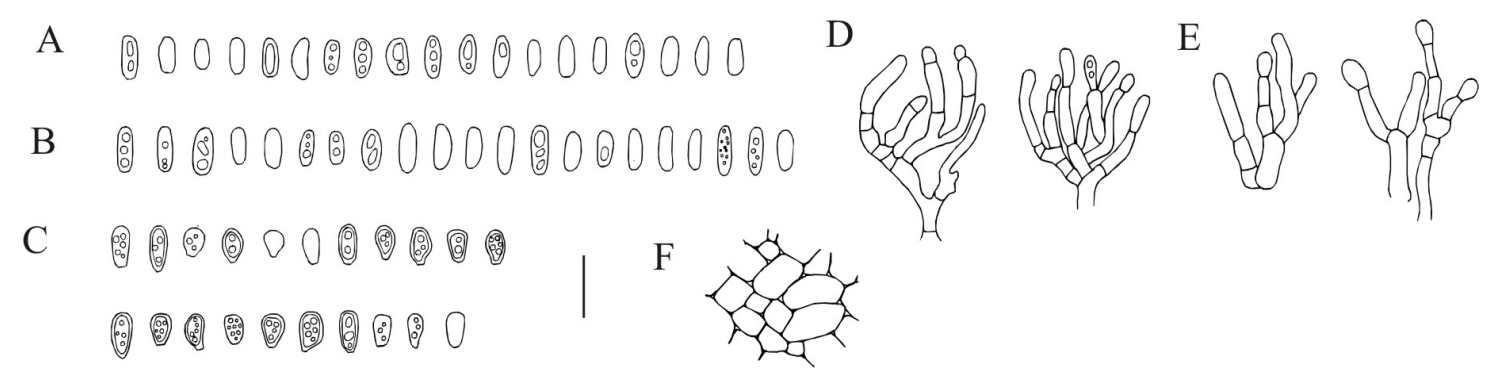

Fig. 34. Mesoconidial state of Scutula dedicata (A = 1980 Kvist; B, D, F = 1929 Häyrén; C, E = 1948 Fagerström), A-C $=$ mesoconidia, $\mathrm{D}, \mathrm{E}=$ conidiophores and conidiogenous cells, $\mathrm{F}=$ excipulum. Bar $10 \mu \mathrm{m}$.

cipulum of textura globulosa, cells thick-walled, 4-10 $\mu \mathrm{m}$ diam.

Hosts: Peltigera aphthosa, P. canina, P. leucophlebia, P. neckeri, P. praetextata, P. rufescens.

The pycnidia and apothecia of Scutula epiblastematica appear in aggregations on distinct infection areas. The infection area is bleached, which indicates a parasitic habit (Triebel et al. 1997). $S$. epiblastematica has an anamorphic microconidial state, and a mesoconidial Libertiella state (cf. L. curvispora) May be confused with S. miliaris. Reported also from Norway and Sweden.

Selected specimens studied (out of 97): Ahvenanmaa. Finström, Grelsby, Mangelbo, 17.V.1989 Alava 22548 (TUR). Varsinais-Suomi. Raasepori, Bromarv, Solböle, 19.V.1927 Linkola \& Häyrén (H). Turku, Ispoinen, 29.V.1911 Linkola (TUR-V). Uusimaa. Espoo, Kauklahti, Fiskarudden, 20.VI.1932 Linkola (H). Pernaja, Hardom, VIII.1912 Klingstedt (H). Satakunta. Pori, Noormarkku, Paasjoki, 24.VIII.1937 Laurila (H). EteläHäme. Hämeenlinna, 30.IV.1925 Kalliola (H)*. Tammela, Kankola 1870 Kullhem (H). Tampere, Messukylä, 29.V.1902 Högman (H)*. Etelä-Savo. Taipalsaari, Karhunpää, 26.VI.1966 Vitikainen 1284 (H). Kuopio, Siika- lahti, 5.V.1946 Sepponen (TUR, H) *. Etelä-Pohjanmaa. Niinimaa, Mustaniemi, Mustakallio, 4.VII.1947 Leppälä (H)*. Pohjois-Häme. Konnevesi, $1 \mathrm{~km}$ NW of village school, 6.VIII.1964 Valovirta (H).* Saarijärvi, Mahlu, 9.VIII.1935 Koskinen (H, two specimens)*. PohjoisSavo. Kuopio, Neulaniemi, 9.XII.1945 Räsänen (H). Pohjois-Karjala. Juankoski, Säyneinen, Pisankoski, 28.V.1853 Huuskonen (H). Keski-Pohjanmaa. Vimpeli, Västerbacka, Huosianmaankallio 25.IX.2003 Haikonen 22976 (H). Kainuu. Kuhmo, Lentiira, Kylmälä, 1877 Vainio (TUR-V). Koillismaa. Kuusamo, Vuotunki, Kiukaankorva, 12.VI.1960 Hämet (H). Kittilän Lappi. Muonio, Äkässaivo, VIII.1976 Huuskonen (H)*.

\section{Scutula heeri (Hepp ex A. Massal.) P.} Karst. - Figs. 36, 37, 46 JJ

Thallus epikapylic, homoiomerous, lighter than host thalli. Ascomata apothecioid, disc plane to convex, black. Ascospores 10-13.5(-18) × 4-5.5 $\mu \mathrm{m}$, mean $12.5 \times 5.0 \mu \mathrm{m}(\mathrm{n}=11$, one collection $)$, ellipsoid, septate, may contain guttules. Paraphyses $4 \mu \mathrm{m}$ diam, branching, septate, slightly constricted at septa. Macroconidia 10-14 × 2.5-3.5 $\mu \mathrm{m}$, mean $11.8 \times 3.1 \mu \mathrm{m}(\mathrm{n}=24$, one collection $)$ elongate, septate, with or without guttules. 

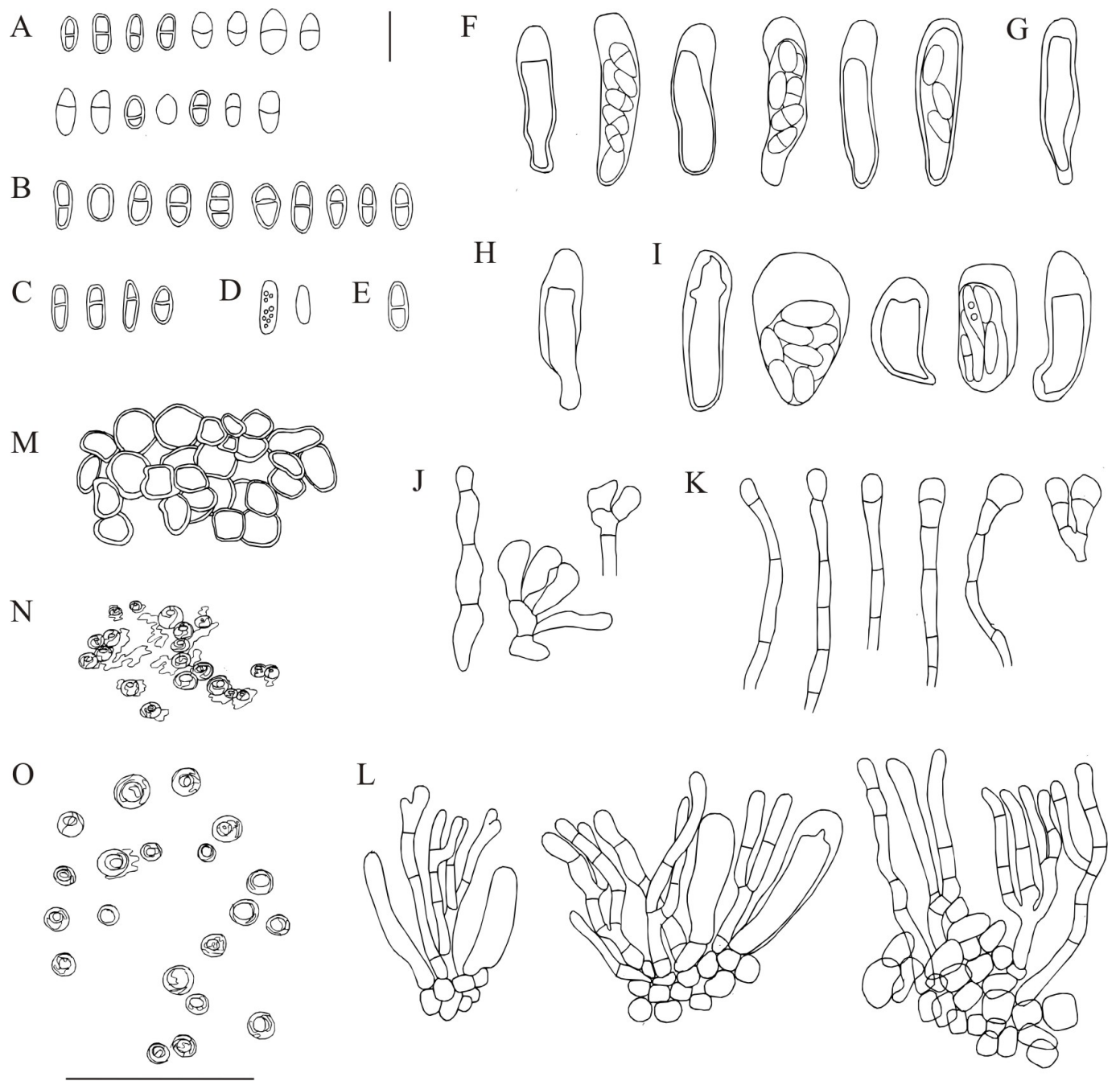

Fig. 35. Scutula epiblastematica (A, F $=1935$ Koskinen; B, H, K =1976 Huuskonen; C, G $=1947$ Leppälä; D, I, J, M $=1946$ Sepponen; $\mathrm{E}, \mathrm{L}=1902$ Högman $; \mathrm{N}=1925$ Kalliola $; \mathrm{O}=1964$ Valovirta $), \mathrm{A}-\mathrm{E}=$ ascospores, $\mathrm{F}-\mathrm{I}=$ asci in different stages of maturity, $\mathrm{J}, \mathrm{K}=$ tips of paraphyses, $\mathrm{L}=$ asci, paraphyses and excipular cells, $\mathrm{M}=$ ectal excipulum, $\mathrm{N}, \mathrm{O}$ =apothecia. Bars (A-M) $10 \mu \mathrm{m},(\mathrm{N}, \mathrm{O}) 1 \mathrm{~mm}$.

\section{Host: Peltigera rufescens.}

The superficial appearance of $S$. heeri is very much like that of $S$. dedicata. They both form an epikapylic thallus with dark apothecia on the host. The Karsteniomyces state of $S$. heeri develops a distinct thallus also in the absence of the teleomorph. Microscopically S. heeri is distinguished from $S$. dedicata by its larger ascospores and much larger macroconidia. S. heeri has been classified as NT (Near Threatened) in the 2010 Red List of Finnish Species (Jääskeläinen et al. 2010). It was first recorded from Finland by Toivanen (2008). Previous reports of the species (Santesson et al. 2004) have proved to be misidentifications. Reported also from Sweden.

Specimens studied: Uusimaa. Hanko, Tvärminne, 3.VII.1911 Linkola (H)*. Helsinki, Vuosaari, 20.IX.2005 Pykälä 27951 (H). Koillismaa. Salla, Oulankajoki, 13.VII.1937 Lehtonen \& Pankakoski $(\mathrm{H})^{*}$. 
A

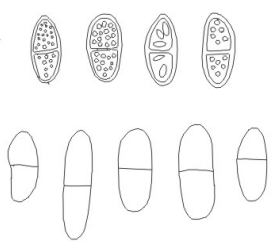

$\mathrm{B}$

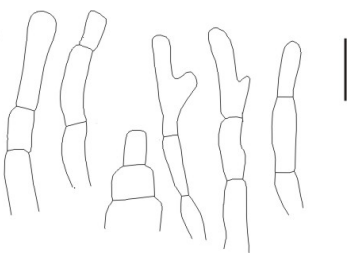

Fig. 36. Scutula heeri (1937 Lehtonen \& Pankakoski), A = ascospores, B = paraphyses. Bar $10 \mu \mathrm{m}$.

A

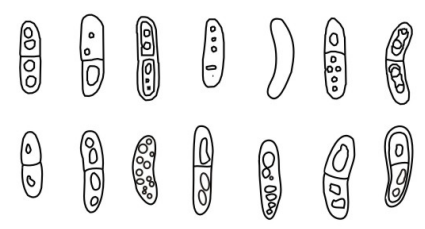

$\mathrm{C}$
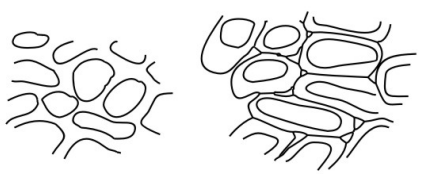
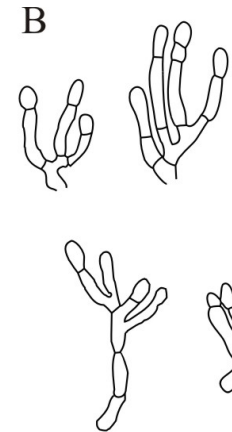

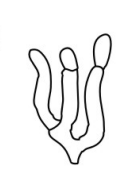

$\mathrm{D}$
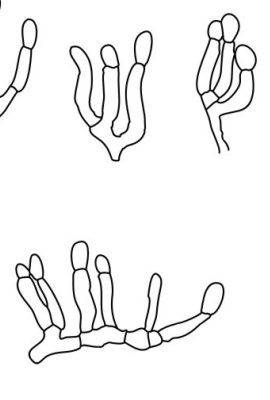

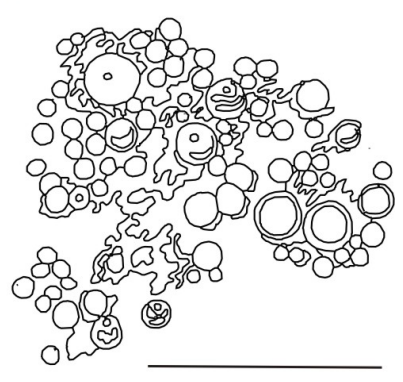

Fig. 37. Macroconidial state of Scutula heeri (1911 Linkola), A = macroconidia, $\mathrm{B}=$ conidiophores and conidiogenous cells, C = ectal excipulum, D = pycnidia and thallus of Scutula heeri on host. Bars (A-C) $10 \mu \mathrm{m}$, (D) $1 \mathrm{~mm}$.

Scutula miliaris (Wallr.) P. Karst. - Figs. 38, $47 \mathrm{KK}$

Thallus endokapylic. Ascomata apothecioid, superficial, round, light-brown to blackish. Asci $28-58 \times 8-14.5$, mean $39 \times 10.9 \mu \mathrm{m}(\mathrm{n}=20$, four collections), ellipsoid, thickened at the apex, 8-spored. Ascospores 8-15 $\times 4-7 \mu \mathrm{m}$, mean 12.2 $\times 5.2 \mu \mathrm{m}(\mathrm{n}=30$, four collections), ellipsoid to spindle-shaped, non-septate or with one septum. Paraphyses of ascal length or slightly longer, 1.5-3 $\mu \mathrm{m}$ diam, a little widened at the apex, septate, branched.

Hosts: Peltigera canina, P. rufescens, $P$. malacea, P. leucophlebia.

The light brown apothecia of Scutula miliaris are scattered or sometimes aggregated on the dorsal side of the host thallus. Scutula miliaris has a microconidial state, and a well distinguished macroconidial Karsteniomyces peltigerae anamorph. It differs from Scutula epiblastematica by not causing visible damage on the host and by its larger ascospores. The Karsteniomyces peltigerae anamorph differs from the other Karsteniomyces types anamorphs by forming an endokapylic thallus, and having large, septate conidia. Reported also from Norway and Sweden.

Selected specimens studied (out of 90): Varsinais-Suomi. Kemiönsaari, Dragsfjärd, Tynglax, 22.IV.1981 Kvist (H)*. Paimio, Hirvonpään alitupa, 27.VI.1955 Kukkonen (H)*. Uusikaupunki, Käätyjärvi-W, 25.XI.1951 Laine (TUR, two specimens). Uusimaa. Helsinki, Meilahti 5.XI.1911 Linkola ( TUR-V). Etelä-Häme. Kuhmoinen, Päijälä, Rumavuori, 14.IV.1974 Oittinen 5 (H)*. Tammela, Mustiala, 1869 Kullhem (H, four specimens). Pohjois-Häme. Jyväskylä, Ristikivenlaakso, 2.VIII.1912 Linkola (TUR-V). Pohjois-Savo. Kuopio, Neulamäki, 14.XII.1933 Lumiala (H)*. Kainuu. Suomussalmi, Kianta, Parish village, 25.VI.1877 leg.? (TUR-V). Perä-Pohjanmaa. Kemijärvi, Pyhätunturi, 12.VIII.1925 Linkola (H). Koillismaa. Kuusamo, Juuma, Jäkälävuoma, 6.VII.1981 Lempiäinen (TUR). Salla, Savinajoki, 8.VII.1939 Laurila (H). Sodankylän Lappi. Pelkosenniemi, Pyhätunturi, 12.VIII.1925 Linkola (H). Inarin Lappi. Utsjoki, Kevo, Keneskoski E, 25.VIII.1974 Ahti 29796 \& Santesson $(\mathrm{H})$. 


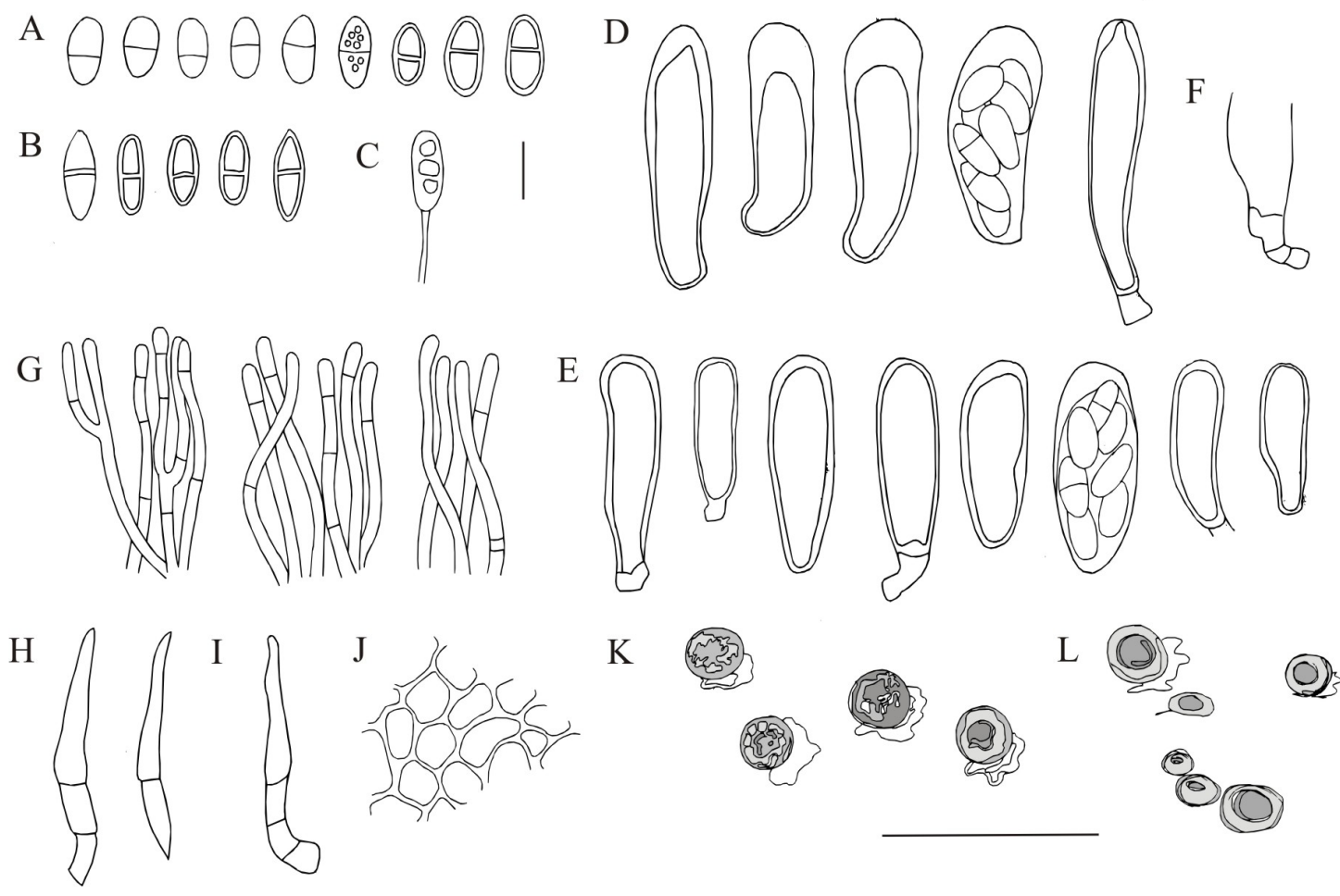

Fig. 38. Scutula miliaris (A, C, D, F, H, J, K = Oittinen 5; B, E, I, L = 1981 Kvist; G = 1933 Lumiala), A-C = ascospores, $\mathrm{D}, \mathrm{E}=$ asci in different stages of maturity, $\mathrm{F}=$ ascus base, $\mathrm{G}=$ paraphyses, $\mathrm{H}, \mathrm{I}=$ setae, $\mathrm{J}=$ excipulum, $\mathrm{K}, \mathrm{L}=$ apothecia. Bars (A-J) $10 \mu \mathrm{m},(\mathrm{K}, \mathrm{L}) 1 \mathrm{~mm}$.

\section{Stigmidium leucophlebiae $\mathrm{Cl}$. Roux \& Triebel} - Figs. 39, 47 LL

Ascomata pseudoperithecioid, immersed, black, globose, $50-70 \mu \mathrm{m}$. Asci 22-30 × 9-14 $\mu \mathrm{m}$, mean $26.5 \times 11.9 \mu \mathrm{m}(\mathrm{n}=8$, two collections), clavate, thickened at the apex, only few (4-5) in each fruit body, 8-spored. Ascospores 12-16 $\times$ 3-4 $\mu \mathrm{m}$, mean $12.9 \times 3.3 \mu \mathrm{m}(\mathrm{n}=13$, two collections), septate, upper cell slightly broader and more rounded than the lower cell, may contain greenish guttules. Paraphyses or periphyses not observed (contra to Roux \& Triebel 1994). Ectal excipulum of textura angularis, cells thickwalled, densely packed, 5-8 $\mu \mathrm{m}$ diam. Medullary excipulum of textura globulosa, cells thin-walled, 2-5 $\mu \mathrm{m}$ diam.

Host: Peltigera leucophlebia.
The only visible signs of $S$. leucophlebiae on the host thallus are the ostioles of the ascomata, which appear as tiny, circular pores, while the rest of the fruit bodies are completely immersed in the matrix. Can be confused with $S$. peltideae. The species was first recorded from Finland by Toivanen (2008). Reported also from Sweden.

Specimens studied: Varsinais-Suomi. Salo, Kisko, 1.IX.1971 Laine (TUR); 1.IX.1971 Alava \& Alho (TUR). Etelä-Häme. Hollola, Upila, 1876 Norrlin (H). Oulun Pohjanmaa. Kiiminki, Talkkunamaa, 5.VI.1923 Räsänen $(\mathrm{H})^{*}$. Koillismaa. Kuusamo, Juuma, 14.VII.1951 Bäck $(\mathrm{H})^{*}$.

Stigmidium peltideae (Vain.) R. Sant. - Figs. 40, 47 MM

Ascomata pseudoperithecioid, immersed, globose, 50-70 $\mu \mathrm{m}$, black. Asci 22-39 × 10-18 $\mu \mathrm{m}$, mean $28.3 \times 13.9 \mu \mathrm{m}(\mathrm{n}=16$, three collec- 

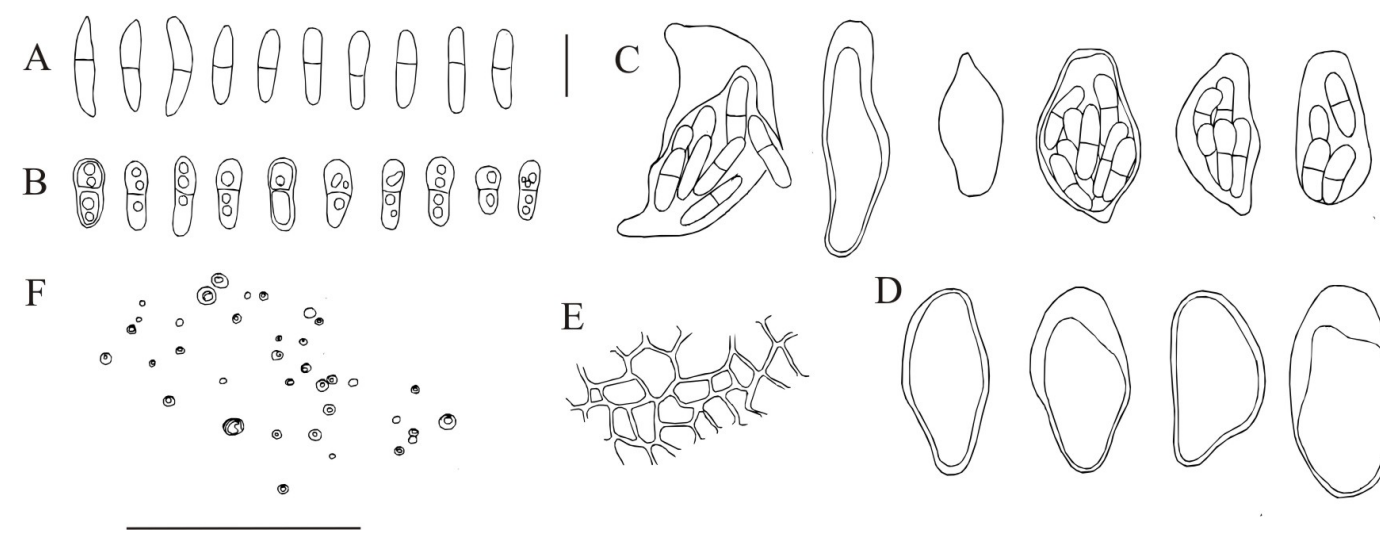

Fig. 39. Stigmidium leucophlebiae (A, C, E, F = 1951 Bäck; B, D = 1923 Räsänen), A, B = ascospores, C, D = asci, E

$=$ extal excipulum, $\mathrm{F}=$ perithecia in the host cortex. Bars $(\mathrm{A}-\mathrm{E}) 10 \mu \mathrm{m},(\mathrm{F}) 1 \mathrm{~mm}$.

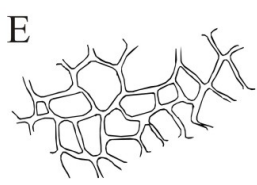

$\mathrm{D}$

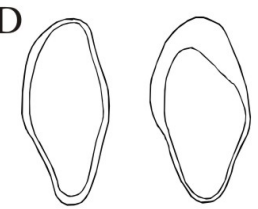

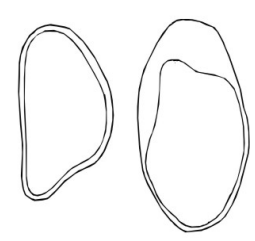

A

B
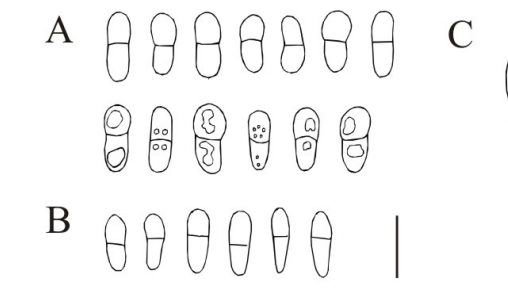

A
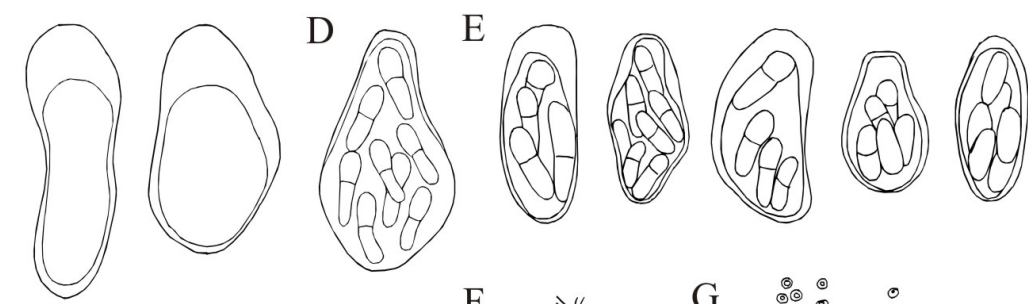

$\mathrm{F}$
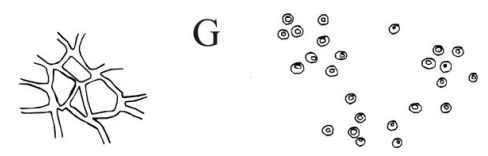

Fig. 40. Stigmidium peltideae (A, C = 1905 Collan; B, E, G = 1947 Huuskonen; D, F = 1936 Häyrén), A, B = ascospores, $\mathrm{C}-\mathrm{E}=$ asci, $\mathrm{F}=$ ectal excipulum, $\mathrm{G}=$ pseudoperithecia in the host thallus. Bars $(\mathrm{A}-\mathrm{F}) 10 \mu \mathrm{m},(\mathrm{G}) 1 \mathrm{~mm}$.

tions), bitunicate, ellipsoid, thickened at the apex, only few (4-5) in each fruit body, 8-spored. Ascospores 8-12.5 × 2.5-4.5 $\mu \mathrm{m}$, mean $10.4 \times$ $3.5 \mu \mathrm{m}$ ( $\mathrm{n}=30$, three collections), septate, sometimes slightly constricted, cell slightly inequal in lenght, with or without guttules. Paraphyses or periphyses not observed. Ectal excipulum of textura angularis, cells thick-walled, densely packed, 5-8 $\mu \mathrm{m}$ diam. Medullary excipulum of thin-walled cells, 5-8 $\mu \mathrm{m}$ diam.

Hosts: Peltigera aphthosa, P. leucophlebia, P. praetextata, $P$. venosa. The species has also been reported from $P$. canina, $P$. membranacea and P. rufescens (Nordin et al. 2010).
Although it is common and widely distributed S. peltideae is reported as new to Finland. As with the previous species, the only visible signs of its presence on the host thallus are the ostioles of the ascomata, which appear as tiny, circular pores, while the rest of the fruit bodies are completely immersed in the matrix. S. peltideae differs from the previous species mainly by its smaller ascospores. Reported also from Norway and Sweden.

Selected specimens studied (out of 26): VarsinaisSuomi. Lohja, Immula, 6.IX.2008 Pykälä 33670 (H). Salo, Kisko, Leilä, 2.IX.1969 Vitikainen 5936 (H). Uusimaa. Espoo, Bastvik, 13.XII.1936 Häyrén (H)*. EteläKarjala. Hamina, Vehkalahti, Vehkjärvi, 7.VIII.1967 Fagerström (H). Etelä-Häme. Hämeenlinna, Ruununmylly, 15.X.1964 Huvinen (H). Etelä-Savo. Mäntyhar- 
ju, Toivola, 10.IX.1917 Linkola (H). Pohjois-Häme. Jyväskylä, Korpilahti, Vaarunvuori, 25.VI.1916 Linkola (H). Pohjois-Savo. Kuopio, Halkosaari, 28.V.1905 Collan $(\mathrm{H})^{*}$. Pohjois-Karjala. Ilomantsi, Kuuksenvaara, 2.IX.1958 Klingstedt (H). Kontiolahti, Kolvananuuro, V.1940 Huuskonen (H). Keski-Pohjanmaa. Evijärvi, Järvelä, 21.VI.1907 Backman (H, two specimens). PeräPohjanmaa. Simo, 3.VI.1915 Räsänen (H). Koillismaa. Kuusamo, Juuma, 14.VII.1951 Bäck (H). Kittilän Lappi. Kittilä, Alakylä, 20.IX.1956 Ahti 268 (H); Levitunturi, Kuru, 25.VII.1936 Räsänen (H). Enontekiön Lappi. Enontekiö, Kaaresuvanto, 20.VII.1947 Huuskonen (H)*.

\section{Thelocarpon epibolum $\mathrm{Nyl}$ - Figs. 41, $47 \mathrm{NN}$}

Ascomata perithecioid, yellowish, superficial. Asci $65-161 \times 17-30 \mu \mathrm{m}$, mean $116.3 \times 21.3$ $\mu \mathrm{m}$ ( $\mathrm{n}=12$, three collections), unitunicate, sackshaped, thin-walled, multispored. Ascospores 5-13 $\times 2-3 \mu \mathrm{m}$, mean $7.5 \times 2.5 \mu \mathrm{m}(\mathrm{n}=34$, three collections), elongate, simple. Paraphyses of ascal length or longer, $1.5 \mu \mathrm{m}$ diam, sometimes slightly swollen at the apices.

Hosts: Peltigera aphthosa, P. canina, P. leucophlebia, $P$. venosa. Also found during this study on Nephroma arcticum and Solorina octospora. Thelocarpon epibolum has a wide range of substrates, and has also been reported from Sphagnum mosses and decaying wood, from polyporaceaous fungi, and from forest litter etc. (Kocourková-Horáková 1998).

Thelocarpon epibolum is easily visible, as the fruit bodies are almost completely superficial and brightly coloured. Two variations are sometimes recognized based on ascopore size. T. epibolum var. epibolum is frequent in Finland, while $T$. epibolum Nyl. var. epithallinum (Leight.) G. Salisb., with larger ascospores, is less common. Here, both variations are included in the distribution map. Recorded also from Norway and Sweden.

Specimens studied: Varsinais-Suomi. Lohja, Virkkala church, 20.VII.2004 Pykälä 25153, 25161 (H); Immula, 6.IX.2008 Pykälä 33669 (H); Karstu, S of Ilvesmäki, 20.IX.2008 Pykälä 33958 (H), 20.IX.2008 Pykälä 33959 (H). Raasepori, Bromarv, Solböle 1964 Laitinen (H). Salo, Kisko, 27.X.1988 Alava 22426 (TUR). Turku, Kakskerta, 17.VIII.1934 Kari (TUR). Vihti, Olkkala 2.XI.1897 Lång (H). Uusimaa. Hanko,Tvärminne, 1910 Häyrén (H). Kirkkonummi, 28.IX.1913 Collander (H). Loviisa, Ruotsinpyhtää, Gäddbergsö, 16.VIII.1984 Vitikainen 11146 (H). Nurmijärvi, Kiljava, 15.VI.1964 Haapasaari
1397 (H). Orimattila, Niemi, 2.IX.1914 Linkola (H). Pernaja, Hardom, 8.1916 Klingstedt $(\mathrm{H})$. Raasepori, Tammisaari, Bromarv, 1964 Laitinen (H); Tammisaari, Älgö 24.VI.1952 Hämet (H). Sipoo, Råberget, 6.VIII.1949 af Hällström (H); Mårtensby, 20.VII.1948 af Hällström $(\mathrm{H})$. Etelä-Karjala. Hamina, Vehkalahti, 18.VII.1914 Krohn (H). Kouvola, Anjalankoski, 12.VI.1967 Fagerström (H). Satakunta. Kankaanpää, Venesjärvi, 8.VII.1934 Laurila (H, two specimens). Pori, Ahlainen, 31.VIII.1939 Laurila $(\mathrm{H})$. Sastamala, Tyrvää, 68128, 8.VIII.1910 Heikinheimo (H). Siikainen, Petkele, 24.VIII.1936 Laurila (H). Etelä-Häme. Hattula, Pekola, 20.IX.1931 Häyrén (H)*. Humppila, Myllynkulma, 29.VIII.1952 Fagerström (H). Janakkala, Harviala, 23.VIII.1931 Linkola (H). Kuhmoinen, Tehi, 18.X.1911 Linkola (H). Orivesi, Mulkoila, 18.VIII.1952 Pusa (H). Vilppula, Pohjaslahti, 8.VII.1987 Kytövuori $87072 a(\mathrm{H})^{*}$. Urjala, Kormunti, 15.VI.1952 Fagerström (H). Ylöjärvi, Kuru, 27.VI.1968 Toivonen (H). Ypäjä, Vähäsuo, 3.XII.1966 Kantee (H). Etelä-Savo. Imatra, Itä-Siitola, 29.VIII.1950 Rauhala (H). Rantasalmi, Voinsalmi, 9.VI.1986 Haikonen $7384(\mathrm{H})^{*}$. Suomenniemi, Kiesilä, 8.VIII.1983 Vitikainen 10725 (H). EteläPohjanmaa. Kristiinankaupunki, Lappfjärd, Pyhävuori, 30.VIII.1946 Railonsala (TUR) on Nephroma arcticum. Vaasa, Sundom, 28.VII.1950 Bäck (H). Pohjois-Häme. Jyväskylä, 21.VI.1912 Leino (H); Korpilahti, 1874 Lang (H); Ylistö 18.VI.1913 Linkola (H). Pihtipudas, Muurasjärvi N-end, 5.VII.1964 Suominen (H). Saarijärvi, Hännilä, 25.VIII.1944 Koskinen (H); Pyhä-Häkki National park, 26.VIII.1943 Koskinen (H). Pohjois-Savo. Joroinen, Huutokosken asemasta 1,5 km Joroisiin, 22.VII.1965 Suominen (H). Kuopio, Suovu 3.VIII.1906 Linkola (H); Korsumäki, 19.V.1946 Räsänen (TUR). Suonenjoki, Kutumäki, 1.VIII.1971 Takala 7502 (H). Pohjois-Karjala. Juuka, Mataravaara, 8.IX.1970 Takala 5763 (H); Tahkovaara, 22.VIII.1960 Huuskonen (H); Kontiolahti, Kolvananuuro, V.1940 Huuskonen (H). Keski-Pohjanmaa. Kannus, Eskola railway yard, 3.VII.1964 Suominen (H). Kainuu. Puolanka, Väyrylä, 29.VII.1970 Alava (TUR). Perä-Pohjanmaa. Keminmaa, church, 24.VII.1964 Suominen (H). Koillismaa. Kuusamo, Juuma, 6.VII.1981 Skytén 3204 (H); Virkkula, Konttainen, 7.VII.1981 Skytén 3261 (H). Kittilän Lappi. Kittilä, Alakylä, 20.IX.1956 Ahti (H). Muonio, Äkäsjokivarsi, VIII.1963 Huuskonen (H). Sodankylän Lappi. Savukoski, Sokli 18.VIII.1975 Vuokko 183 (H). Enontekiön Lappi. Enontekiö, Hetta, 1867 Norrlin (H); 5.IX.1965 Takala 1998 (H). Kilpisjärvi, Saana, 1.VIII.1956 Huuskonen (TUR) on Solorina octospora. Inarin Lappi. Inari, Paatsjoki, Renvall $(\mathrm{H})$.

\section{Xenonectriella lutescens (Arnold) Weese - Figs. 42, $47 \mathrm{OO}$}

Ascomata perithecioid, $150 \mu \mathrm{m}$ diam, yellowish in dried herbaria specimens, colour around the ostiole lighter or darker. Asci 74-99 $\times$ 20-28 $\mu \mathrm{m}$, mean $86.2 \times 23.7 \mu \mathrm{m}(\mathrm{n}=9$, one collection), cylindrical, thick-walled. Ascospores 19-25 × 7-9 $\mu \mathrm{m}$, mean $22.6 \times 8.2 \mu \mathrm{m}(\mathrm{n}=30$, one collection $)$, broadly fusoid, muricate, outer wall thick, $\mathrm{CR}+$ 


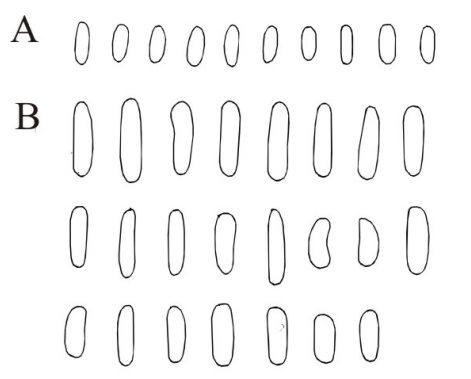

C 000000
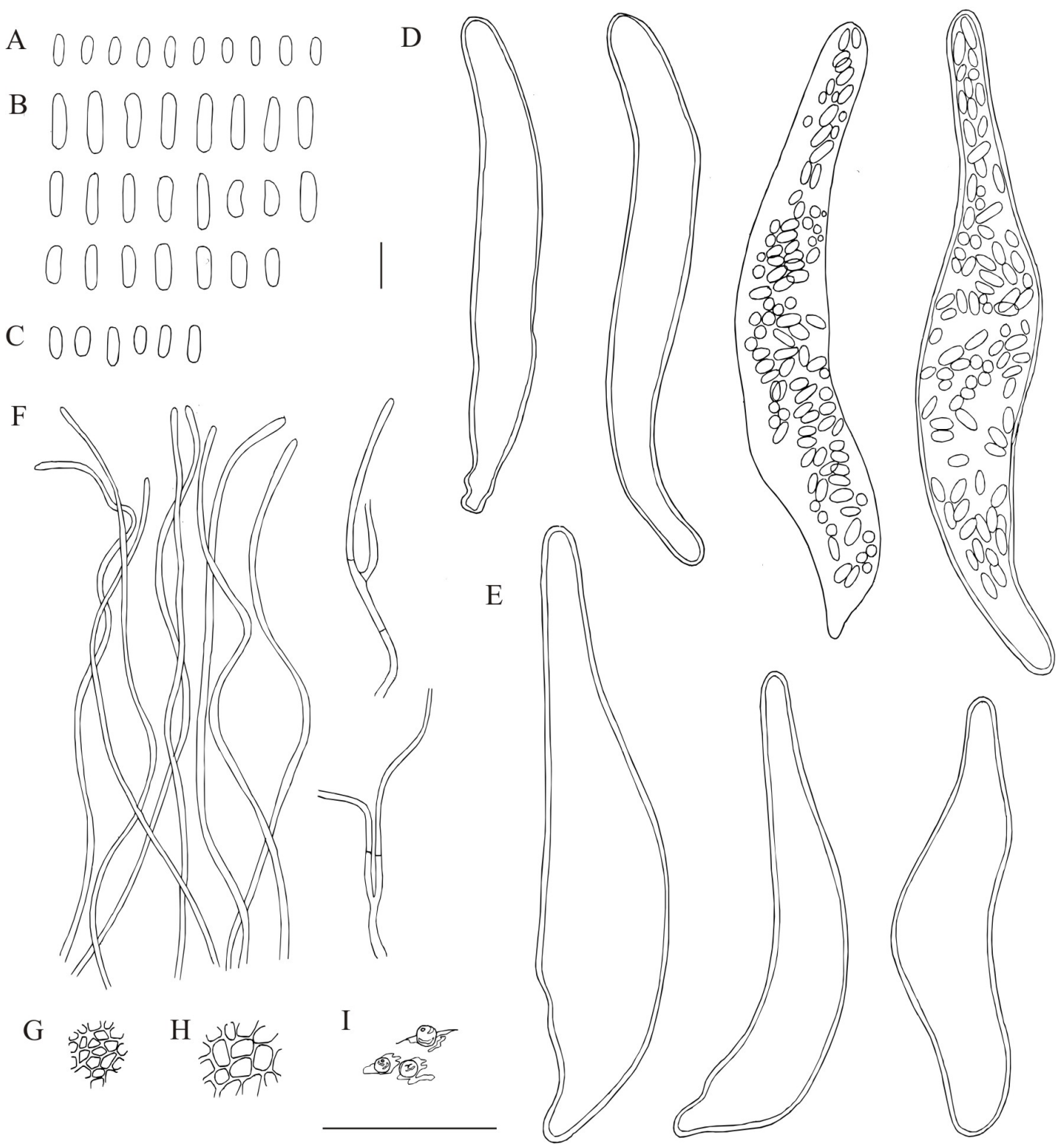

Fig. 41. Thelocarpon epibolum (A, D, F-H = Haikonen 7384; B, E = Kytövuori 87072a; C, I = 1931 Häyrén), A-C = ascospores, $\mathrm{D}, \mathrm{E}=$ asci, $\mathrm{F}=$ paraphyses, $\mathrm{G}=$ excipulum, $\mathrm{H}=$ ectal excipulum, $\mathrm{J}=$ perithecia. $\mathrm{Bars}(\mathrm{A}-\mathrm{H}) 10 \mu \mathrm{m},(\mathrm{J}) 1 \mathrm{~mm}$. 

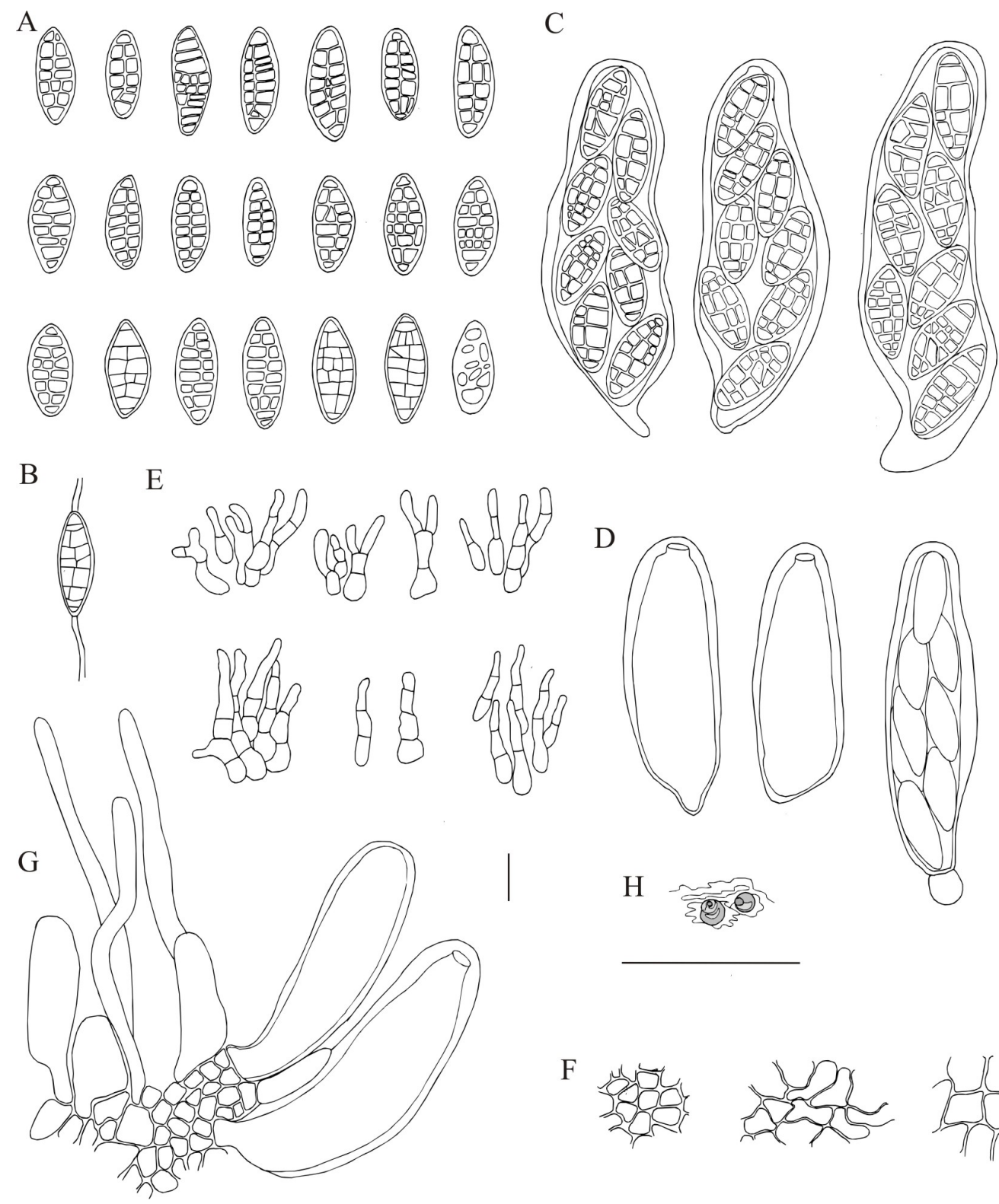

D
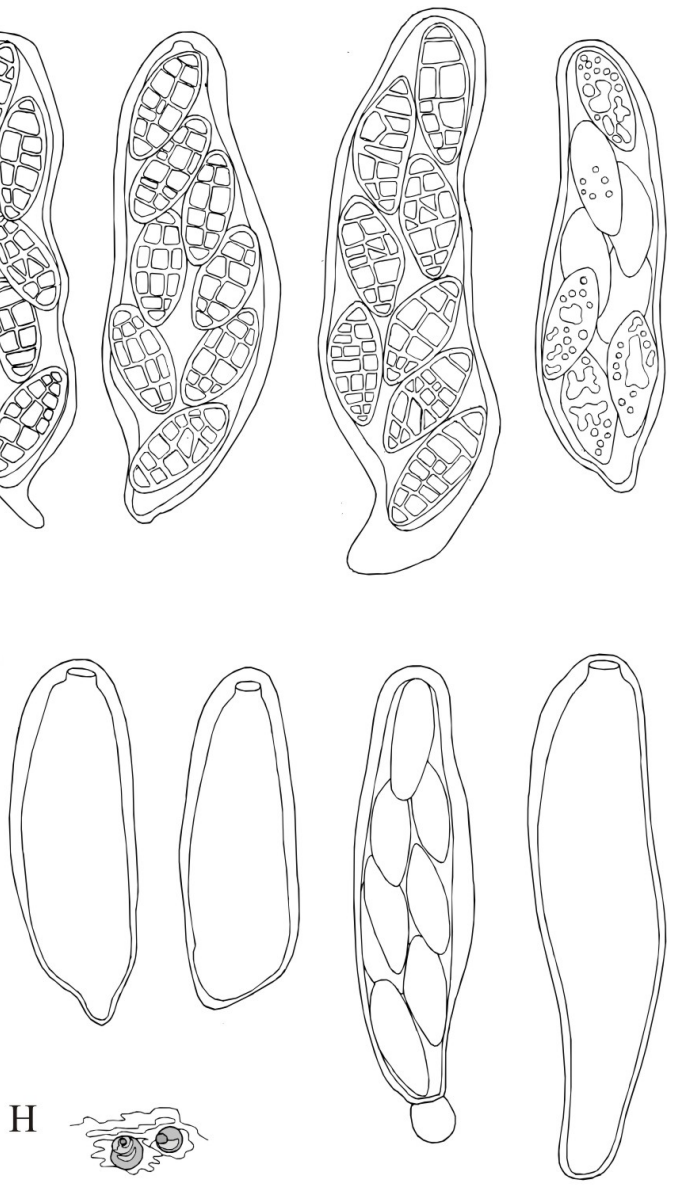

Fig. 42. Xenonectriella lutescens (1916 Anttila), $\mathrm{A}=$ ascospores, $\mathrm{B}=$ germinated ascospore, $\mathrm{C}=$ mature asci, $\mathrm{D}=$ unripe asci, $\mathrm{E}=$ periphyses, $\mathrm{F}=$ excipulum, $\mathrm{G}=$ paraphyses, young asci and excipulum, $\mathrm{H}=$ perithecia. $\mathrm{Bars}(\mathrm{A}-\mathrm{G}) 10 \mu \mathrm{m}$, (H) $1 \mathrm{~mm}$. 
A

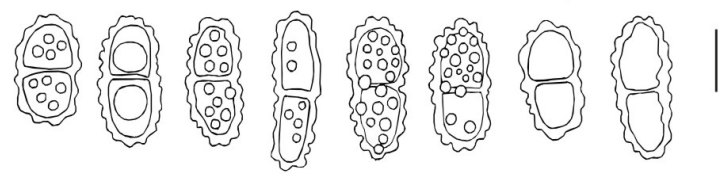

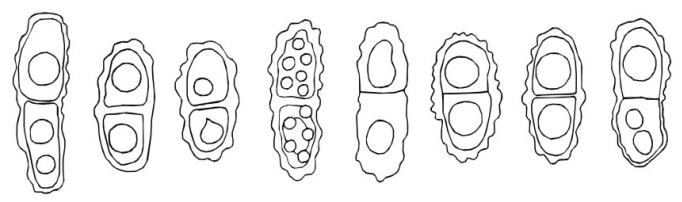

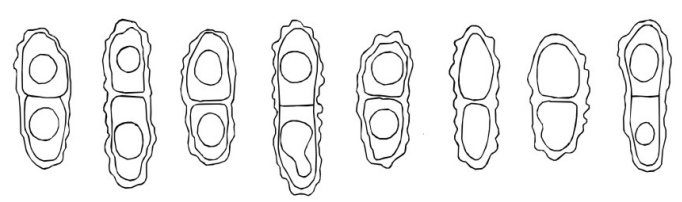

B

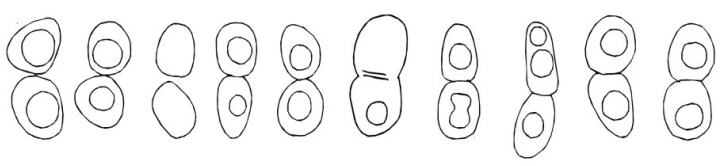

$\mathrm{C}$

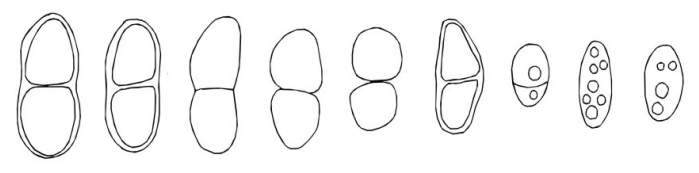

G

$\mathrm{F}$

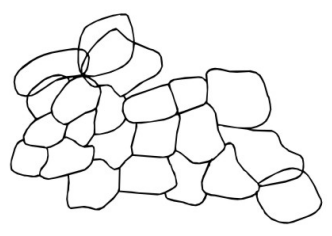

$\mathrm{H}$

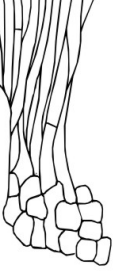

$\mathrm{D}$

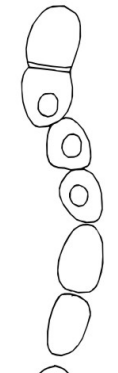

E
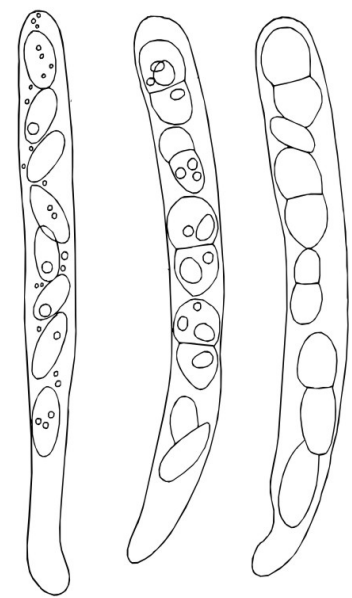

E
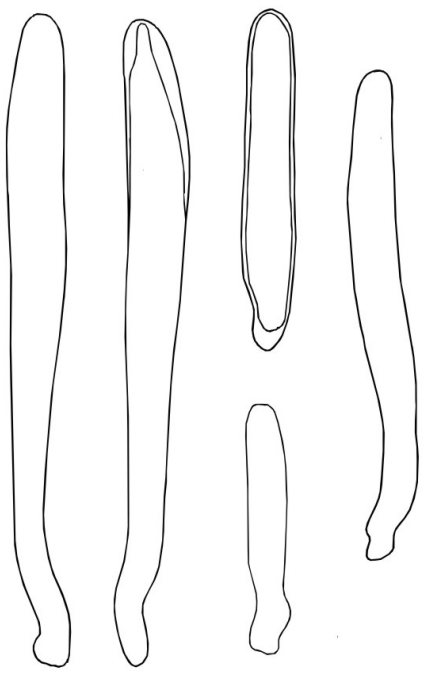

I

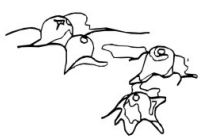

$\mathrm{J}$

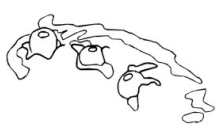

Fig. 43. Xenonectriella ornamentata (A, B, D, F, H, I = Vitikainen 10057a; E, G, J = Ahti \& Vitikainen 8284; C = Ahti \& Vitikainen 8299), $\mathrm{A}=$ mature ascospores, $\mathrm{B}-\mathrm{D}=$ unripe ascospores, $\mathrm{F}=$ detail of neck of perithecia, $\mathrm{G}, \mathrm{H}=$ ectal excipulum, I, J = elongated necks of ostioles rupturing the host cortex, $\mathrm{H}=$ marginal excipulum. Bars $(\mathrm{A}-\mathrm{H}) 10 \mu \mathrm{m}$, (I, J) $1 \mathrm{~mm}$. 
at maturity. Paraphyses of ascal lenght or longer, 5-7 $\mu \mathrm{m}$ diam, not easily visible. Periphyses ca $4 \mu \mathrm{m}$ wide at base, septate, bending and branching. Ectal excipulum cells thick-walled, 6-7 $\mu \mathrm{m}$ diam. Medullary excipulum cells thin-walled, 4-5 $\mu \mathrm{m}$ diam, globose.

Hosts: Peltigera canina, P. didactyla. Reported also from Collema fasciculare (L.) Weber ex F.H. Wigg. (Nordin et al. 2010) and Solorina sp. (Rossman 1999).

Xenonectriella is reported as a new genus to Finland. Ascomata are partially or totally immersed in the substratum, with the protruding papillae visible as orange spots. Reported also from Norway.

Specimens studied: Varsinais-Suomi. Lohja, Virkkala church, 20.VII.2004 Pykälä 25161 (H). Uusimaa. Sipoo, Löparö, 12.VIII.1916 Anttila (H)*. Etelä-Häme. Längelmäki, Päijälä, 10.VII.1986 Miekk-oja (H). Etelä-Savo. Kouvola, 20.VIII.1949 Klingstedt $(\mathrm{H})$.

Xenonectriella ornamentata (D. Hawksw.) Rossman - Figs. 43, $46 \mathrm{CC}$

Ascomata perithecioid, immersed in the host thallus at first but breaking through the cortex at maturity, obpyriform to subglobose, orange-red to bright red, translucent, glabrous, the exposed part 100-150 $\mu \mathrm{m}$ diam. Asci 67-101 × 7-10 $\mu \mathrm{m}$, mean $87.7 \times 8.6 \mu \mathrm{m}(\mathrm{n}=20$, two collections $)$, unitunicate, cylindrical, thin-walled, producing 8 -spore initials, but mature asci are constantly 4-spored. Ascospores 15-28 × 7.5-10.5 $\mu \mathrm{m}$, mean $22.4 \times 8.5 \mu \mathrm{m}(\mathrm{n}=24$, one collection $)$, elongate, thick-walled, septate, with or without guttules, ornamented with conspicuous, irregularly shaped tubercles. Paraphyses absent. Periphyses thin, hyaline, not easily visible. Ectal excipulum cells thin-walled, 4-12 $\mu \mathrm{m}$ diam.

Hosts: Peltigera didactyla, P. rufescens. Reported also from Peltigera lepidophora (Nordin et al. 2010).

Ascomata of Xenonectriella ornamentata are partially or totally immersed in the substratum, with the protruding papillae visible as orange spots. The species was recorded as new to Finland by Alstrup (2004, as Pronectria ornamentata). Reported also from Norway and Sweden.

Specimens studied: Koillismaa. Kuusamo, Paljakka, 14.VI.1980 Vitikainen $10057 a(\mathrm{H})^{*}$. Salla, Jyrhämä, 6.VIII.1937 Auer (TUR). Inarin Lappi. Utsjoki, Kevo, Könkäänpahta, 21.VIII.1974 Ahti \& Vitikainen 8284 $(\mathrm{H})^{*}, 8299(\mathrm{H})^{*}$. 

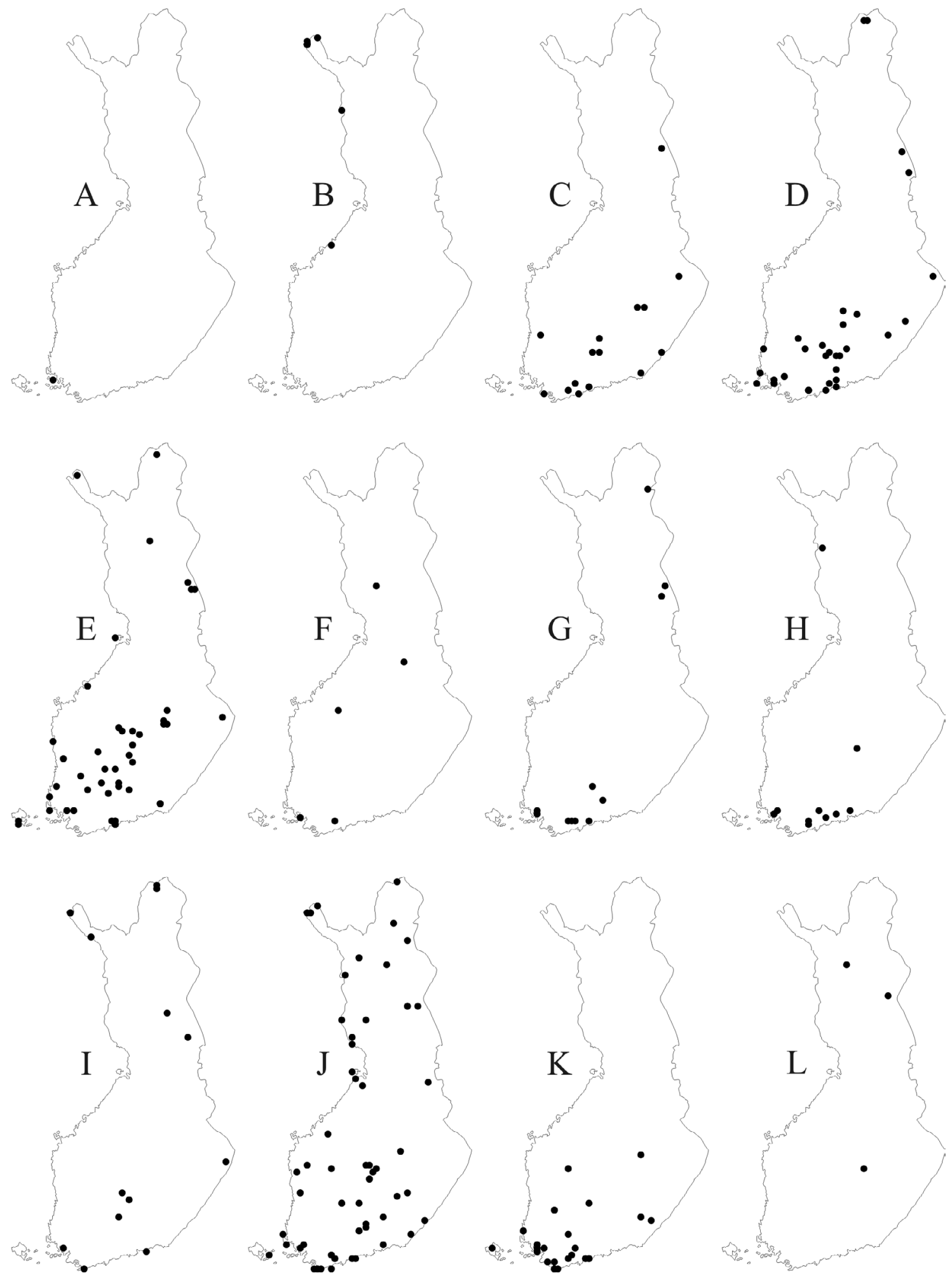

Fig. 44. Distribution maps of species A-L. 

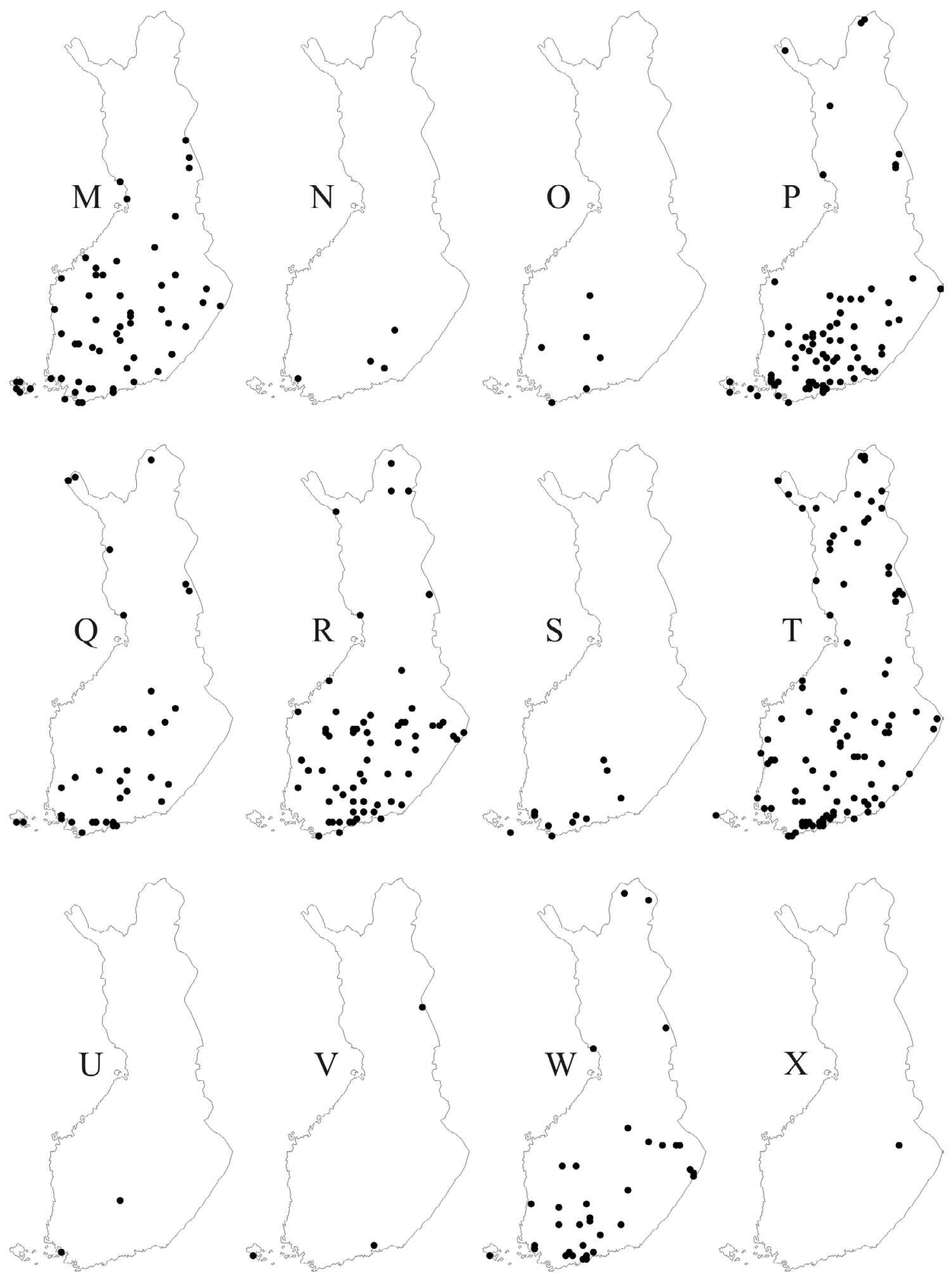

Fig. 45. Distribution maps of species M-X. 

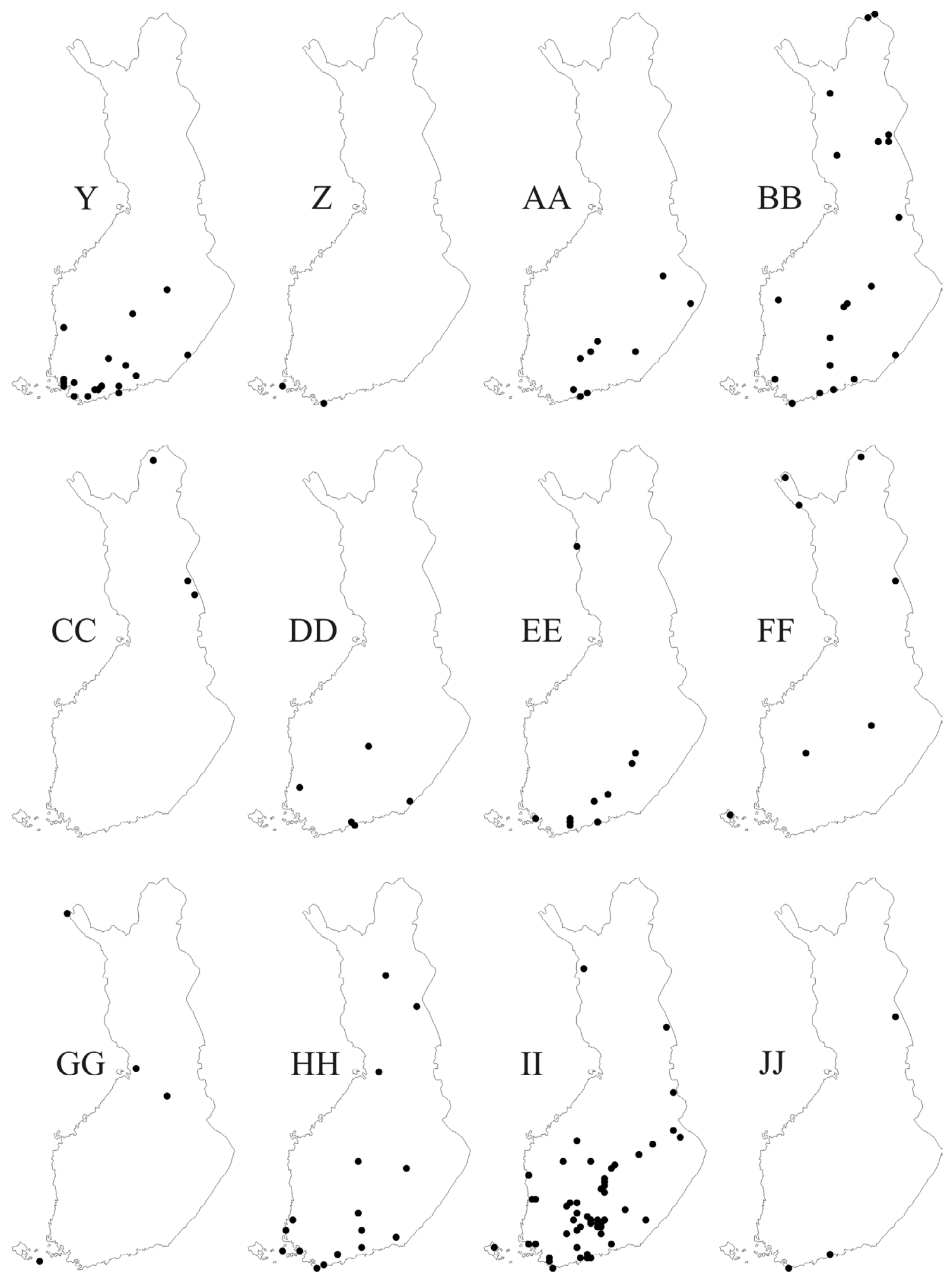

Fig. 46. Distribution maps of species Y-JJ. 

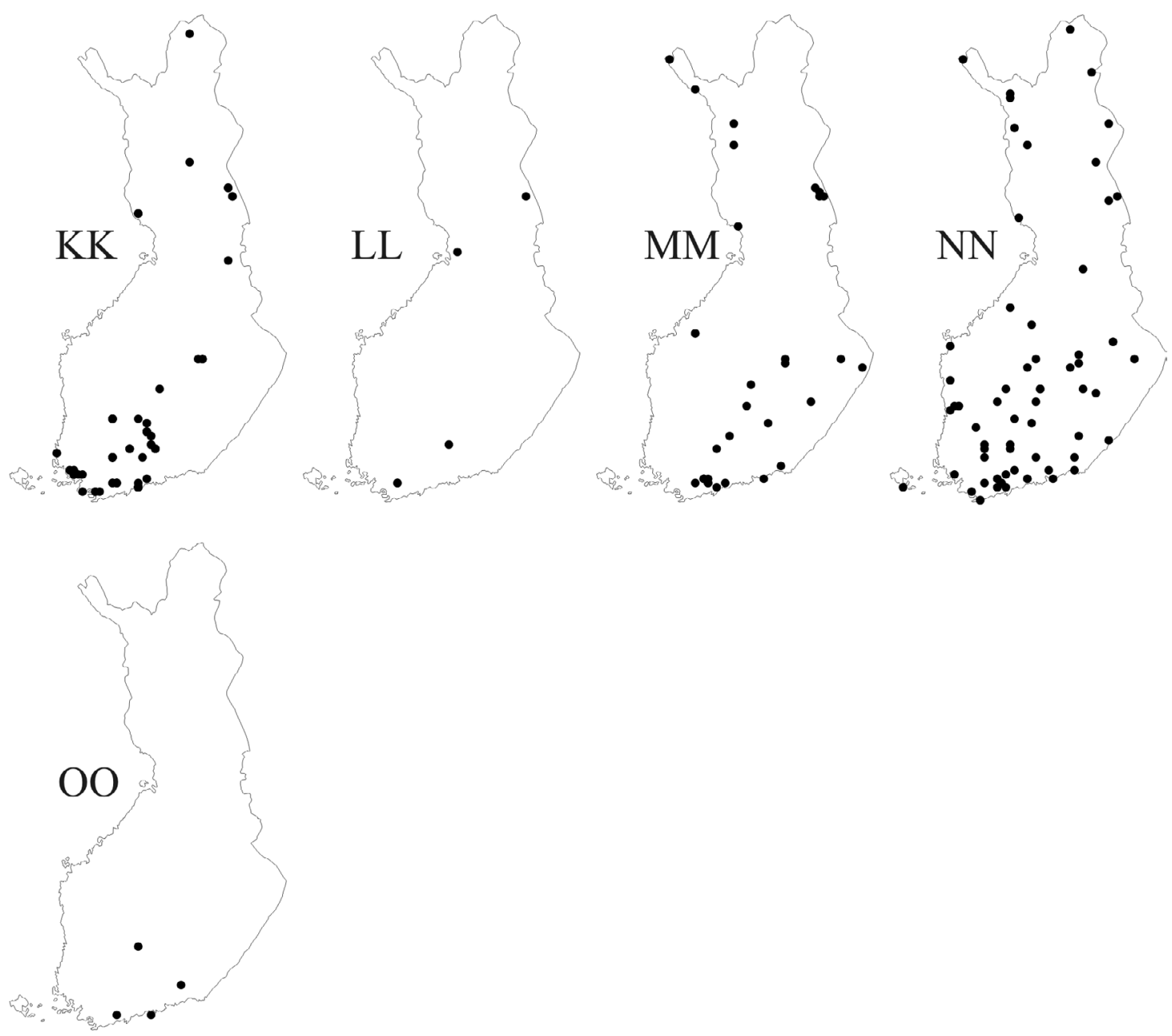

Fig. 47. Distribution maps of species KK-OO.

Appendix. The distribution of peltigericolous species in Finland. A) Arthonia fuscopurpurea. B) Arthonia peltigerea. C) Capronia peltigerae. D) Corticifraga fuckelii. E) Corticifraga peltigerae. F) Dacampia rufescentis. G) Graphium aphthosae. H) Hawksworthiana peltigericola. I) Hobsoniopsis santessonii. J) Illosporium carneum. K) Karsteniomyces peltigerae. L) Lasiosphaeriopsis salisburyi. M) Libertiella curvispora. N) Libertiella fennica. O) Libertiella malmedyensis. P) Lichenopeltella peltigericola. Q) Lichenopeltella santessonii. R) Nanostictis peltigerae. S) Nectriopsis lecanodes. T) Niesslia peltigericola. U) Pezizella epithallina. V) Phoma epiparmelia. W) Phoma peltigerae. X) Plectocarpon peltigerae. Y) Polycoccum peltigerae. Z) Polycoccum superficiale. AA) Polydesmia lichenis. BB) Pronectria erythrinella. CC) Xenonectriella (Pronectria) ornamentata. DD) Pronectria robergei. EE) Pronectria tenuispora. FF) Pyrenidium actinellum. GG) Rhagadostoma brevisporum. HH) Scutula dedicata. II) Scutula epiblastematica. JJ) Scutula heeri. KK) Scutula miliaris. LL) Stigmidium leucophlebiae. MM) Stigmidium peltideae. NN) Thelocarpon epibolum. OO) Xenonectriella lutescens. 
Acknowledgements: We thank Veikko Rinne for important assistance with the making of the distribution maps and Ernest Emmett for improving the English. The research group was funded by the Ministry of Environmenet in Finland during the research program of deficiently known and threatened forest species (PUTTE).

\section{References}

Alstrup, V. 2004: New records in distribution of lichens and lichenicolous fungi. - Graphis Scripta 16: 46-57.

Hawksworth, D. L. 1978: Notes on British lichenicolous fungi: II. - Notes from the Royal Botanical Garden Edinburgh 36: 181-197.

Hawksworth, D. L. 1980: Notes on some fungi occurring on Peltigera, with a key to accepted species. Transactions of the British Mycological Society 74: 363-386.

Hawksworth, D. L. 1986: Notes on British lichenicolous fungi: V. - Notes from the Royal Botanic Garden Edinburgh 43: 497-519.

Hawksworth, D. L. \& Miadlikowska, J. 1997: New species of lichenicolous fungi occurring on Peltigera in Ecuador and Europe. - Mycological Research 101: $1127-1134$

Jääskeläinen, K., Pykälä, J., Rämä, H., Vitikainen, O., Haikonen, V., Högnabba, F., Lommi, S. \& Puolasmaa, A. 2010: Jäkälät - Lichens. In: Rassi, P., Hyvärinen, E., Juslén, A. \& Mannerkoski, I. (eds) 2010: The 2010 Red List of Finnish Species: 278-310. Ympäristöministeriö \& Suomen ympäristökeskus.

Kocourková-Horáková, J. 1998: Distribution and ecology of the genus Thelocarpon (Lecanorales, Thelocarpaceae) in the Czech Rupublic. - Czech Mycology 50: 271-302.

Lawrey, J. D. \& Diederich, P. 2003: Lichenicolous fungi: interactions, evolution and biodiversity. Bryologist 106: 80-120.

Lawrey, J. D. \& Diederich, P. 2011: Lichenicolous fungi - worldwide checklist, including isolated cultures and sequences available. - URL: http://www.lichenicolous.net [7/24/2011].

Lumbsch, H. T. \& Huhndorf, S.M. (eds.) 2007: Outline of Ascomycota - 2007. - Myconet 13: 1-58. The Field Museum. Chicago.

Martínez, I. \& Hafellner, J. 1998: Lichens and lichenicolous fungi on Peltigerales in the Iberian Peninsula and the Canary Islands. - Mycotaxon 69: 271-310.

Nordin, A., Moberg, R., Tønsberg, T., Vitikainen, O., Dalsätt, Å., Myrda, M. \& Ekman, S. 2010: Santesson's Checklist of Fennoscandian Lichen-forming and Lichenicolous Fungi. Museum of Evolution, Uppsala University. Uppsala. Sweden.

Rossman, A.Y., Samuels, G.J., Rogerson, C.T. \& Lowen, R. 1999: Genera of Bionectriaceae, Hypocreaceae and Nectriaceae (Hypocreales, Ascomycetes) - Studies in Mycology 42: 1-248.
Roux, C. \& Triebel, D. 1994: Révision des espèces de Stigmidium et de Sphaerellothecium (champignons lichénicoles non lichénisés, Ascomycetes) correspondant à Pharcidia epicymatia sensu Keissler ou à Stigmidium schaereri auct. - Bulletin de la Société Linnéenne de Provence 45: 451-542.

Santesson, R. 1960: Lichenicolous fungi from northern Spain. - Svensk Botanisk Tidskrift. 54: 499-522.

Santesson, R., Moberg, R., Nordin, A., Tønsberg, T. \& Vitikainen, O. 2004: Lichenforming and lichenicolous fungi of Fennoscandia. Museum of Evolution, Uppsala University. Majornas CopyPrint AB, Göteborg. $359 \mathrm{pp}$.

Sikaroodi, M., Lawrey, J.D., Hawksworth, D.L., \& De Priest, P.T. 2001: The phylogenetic position of selected lichenicolous fungi: Hobsonia, Illosporium, and Marchandiomyces - Mycological Research 105: 453-460.

Spooner, B.M. \& Kirk, P.M. 1990: Observations on some genera of Trichothyriaceae. - Mycological Research 94: 223-230.

Stenroos, S., Ahti, T., Lohtander, K. \& Myllys, L. (toim.) 2011: Suomen jäkäläopas. - Norrlinia 21: 1-534. [In Finnish]

Toivanen, A. 2008: Microfungi living on Peltigera in Finland. - MSc. study. University of Helsinki. $111 \mathrm{pp}$. [In Finnish]

Triebel, D., Wedin, M. \& Rambold, G. 1997: The genus Scutula (lichenicolous ascomycetes, Lecanorales): species on the Peltigera canina and P. horizontalis groups. - Symbolae Botanicae Upsalienses 32: 323337

Vitikainen, O. 1994: Taxonomic revision of Peltigera (lichenized Ascomycotina) in Europe. - Acta Botanica Fennica 152: 1-96.

Vitikainen, O., Ahti, T., Kuusinen, M., Lommi, S. \& Ulvinen, T. 1997: Checklist of lichens and allied fungi of Finland. - Norrlinia 6: 1-123.

Zhurbenko, M.P. \& Grube, M. 2009: Arthonia pannariae (Arthoniaceae, Arthoniales), a new lichenicolous fungus from northern Holarctic. - Graphis Scripta 22: 47-51. 